\title{
Al-Ca and Al-Fe metal-metal composite strength, conductivity, and microstructure relationships
}

\author{
by
}

\section{Hyongjune Kim}

\begin{abstract}
A dissertation submitted to the graduate faculty
in partial fulfillment of the requirement for the degree of DOCTOR OF PHILOSOPHY
\end{abstract}

\author{
Major : Materials Science and Engineering \\ Program of Study Committee: \\ Alan M. Russell, Major Professor \\ Iver E. Anderson \\ Scott Chumbley \\ Ersan Ustundag \\ Gap-Yong Kim
}

Iowa State University

Ames, Iowa

2011

Copyright (C) Hyongjune Kim, 2011. All right reserved. 
TABLE OF CONTENTS

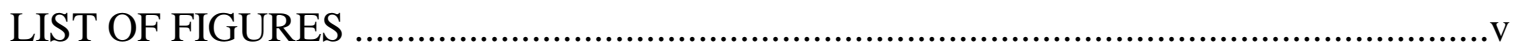

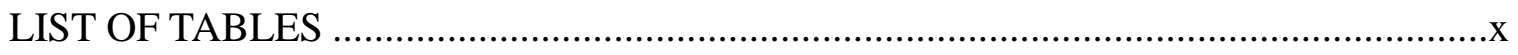

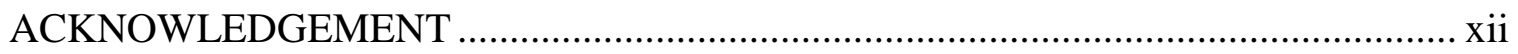

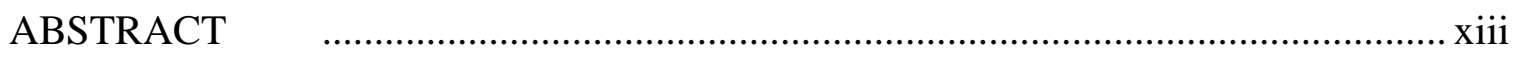

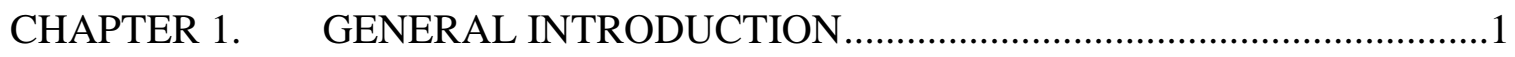

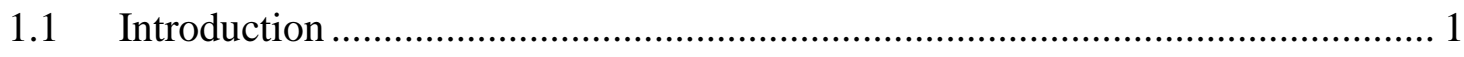

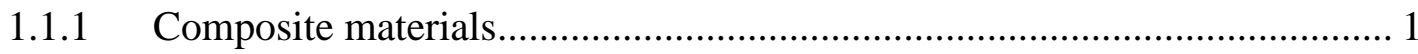

1.1.2 Deformation processed metal-metal composites (DMMC's) ….................... 3

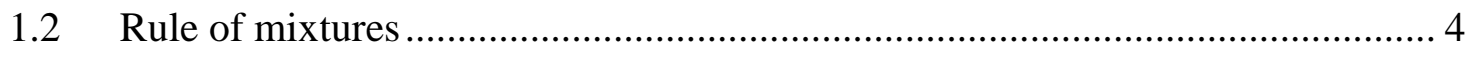

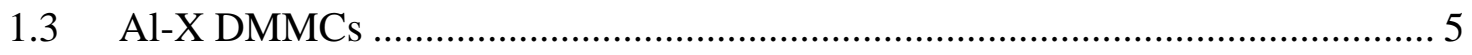

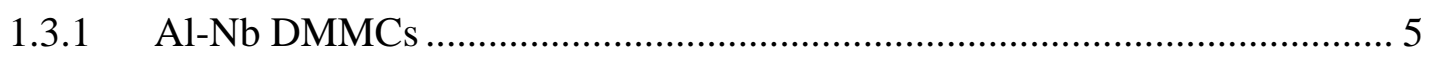

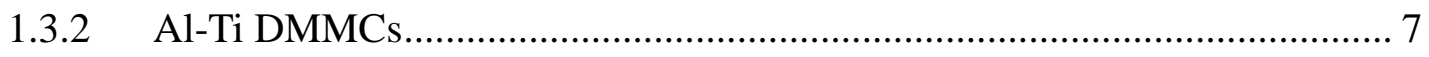

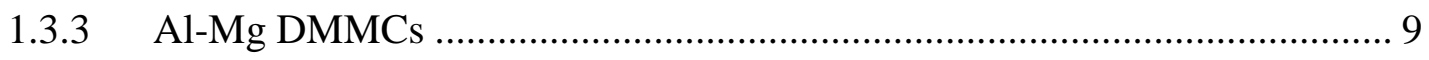

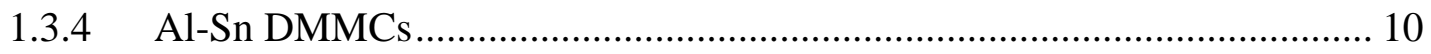

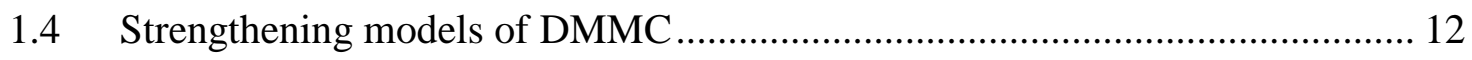

1.4.1 Dislocation substructure incompatibility model ........................................ 12

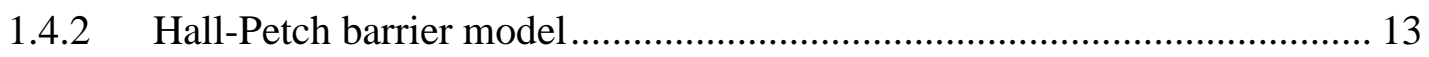

1.4.3 Modified linear rule of mixture model........................................................ 14

1.5 Electrical properties of deformation processed composites ............................... 14

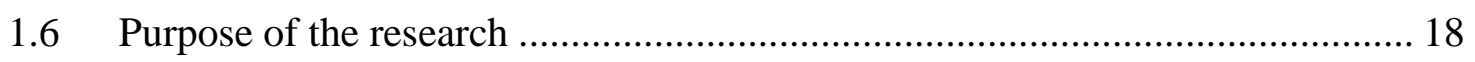

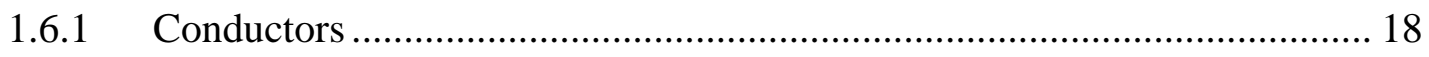


1.6.2 Reinforced aluminum conductors ................................................... 19

1.6.3 Aluminum-Iron composite conductor ............................................... 21

1.6.4 Aluminum-Calcium composite conductor ........................................... 22

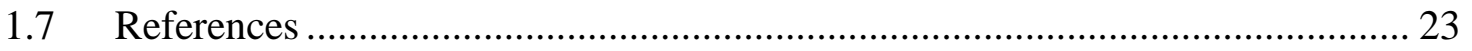

CHAPTER 2. EXPERIMENTAL PROCEDURES ...............................................27

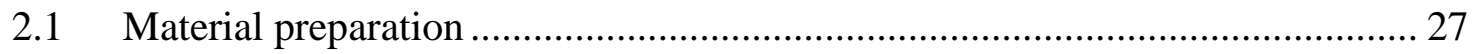

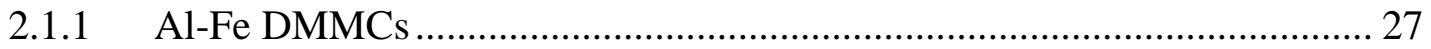

2.1.2 Preceding experiment for Al-Ca DMMCs ......................................... 29

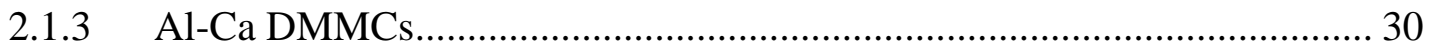

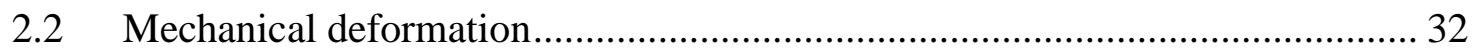

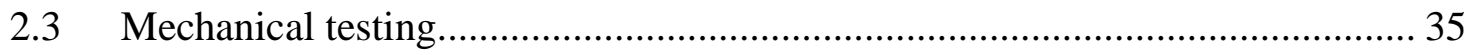

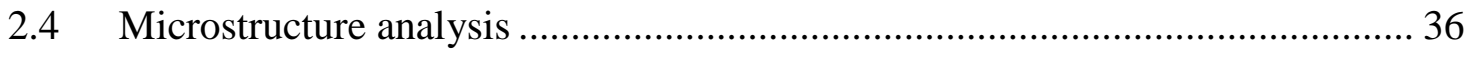

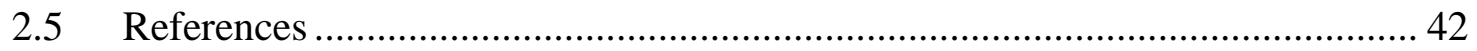

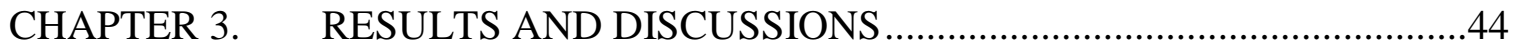

3.1 Microstructure ..................................................................................... 44

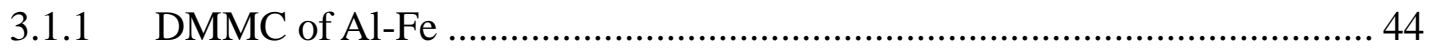

3.1.2 DMMC of 90 vol\% $\mathrm{Al}$ powders and 10vol\% Ca granules........................ 46

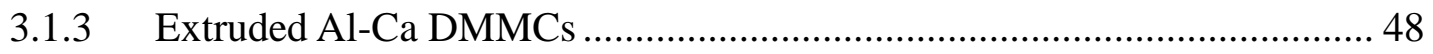

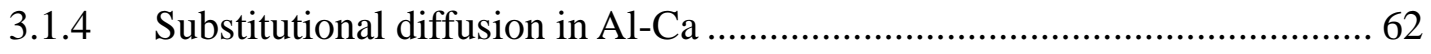

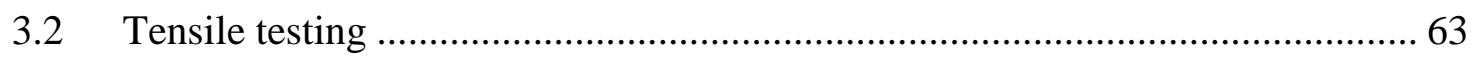

3.2.1 Tensile tests with heat treated Al-Ca DMMCs at $\eta=6.27 \ldots \ldots \ldots \ldots \ldots \ldots \ldots \ldots . . . .63$

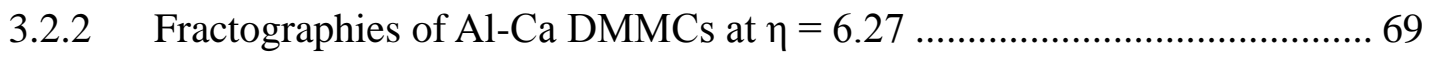

3.2.3 Quantitative analysis for Ca filaments .............................................. 70 
3.2.4 Ultimate tensile strength and mean free path..................................... 72

3.2.5 Ultimate tensile strength with the rule of mixtures................................ 75

3.2.6 Strengthening of Al-9vol\%Ca DMMC ….......................................... 76

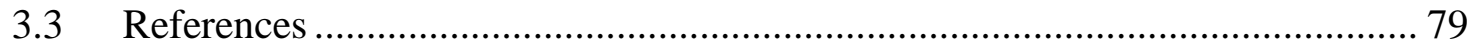

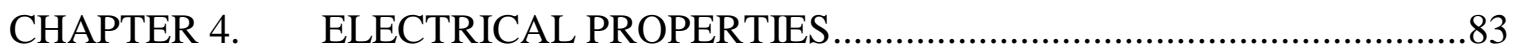

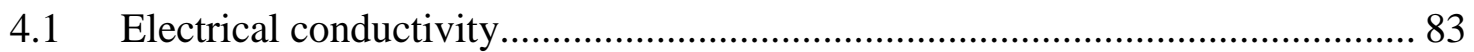

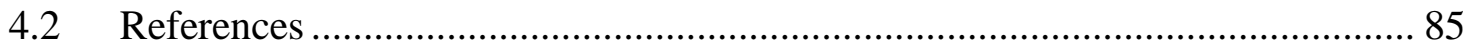

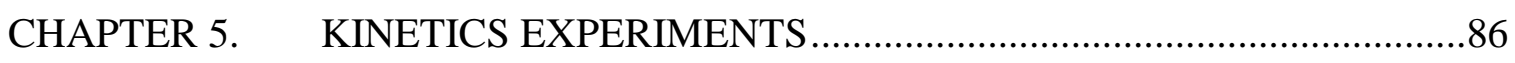

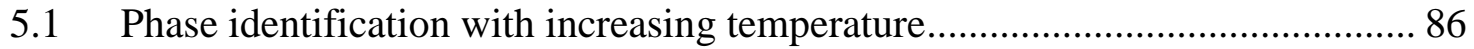

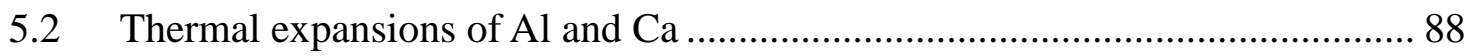

$5.3 \quad$ Variation of grain size with increasing temperature ...................................... 90

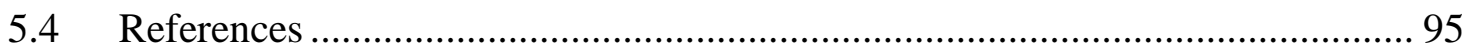




\section{LIST OF FIGURES}

Figure 1.1 The influence of deformation ratio on the ultimate tensile strength [15]........ 6

Figure 1.2 Back-scattered electron SEM micrograph of Al-20Ti, $\eta=2.5: A$, transverse view (specimen rod axis normal to the plane of the micrograph) and B, longitudinal view (specimen rod axis parallel to the plane of the micrograph).

The $\mathrm{Al}$ is dark gray, and the $\mathrm{Ti}$ is light gray in these images [17]. 8

Figure 1.3 The dependence of ultimate tensile strength on mean free path for $\mathrm{Al}-20 \mathrm{Mg}$ and $\mathrm{Al}-13 \mathrm{Mg}[5]$ 10

Figure 1.4 A schematic illustration of the conversion from a cylindrical filament into spheres. The initial cylinder of uniform radius second phase material (right) develops perturbations (center) that eventually lead to separate spheres of

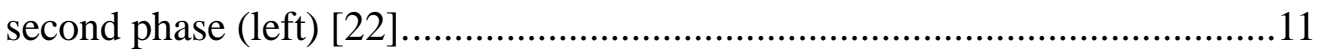

Figure 1.5 A plot of resistivity of Al-20vol\% Ti specimen at $\eta=12.1$ during a heating cycle of $0.055 \mathrm{Ks}^{-1}$ followed by cooling to room temperature. 16

Figure 1.6 Electrical resistivity of Au-Ag and Au-Pt DMMCs as a function of the amount of imposed deformation [28] 17

Figure 1.7 Commercial Al conductors with reinforced materials. (a) ACSR (Aluminum Conductor Steel Reinforced) [29], (b) ACAR (Aluminum Conductor Aluminum alloy reinforced) [30], (c) ACCR (Aluminum Conductor Ceramic Reinforced) [31] 20 
Figure 2.1 Plots of yield Strength of High-purity Iron and 1060-O Aluminum Alloy [2-3]

Figure 2.2 Schematic drawing of preparation $1100 \mathrm{Al}$ alloy can and specimens ............ 31

Figure 2.3 Al-Ca equilibrium phase diagram [6] ................................................. 34

Figure 2.4 SEM image of transverse cross section of the bundled-wire specimen for measuring the true strain of $\eta=12.45$ 35

Figure 2.5 Photograph of pin vice grip used for tensile tests for small diameter specimens

Figure 2.6 Schematic drawing of specimen with Mo strips for tensile tests. 40

Figure 2.7 Photograph of specimen for kinetics 41

Figure 3.1 Transverse (a) and longitudinal (b) section SEM micrographs of as-extruded Al-20Vol\%Fe $(\eta=2.6)$. Fe phase appears light gray; the Al matrix is a darker gray. 44

Figure 3.2 Longitudinal section SEM micrographs of Al-20Vol\%Fe at $\eta=7.18$. Fe phase appears lighter gray than the $\mathrm{Al}$ matrix 45

Figure 3.3 XRD pattern of Al-20vol\%Fe compared to reference patterns of $\mathrm{Al}$ and $\mathrm{Fe}$. . 46 Figure 3.4 Longitudinal section optical microscopy image of Al-10vol\%Ca 47

Figure 3.5 XRD pattern of $\mathrm{Al}-10 \mathrm{vol} \% \mathrm{Ca}$ compared to reference patterns of $\mathrm{Al}$ and $\mathrm{CaO}$. 48

Figure 3.6 Transverse (a) and longitudinal (b) section SEM micrographs of as-extruded $\mathrm{Al}-9 \mathrm{Vol} \% \mathrm{Ca}(\eta=2.25)$. Ca filaments appear lighter gray than the Al matrix in these back-scattered-electron images. Black regions are voids, which are common in $\mathrm{P} / \mathrm{M}$ metals. 49 
Figure 3.7 Longitudinal section SEM micrographs of Al-9Vol\%Ca $(\eta=4.89)$ at different magnifications. Ca filaments appear lighter gray than the Al matrix in these back-scattered-electron images. Black regions are voids. 50

Figure 3.8 Longitudinal section SEM micrographs of Al-9Vol\%Ca $(\eta=7.32)$ at two different magnifications. Ca filaments appear lighter gray than the Al matrix in these back-scattered-electron images. Black regions are voids. 50

Figure 3.9 Transverse (a) and longitudinal (b) section SEM micrographs of Al-9Vol\%Ca $(\eta=13.76)$. Ca filaments appear lighter gray than the Al in these backscattered-electron images. Black regions are voids, which are common in $\mathrm{P} / \mathrm{M}$ metals. 51

Figure 3.10 DSC measurement for Al-9vol $\% \mathrm{Ca}$ at $\eta=8.55$ 53

Figure 3.11 Transverse section SEM micrographs of Al-9Vol\%Ca $(\eta=6.27)$ with different temperature heat treatments for 1 hour. (a) $200^{\circ} \mathrm{C}$, (b) $225^{\circ} \mathrm{C}$ (c) $250^{\circ} \mathrm{C}$ (d) $275^{\circ} \mathrm{C}$ (e) $300^{\circ} \mathrm{C}$ (f) $325^{\circ} \mathrm{C}$. The $\mathrm{Al}$ matrix is dark gray; Ca filaments are light gray 55

Figure 3.12 Transverse section SEM micrographs of Al-9Vol\%Ca $(\eta=6.27)$ after different one-hour heat treatments. . (a) $200^{\circ} \mathrm{C}$, (b) $225^{\circ} \mathrm{C}$ (c) $250^{\circ} \mathrm{C}$ (d) $275^{\circ} \mathrm{C}$ (e) $300^{\circ} \mathrm{C}$ (f) $325^{\circ} \mathrm{C}$. The $\mathrm{Al}$ matrix is dark gray; Ca filaments are light gray.56 Figure 3.13 Transverse section SEM micrographs of Al-9Vol\%Ca $(\eta=6.27)$ with different one-hour heat treatments. (a) $200^{\circ} \mathrm{C}$, (b) $225^{\circ} \mathrm{C}$ (c) $250^{\circ} \mathrm{C}$ (d) $275^{\circ} \mathrm{C}$ (e) $300^{\circ} \mathrm{C}$ (f) $325^{\circ} \mathrm{C}$. The $\mathrm{Al}$ matrix is dark gray; Ca filaments are light gray. 57 
Figure 3.14 XRD patterns obtained at APS of two specimens $(\eta=6.27)$, one was a nonheat treated (noHT) specimen, and the other was heat treated at $275^{\circ} \mathrm{C}$ for 4 hours (275_04h). 60

Figure 3.15 XRD patterns of three specimens $(\eta=6.27)$ of non-heat treated (noHT), heat treated at $225^{\circ} \mathrm{C}$ for 4 hours $\left(225 \_04 \mathrm{~h}\right)$ and $275^{\circ} \mathrm{C}$ for 4 hours $\left(275 \_04 \mathrm{~h}\right) \ldots . .61$

Figure 3.16 XRD patterns of specimens heat treated at $275^{\circ} \mathrm{C}$ for 1 minute, 5 minutes, 10 minutes, 1 hour and 4 hours $\left(275 \_01 \mathrm{~m}, 275 \_05 \mathrm{~m}, 275 \_10 \mathrm{~m}, 275 \_01 \mathrm{~h}\right.$, and 275_04h). 62

Figure 3.17 Stress-strain plots of pure Al specimens with $\eta=6.27 \ldots \ldots \ldots \ldots \ldots \ldots \ldots \ldots \ldots . . .66$

Figure 3.18 Stress-strain plots of Al-3vol\%Ca specimens with $\eta=6.27 \ldots \ldots \ldots \ldots \ldots \ldots \ldots . . .66$

Figure 3.19 Stress-strain plots of Al-6vol\%Ca specimens with $\eta=6.27 \ldots \ldots \ldots \ldots \ldots \ldots \ldots . \ldots . \ldots \ldots$

Figure 3.20 Stress-strain plots of Al-9vol\%Ca specimens with $\eta=6.27 \ldots \ldots \ldots \ldots \ldots \ldots \ldots . . . . . \ldots 7$

Figure 3.21 Stress-strain plots of non heat-treated specimens with $\eta=6.27 \ldots \ldots \ldots \ldots \ldots . . .68$

Figure 3.22 Stress-strain plots of heat-treated specimens with $\eta=6.27 \ldots \ldots \ldots \ldots \ldots \ldots \ldots \ldots . . .68$

Figure 3.23 SEM micrographs of fracture surfaces for Al-9Vol\%Ca $(\eta=6.27)$ wires with heat treatments. (a) without heat treatment (b) $200^{\circ} \mathrm{C}, 4$ hours (c) $200^{\circ} \mathrm{C}, 4$ hours (d) $350^{\circ} \mathrm{C}$ for 4 hours.

Figure 3.24 SEM micrographs of fracture surfaces for Al-9Vol\%Ca $(\eta=6.27)$ wires with heat treatments. (a) without heat treatment (b) $200^{\circ} \mathrm{C}, 4$ hours (c) $200^{\circ} \mathrm{C}, 4$ hours (d) $350^{\circ} \mathrm{C}$ for 4 hours. 70

Figure 3.25 SEM micrographs of polished fracture surfaces for $\mathrm{Al}-9 \mathrm{Vol} \% \mathrm{Ca}(\eta=6.27)$ wires with heat treatments. (a) $200^{\circ} \mathrm{C}, 4$ hours (b) $350^{\circ} \mathrm{C}$ for 4 hours. 72 
Figure 3.26 Stress-strain plots of Al-9vol\%Ca specimens with $\eta=6.27,8.55,12.45$ and 13.76. Note: The samples were too small to allow use of an extensometer, so the slopes of the elastic portions of the plots do not accurately represent elastic modulus. 73

Figure 3.27 The relationship between ultimate tensile strength and mean free path between $\mathrm{Ca}$ filaments. This sharp increase in strength as mean free path decreases is typical of DMMCs [4,15-20]. This topic is discussed in greater detail in Section 3.2.6.................................................................... 75

Figure 3.28 UTS on deformation true strain and exponential regression of UTS for Al-

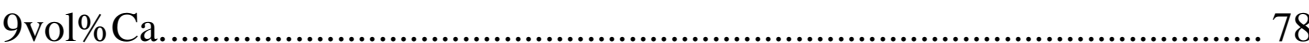

Figure 4.1 Schematic drawing of specimen with test leads for electrical resistivity

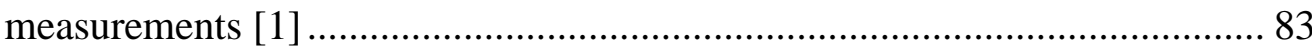

Figure 5.1 XRD patterns of Al-9vol\% Ca at $\eta=8.55$ during heating from room temperature to $430^{\circ} \mathrm{C}$. Peaks shift leftward as temperature rises as lattice parameter increases from thermal expansion........................................................... 87

Figure 5.2 Increase of d-spacing by thermal expansion of $\mathrm{Al}$ (111) and $\mathrm{Ca}$ (111). The black arrows indicate the shifted d-spacing with increase temperature......... 89

Figure 5.3 Variations of the lower bound of grain size for $\mathrm{Al}$ and $\mathrm{Ca}$ phases in $\mathrm{Al}-9 \% \mathrm{Ca}$ composite with increasing temperature as determined by FWHM measurements and the Scherrer equation. 94 


\section{LIST OF TABLES}

Table 1.1 Comparison of UTS: $\rho$ ratios of the commercial alloy (7079, T73 condition) with the highest ratio to Al-20vol\% Ti DMMC in two conditions 18

Table 2.1 Heat treatment conditions of Al-9vol\%Ca $(\eta=6.27)$ for XRD analysis at $1-\mathrm{BM}$ beamline at APS 38

Table 2.2 Heat treatment conditions of Al-9vol\%Ca $(\eta=8.55,13.76)$ for XRD analysis at 1-ID-C beamline at APS 39

Table 3.1 Heat treatment conditions of Al-9vol\%Ca $(\eta=6.27)$ for microstructure analysis with SEM and EDS 54

Table 3.2 Elemental analysis by standardless EDS for Al-9vol\%Ca $(\eta=6.27)$ with heat treatment at $325^{\circ} \mathrm{C}$ for 1 hour.

Table 3.3 Heat treatment conditions and results of tensile tests of Al-Ca wires at $\eta=6.27$

Table 3.4 Elemental analysis by standardless EDS for Al-9vol\%Ca $(\eta=6.27)$ with heat treatment at $350^{\circ} \mathrm{C}$ for 4 hours 72

Table 3.5 Average values of ultimate tensile strength and maximum strain for Al$9 \mathrm{vol} \% \mathrm{Ca}$ specimens without heat treatment at $\eta=6.27,8.55,12.45$ and 13.76 .

Table 4.1 Electrical conductivity for $\mathrm{Al}-9 \mathrm{vol} \% \mathrm{Ca}$ at $\eta=8.55$ with heat treatments at $300^{\circ} \mathrm{C}$ for various times. 84

Table 5.1 Changing of $\mathrm{d}$-spacing by thermal expansion of $\mathrm{Al}(111)$ and $\mathrm{Ca}$ (111)..... 90 
Table 5.2 Grain size as calculated from FWHM data for selected diffraction peaks in Al

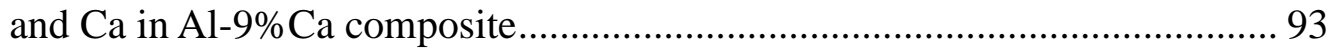




\section{ACKNOWLEDGEMENT}

I would like to sincerely thank my advisor, Dr. Alan M. Russell, for his guidance, thecnical support, and encouragement throughout the research process. I would also like to thank Dr. Iver E. Anderson, Dr. Scott Chumbley, Dr. Ersan Ustundag, and Dr. GapYong Kim for serving on my advisory committee and providing additional technical guidance.

This work was performed at the Ames Laboratory under contract number DE-AC0207CH11358 with the U.S. Department of Energy.

I would like to thank Ben Rattle and Andrew Frerichs for their valuable technical expertise and helpful discussions. I would also like to extend thanks to Insok Seo and Eunsoo Park for their technical advice and help.

I also would like to greatly thank my parents, Seokgoo Kim and Hangsoon Yun, and my parents-in-law, Jeonghoon Cho and Myongsoon Kim, and other my family members, for their love and support.

Finally, I would to thank my wonderful wife, Hyejin Cho, for her unwavering love, support, and encouragement throughout this whole process 


\begin{abstract}
Deformation processed metal-metal composites (DMMC's) are composites formed by mechanical working (i.e., rolling, swaging, or wire drawing) of two-phase, ductile metal mixtures. Since both the matrix and reinforcing phase are ductile metals, the composites can be heavily deformed to reduce the thickness and spacing of the two phases. Recent studies have shown that heavily drawn DMMCs can achieve anomalously high strength and outstanding combinations of strength and conductivity. In this study, Al-Fe wire composite with $0.07,0.1$, and 0.2 volume fractions of Fe filaments and Al-Ca wire composite with $0.03,0.06$, and 0.09 volume fractions of Ca filaments were produced in situ, and their mechanical properties were measured as a function of deformation true strain. The Al-Fe composites displayed limited deformation of the Fe phase even at high true strains, resulting in little strengthening effect in those composites. Al9vol\%Ca wire was deformed to a deformation true strain of 13.76 . The resulting $\mathrm{Ca}$ second-phase filaments were deformed to thicknesses on the order of one micrometer. The ultimate tensile strength increased exponentially with increasing deformation true strain, reaching a value of $197 \mathrm{MPa}$ at a true strain of 13.76 . This value is 2.5 times higher than the value predicted by the rule of mixtures. A quantitative relationship between UTS and deformation true strain was determined. X-ray diffraction data on transformation of $\mathrm{Al}+\mathrm{Ca}$ microstructures to $\mathrm{Al}+$ various $\mathrm{Al}-\mathrm{Ca}$ intermetallic compounds were obtained at the Advanced Photon Source at Argonne National Laboratory. Electrical conductivity was measured over a range of true strains and post-deformation
\end{abstract}


heat treatment schedules. 


\section{CHAPTER 1. GENERAL INTRODUCTION}

\subsection{Introduction}

\subsubsection{Composite materials}

Composite materials consist of at least two different phases that often provide combinations of properties that cannot be obtained from either individual phase (e.g., light weight and high strength) [1-2]. The continuous phase of the composite, the matrix, serves to surround the second phase and provides bulk form to the material. The reinforcing phase structural constituents are typically fibers or particles. The reinforcing phase of the composite is generally comprised of a harder or stiffer material than the matrix phase [1-2]. The strength and rigidity of a composite can be controlled by varying the shape, amount, surface functionality and orientation of the reinforcing phase.

There are two classification systems of composite materials: based on the matrix material (metal, ceramic, polymer) and based on the material structure. [1, 3]

- Classification of composites based on matrix material

- Metal Matrix Composites (MMC)

- Ceramic Matrix Composites (CMC)

- Polymer Matrix Composites (PMC)

Metal Matrix Composites (MMC) are composed of a metallic matrix (e.g., aluminum, 
magnesium, iron, cobalt, copper) and a dispersed ceramic (e.g., oxides, carbides) or metallic (e.g., lead, tungsten, molybdenum) phase.

Ceramic Matrix Composites (CMC) are composed of a ceramic matrix and embedded fibers of other ceramic material (dispersed phase).

Polymer Matrix Composites (PMC) are composed of a matrix comprised of a thermosetting polymer (e.g., unsaturated polyester, epoxy) or a thermoplastic polymer (polycarbonate, polyvinylchloride, nylon, polystyrene) and embedded glass, carbon, steel or Kevlar fibers (dispersed phase).

- Classification of composite materials based on reinforcing material structure

- Particulate Composites

- Fibrous Composites

- Laminate Composites

Particulate Composites consist of a matrix reinforced by a particulate dispersed phase.

Fibrous composites can be classified by the length of fiber. Short-fiber reinforced composites consist of a matrix reinforced by a dispersed phase in the form of discontinuous fibers (length $<100 \cdot$ diameter). Long-fiber reinforced composites. Longfiber reinforced composites consist of a matrix reinforced by a dispersed phase in the form of continuous fibers.

When a fiber-reinforced composite consists of several layers with different fiber orientations, it is called multilayer (angle-ply) composite. 


\subsubsection{Deformation processed metal-metal composites (DMMC's)}

Deformation processed metal-metal composites (DMMC's) are composites formed by mechanical working (i.e., rolling, swaging, or wire drawing) of two-phase, ductile metal mixtures. Since both the matrix and reinforcing phase are ductile metals, the composites can be heavily deformed to reduce the thickness and spacing of the two phases [3-4].

Many of the first DMMC's developed during the 1970's and 1980's used a face centered cubic (fcc) matrix and a body centered cubic (bcc) second phase. Among the fcc metals, $\mathrm{Cu}$ and $\mathrm{Al}$ are the most thoroughly studied matrix metals [2, 4-15]. The $\mathrm{Cu}-\mathrm{Nb}$ DMMC, typically with 18 to $20 \mathrm{vol} . \% \mathrm{Nb}$, is the best known of these and possesses an ultimate tensile strength of $2200 \mathrm{MPa}$ at a deformation true strain of 11.5 [15]. The deformation true strain is characterized by a parameter $\eta=\ln \left(A_{i} / A_{f}\right)$, where $A_{i}$ and $A_{f}$ are the specimen's initial and final transverse areas respectively. The $\mathrm{Cu}-\mathrm{Nb}$ DMMCs also display good electrical and thermal conductivity; this is somewhat unusual since conductivity is usually low in high-strength metals. The typical microstructure of fcc matrix/bcc fiber DMMCs is a convoluted ribbon shaped second phase embedded in the matrix, resulting from a $\langle 110\rangle$ wire texture in the second phase, which limits the deformation of the second phase to plane strain.

In the 1990's, DMMC's with hexagonal close packed (hcp) metals were studied. Russell at Ames Laboratory reported a Ti-Y DMMC with tensile strength of 950MPa at $\eta=7.3$ [16]. For fcc/hcp DMMC's such as Al-Ti [17] and Al-Mg [5], the microstructures 
are quite similar to that of fcc/bcc DMMC's, since the $\langle 10 \overline{1} 0\rangle$ fiber texture of hcp metals results in the same plane strain phase shape as that seen in bcc metal.

Research has also been performed on fcc/fcc DMMC's. A Cu-Ag DMMC studied by Frommeyer et alia [18] and a Au-Ag DMMC studied by Russell et alia [19] have been reported. The typical microstructure for fcc/fcc DMMC's is cylindrical second phase filaments embedded in the matrix. In a fcc metal's unit cell, axially symmetric flow can easily occur with either <111> or <001> fiber texture due to the large number of slip systems present to accommodate plastic flow. Therefore, no plane strain mode is observed in fcc/fcc DMMC's.

\subsection{Rule of mixtures}

The rule of mixtures is a method to estimate composite material properties, based on an assumption that a composite property is the volume weighted average of the individual phases' properties $[1,3,20]$. The following properties of composite materials can usually be estimated with reasonable accuracy by the rule of mixtures:

- Density

- Coefficient of thermal expansion

- Modulus of elasticity

- Shear modulus

- Poisson's ratio

- Tensile strength 
Most of the properties (density, modulus of elasticity(longitudinal direction), Poisson's ratio and tensile strength) can be expressed by an equation, $F=F_{m} V_{m}+F_{f} V_{f}$, where $F, F_{m}$ and $F_{f}$ are properties of the composite, matrix, and dispersed phase respectively, $V_{m}$ and $V_{f}$ are volume fraction of the matrix and of the dispersed phase respectively.

\subsection{Al-X DMMCs}

\subsubsection{Al-Nb DMMCs}

J. Bevk and J. P. Harbison at Harvard University produced $\mathrm{Cu}-\mathrm{Nb}$ wire composites with $0.105,0.148$, and 0.182 volume fraction of $\mathrm{Nb}$ filaments and measured their mechanical properties as a function of filament size and interfilament spacing [15]. The yield stress and the ultimate tensile strength (UTS) increased with both $\mathrm{Nb}$ volume fraction and the deformation true strain values. These values were four times higher than the values predicted by the rule of mixtures. Figure 1.1 shows the ultimate tensile strength for $\mathrm{Cu}, \mathrm{Nb}$, and $\mathrm{Cu}-20 \mathrm{vol} \% \mathrm{Nb}$, as well as the rule of mixtures prediction for the $\mathrm{Cu}-20 \mathrm{vol} \% \mathrm{Nb}$ composite. 


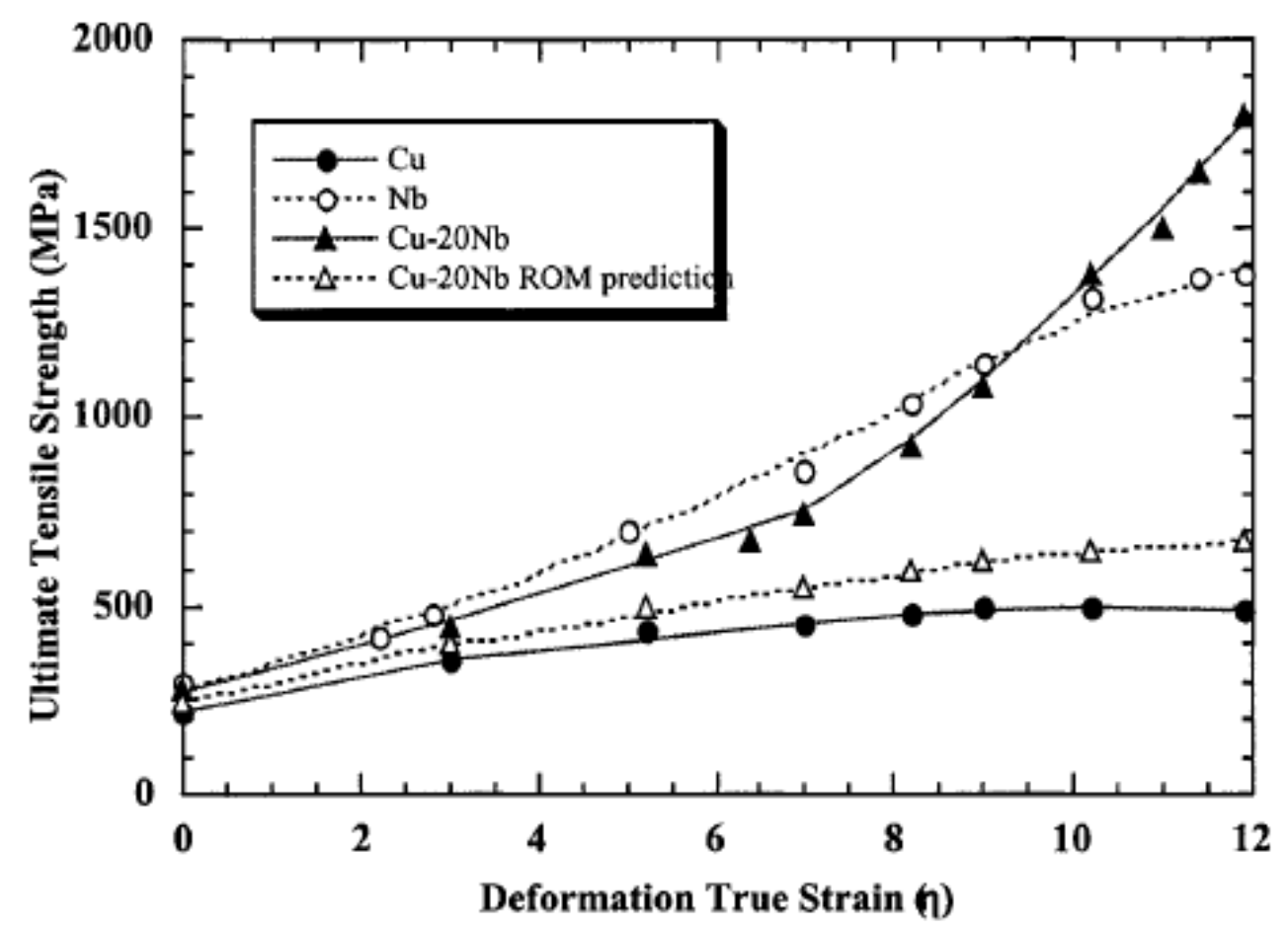

Figure 1.1 The influence of deformation ratio on the ultimate tensile strength [15].

Thieme at M.I.T reported an Al-Nb DMMC in 1993 [13]. The microstructure and work hardening behavior were quite similar to $\mathrm{Cu}-\mathrm{Nb}$ DMMC. During extrusion and wire drawing of a mixture of 0.2 volume fraction of $\mathrm{Nb}$ and 0.8 volume fraction of $\mathrm{Al}$ powders, the $\mathrm{Nb}$ particles deform rapidly into very thin ribbons with increasing strain as plain deformation extends to higher deformation true strain than in $\mathrm{Cu}-\mathrm{Nb}$. An UTS of 1030MPa was achieved at a deformation true strain of $\eta=11.1$. This value is 2.1 times higher than the UTS based on the rule of mixtures using UTS values of 100\% $\mathrm{Al}$ and $100 \% \mathrm{Nb}$ wires. The electrical resistivity of $\mathrm{Al}-20 \mathrm{vol} \% \mathrm{Nb}$ was measured in wires at deformation true strain, $\eta=10.2$. At room temperature, electrical resistivity was 4.4 $\mu \Omega \cdot \mathrm{cm}$. This compares with pure Al's room temperature resistivity of $2.63 \mu \Omega \cdot \mathrm{cm}$. At 
$78 \mathrm{~K}$, the electrical resistivity of Al-20vol\% $\mathrm{Nb}$ was $0.96 \mu \Omega \cdot \mathrm{cm}$.

\subsubsection{Al-Ti DMMCs}

Russell, Lund, and Chumbley $[17,21]$ at Ames Laboratory produced an Al-Ti DMMC. An 0.8 volume fraction of $\mathrm{Al}$ and 0.2 volume fraction $\mathrm{Ti}$ composite was produced by powder metallurgy and deformation processing. Figure 1.2 shows a backscattered electron SEM micrograph of Al-20vol\% $\mathrm{Ti}, \eta=2.5$. The classic convoluted ribbon shape of Ti filaments is seen in Figure 1.2. At deformation true strain $\eta=13.9$, the width of the second phase of Ti filaments was reduced to less than a micrometer. The ultimate tensile strength of the composite was $890 \mathrm{MPa}$, and its electrical resistivity was $4.3 \mu \Omega \cdot \mathrm{cm}$, which is a higher ratio of ultimate tensile strength to resistivity than the ratios in any commercially available Al alloy. Strength and resistivity were unaffected by a 24hour anneal at $473 \mathrm{~K}$. The composite's $\mathrm{Al}$ and Ti react to form $\mathrm{Al}_{3} \mathrm{Ti}$ at $600 \mathrm{~K}$. 

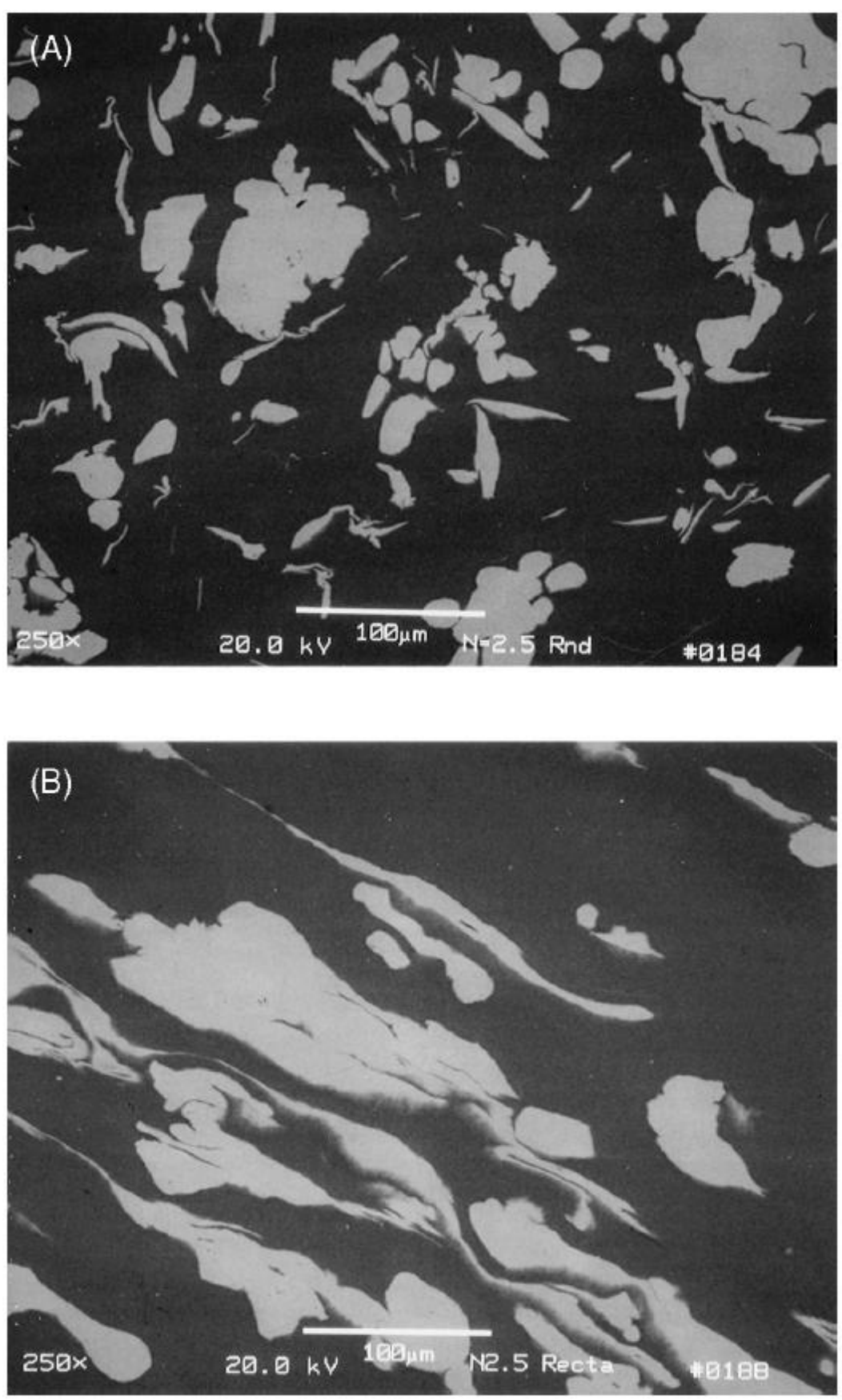

Figure 1.2 Back-scattered electron SEM micrograph of Al-20Ti, $\eta=2.5: A$, transverse view (specimen rod axis normal to the plane of the micrograph) and $\mathrm{B}$, longitudinal view (specimen rod axis parallel to the plane of the micrograph). The Al is dark gray, and the Ti is light gray in these images [17]. 


\subsubsection{Al-Mg DMMCs}

$\mathrm{Xu}$ and Russell [5] at Ames Laboratory produced Al-20 vol\% Mg and Al-13 vol\% Mg DMMCs. The hcp Mg second phase also assumed a convoluted, ribbon shape due to a plane strain mode. The microstructures, mechanical properties and electrical resistivity have been evaluated for deformation processed $\mathrm{Al}-20$ vol\% $\mathrm{Mg}$ and $\mathrm{Al}-13 \mathrm{vol} \% \mathrm{Mg}$ composites. The heavy deformation results in a reduction in $\mathrm{Mg}$ filament spacing $\left(\sigma_{\mathrm{t}}\right)$. The dependence of strength (MPa) on this spacing is (Figure 1.3):

$$
\begin{aligned}
& \mathrm{UTS}=585 \sigma_{\mathrm{t}}^{-0.61} \quad \text { for } \quad \mathrm{Al}-20 \mathrm{Mg} \\
& \mathrm{UTS}=498 \sigma_{\mathrm{t}}{ }^{-0.54} \quad \text { for } \mathrm{Al}-13 \mathrm{Mg}
\end{aligned}
$$

Both the size and spacing of the convoluted, ribbon-shaped $\mathrm{Mg}$ filaments were decreased during deformation. The strength of these composites increases exponentially with reduced spacing of $\mathrm{Mg}$ filaments. The electrical resistivity of $\mathrm{Al}-\mathrm{Mg}$ composites is slightly higher than that of pure $\mathrm{Al}$. An ultimate tensile strength of $310 \mathrm{MPa}$ for $\mathrm{Al}-13 \mathrm{Mg}$ and $420 \mathrm{MPa}$ for $\mathrm{Al}-20 \mathrm{Mg}$ was reported. 


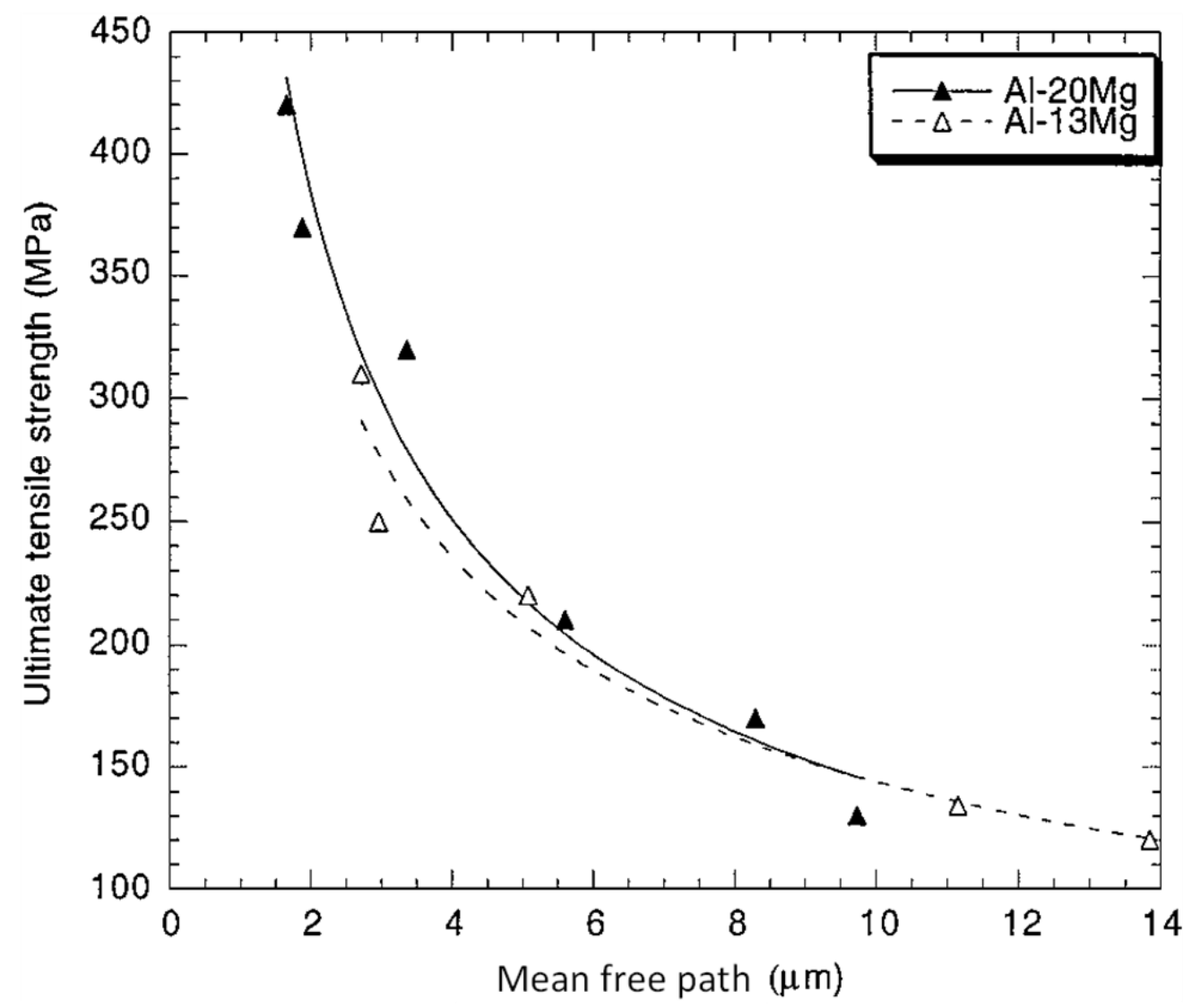

Figure 1.3 The dependence of ultimate tensile strength on mean free path for Al-20Mg and $\mathrm{Al}-13 \mathrm{Mg}[5]$.

\subsubsection{Al-Sn DMMCs}

$\mathrm{Xu}$ and Russell [4] at Ames Laboratory reported production and characterization of Al-Sn DMMCs. Al-Sn composite can be deformation processed to a deformation true strain of 7.41. The Sn second phase adopts a convoluted, ribbon-shaped filamentary morphology after axisymmetric deformation, which is due to texture effects in the Sn that restrict its plastic flow to plane strain.

Over a period of weeks after deformation, the Sn second-phase filaments partially 
spheroidize . A cylindrical filament with a longitudinal perturbation in radius has two principal radii of curvature as shown in Figure 1.4. This is thought to be due to rapid diffusion along the $\mathrm{Sn}-\mathrm{Al}$ interface resulting from the low melting temperature of $\mathrm{Sn}$ and to irregularities in the initial shape of the Sn filaments.

A chemical potential gradient is proposed as the driving force for spheroidization. A critical wavelength of $\lambda c_{\text {rit }}=2 \pi R$ can be used to determine the spheroidization tendency of a Sn cylinder. When $\lambda>2 \pi R$, spheroidization is predicted to occur.

The ultimate tensile strength of Al-20vol\% Sn composite increases exponentially with deformation true strain, $\eta$. The relationship between UTS and deformation true strain is UTS $=72.6 \exp (0.20 \eta)$.

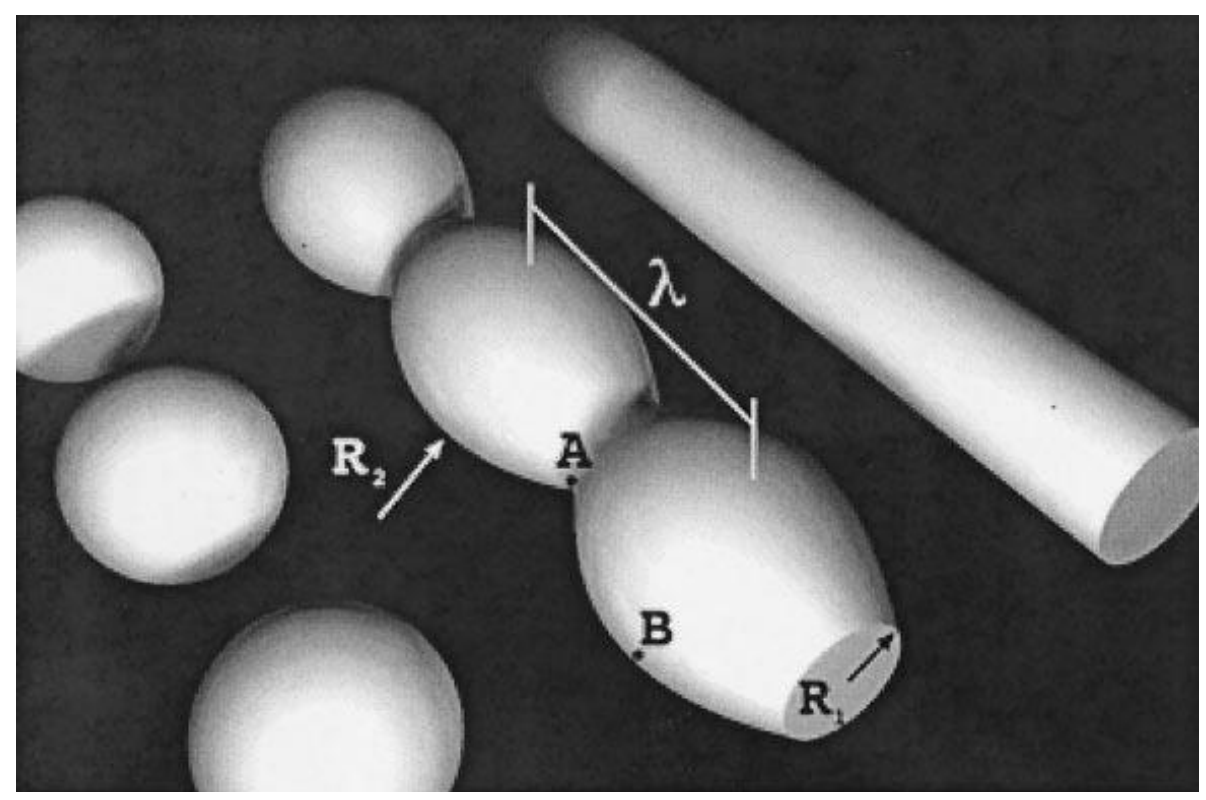

Figure 1.4 A schematic illustration of the conversion from a cylindrical filament into spheres. The initial cylinder of uniform radius second phase material (right) develops perturbations (center) that eventually lead to separate spheres of second phase (left) [22]. 


\subsection{Strengthening models of DMMC}

Anomalously high ultimate tensile strength is an important property of DMMCs. Strengthening mechanisms in DMMCs have been extensively studied. Several theories have been proposed to explain the strengthening mechanism in DMMCs; three of these are described briefly here.

- The dislocation substructure incompatibility model by Courtney and Funkenbusch.

- The Hall-Petch barrier model proposed by Spitzig, Verhoeven, and Chumbley.

- The modified linear rule of mixture model of Raabe and Hangen.

\subsubsection{Dislocation substructure incompatibility model}

Funkenbuch and Courtney [18] argue that strengthening is caused by the unusually high density of geometrically necessary dislocations generated at the many phase boundaries present during deformation. These dislocations act as barriers that separate each phase into many sub-cells. Therefore, it is exceedingly difficult for other dislocations to generate or move, which leads to high strength in these DMMCs. Bevk [15] reported the presence of sub-cells of dislocation tangles in Cu-Nb DMMC. Embury and Fisher [23] also found a similar phenomenon in pearlite to support this explanation. Everett [24] proposed further evidence to confirm this model. The ultimate tensile strengths of deformation processed composites and layered composites have been 
compared. Deformation processed composites had two times higher ultimate tensile strength than non-mechanically processed composites with the same composition. The proponents of the dislocation substructure incompatibility model argue that the only difference between the microstructures of these two specimens is the much higher dislocation density in the DMMC specimen, hence it was concluded that geometrically necessary dislocations cause the high strength seen in DMMCs.

\subsubsection{Hall-Petch barrier model}

Spitzig, Verhoeven, and Chumbley [11] studied $\mathrm{Cu}-\mathrm{Nb}$ DMMCs and suggested that the second-phase reinforcements, which are generally in the form of ribbons or filaments, behave as planar dislocation barriers and that strengthening results from difficulty in transmitting slip between the two phases. During deformation the $\mathrm{Cu}$ matrix develops a cellular structure at the lower deformation true strains $(\eta<5)$, a mixture of cells and recrystallized grains at the intermediate deformation true strains $(5<\eta<9)$, and primarily recrystallized grains at the higher deformation true strains $(\eta>10)$. Observations of (1) dynamic recovery and recrystallization of the $\mathrm{Cu}$ matrix and (2) maximum dislocation densities of about $10^{10} \mathrm{~cm}^{-2}$ in the $\mathrm{Cu}$ and the $\mathrm{Nb}$ filaments, are in contradiction to models relying on the development of large dislocation densities $\left(\sim 10^{13} \mathrm{~cm}^{-2}\right)$ as the mode of strengthening in $\mathrm{Cu}-\mathrm{Nb}$ composites. These investigators argued that continued strengthening in the $\mathrm{Cu}-\mathrm{Nb}$ composites with increasing mechanical deformation is a consequence of a deformation-recovery-recrystallization cycle that occurs in the $\mathrm{Cu}$ matrix, thereby, allowing further reductions and refinement of the $\mathrm{Nb}$ 
filament sizes and spacings. Strengthening in $\mathrm{Cu}-\mathrm{Nb}$ composites appears to arise from the $\mathrm{Nb}$ filaments acting as planar barriers to dislocation motion. The large plastic strains developed during mechanical processing result in a drastic reduction in the spacing of these $\mathrm{Nb}$ filaments, and the observed dependence of strengthening on this spacing is in accord with the Hall-Petch relationship. The Hall-Petch constant indicates that pronounced strengthening in the $\mathrm{Cu}-\mathrm{Nb}$ composites is a consequence of the difficulty in transmitting plastic flow between the two phases.

\subsubsection{Modified linear rule of mixture model}

Finally, Raabe and Hangen [25] developed a modified linear rule-of-mixture model. In this model, the sum of volumetric weighted averages of the individual pure metal and a Hall-Petch type contribution resulting from fcc/bcc grain boundaries contribute to the strength of DMMCs. The Hall-Petch term can be calculated from Sevillano's expression [26] for the critical stress for dislocation movement between two impenetrable walls. This model gave the best agreement between theoretical predictions and experimental results.

\subsection{Electrical properties of deformation processed composites}

Spitzig, Verhoeven, and Chumbley [11] at Ames Laboratory showed that deformation processed $\mathrm{Cu}-\mathrm{X}$ (where $\mathrm{X}$ is bcc metal) composite possessed a better combination of strength and electrical conductivity than that of commercially available $\mathrm{Cu}$ alloys. If there is significant solubility of the $\mathrm{X}$ metal in $\mathrm{Cu}$, the electrical conductivity 
will decrease sharply. Kim, Berge, and Verhoeven [27] showed the conductivity of Cu$15 \mathrm{vol} \% \mathrm{Cr}$ decreased monotonically with temperature upon heating, except over a 400 $500^{\circ} \mathrm{C}$ temperature. The decreased conductivity was believed to result from precipitation of $\mathrm{Cr}$.

The electrical properties of Al-20vol\% Ti were also studied [17]. Electrical resistivity, $\rho$, and the ultimate tensile strength of the Al-20vol\%Ti composite at $\eta=12.1$ were measured at $300 \mathrm{~K}$ both before and after 24 hours anneal at $473 \mathrm{~K}$ in vacuum. The annealing treatment had no significant effect on either electrical resistivity or strength at room temperature. Also, the electrical resistivity of Al-20vol\% Ti composite $\eta=12.1$ was measured as a function of heating and cooling. As the temperature increased to around $340^{\circ} \mathrm{C}$, the $\mathrm{Al}$ reacted with $\mathrm{Ti}$ to form $\mathrm{Al}_{3} \mathrm{Ti}$, which permanently increased electrical resistivity. Figure 1.5 shows a plot of electrical resistivity of Al-20vol\%Ti during heating and cooling. 


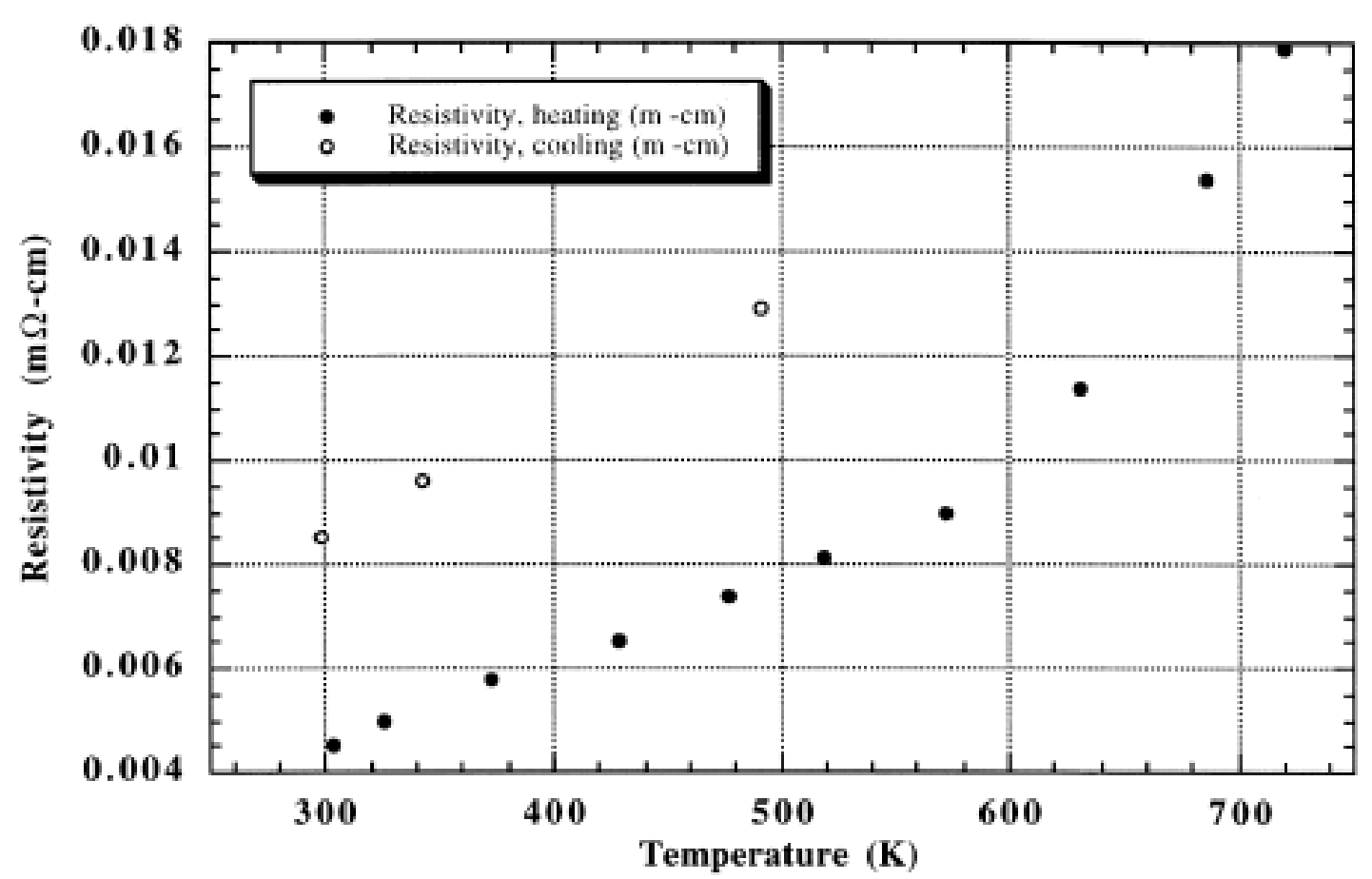

Figure 1.5 A plot of resistivity of Al-20vol\%Ti specimen at $\eta=12.1$ during a heating cycle of $0.055 \mathrm{Ks}^{-1}$ followed by cooling to room temperature.

Russell, et al [19] produced a series of Au-10vol\%Ag DMMCs. The Au-Ag specimen studied had an ultimate tensile strength of $550 \mathrm{MPa}$ and an electrical resistivity only $8 \%$ higher than that of pure Au at a deformation processing true strain of 5.6. Also, Gantovnik, Russell, and Chumbley [28] studied Au-7vol\%Ag, Au-14vol\%Ag, and Au7vol\%Pt DMMCs to combine high strength with high electrical conductivity. The Au7vol\%Ag DMMC at a deformation true strain of 6.3 had an electrical resistivity of 2.418 $\mu \Omega \cdot \mathrm{cm}$ (pure gold is $2.35 \mu \Omega \cdot \mathrm{cm}$ ). Figure 1.6 shows the dependence of the resistivity at 295K of Au-Ag and Au-Pt DMMCs as a function of the deformation. 


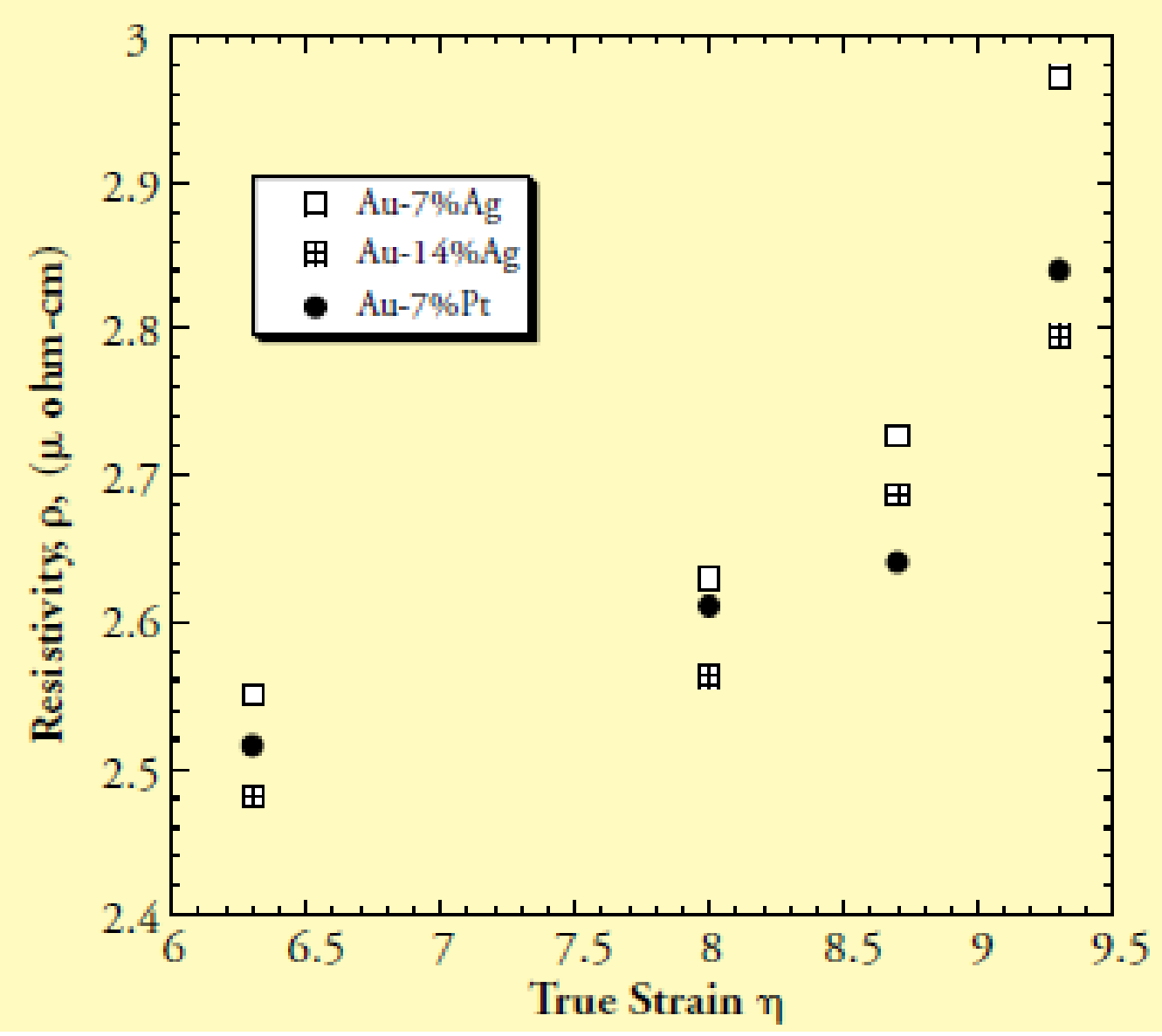

Figure 1.6 Electrical resistivity of $\mathrm{Au}-\mathrm{Ag}$ and $\mathrm{Au}-\mathrm{Pt}$ DMMCs as a function of the amount of imposed deformation [28]

Previous studies [4-5, 16-17, 19, 22, 27-28] for electrical resistivity of DMMCs show that DMMCs have much higher UTS: $\rho$ ratio than that of precipitation-hardened alloys. In the case of Al-Ti DMMC [17], the matrix of the Al-20vol\%Ti DMMC is essentially $99.99 \%$ purity $\mathrm{Al}$ containing some $\mathrm{Al}_{2} \mathrm{O}_{3}$ fragments but with no solid solution elements, GP zones, or other phases or precipitates. Although the electrical resistivity of pure Ti is rather high for a metal $(\rho=42 \mu \Omega \cdot \mathrm{cm}), 80 \%$ of the cross-sectional area of the DMMC is comprised of long strands of high-purity $\mathrm{Al}(2.65 \mu \Omega \cdot \mathrm{cm}$ at $300 \mathrm{~K})$ that form a 
parallel conduction path with the Ti filaments. Table 1.1 shows UTS: $\rho$ ratios of Al20vol\% Ti and commercial Al alloy.

Table 1.1 Comparison of UTS: $\rho$ ratios of the commercial alloy (7079, T73 condition) with the highest ratio to Al-20vol\% Ti DMMC in two conditions

UTS: $\rho$ ratio $\left(\mathrm{MPa} \cdot(\mu \Omega \cdot \mathrm{cm})^{-1}\right)$

Commercial alloy 7049, T73 condition

125.6

Al-20Ti DMMC as drawn $(\eta=12.1)$

138.6

Al-20Ti DMMC with 24 hours, 473K anneal $(\eta=12.1) \quad 138.1$

\subsection{Purpose of the research}

\subsubsection{Conductors}

Electricity is transmitted over long distances on multi-stranded metal cables called “conductors". Four factors dominate materials selection for conductors:

- Cost

- Conductivity (resistivity)

- Strength

- Microstructure stability at elevated temperature

Although the best conducting metals at ambient temperature are $\mathrm{Ag}$ and $\mathrm{Cu}, \mathrm{Al}$ is 
used in nearly all high-voltage lines because it is much lighter and less costly. Materials for conductors should be considered with following eight factors of conductor performance;

- High electrical conductivity

- High strength

- Low weight

- Moderate cost

- Corrosion resistance

- Fatigue resistance

- Creep resistance

- Stability against high-temperature degradation

\subsubsection{Reinforced aluminum conductors}

Pure Al has low resistivity but poor strength, so pure $\mathrm{Al}$ is often reinforced with mild steel, stainless steel (as a core), aluminum alloy, or ceramic filaments to allow the conductor cable to span long distances between pylons without plastically deforming under its own weight and ice or wind loading. Some commonly used reinforced aluminum conductor configurations are shown in Figure 1.7. 
(a)

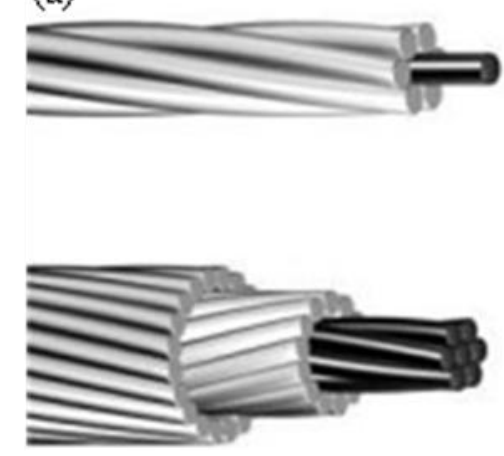

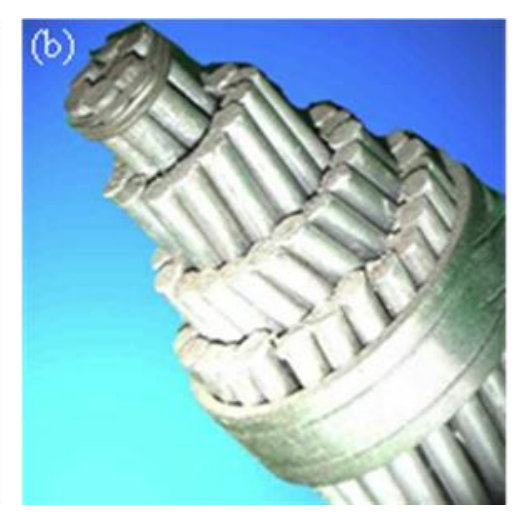

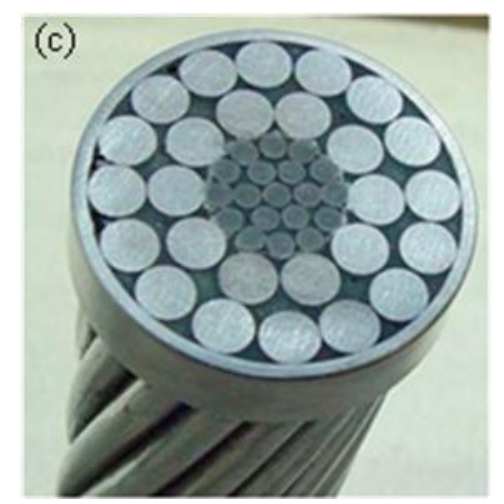

Figure 1.7 Commercial Al conductors with reinforced materials. (a) ACSR (Aluminum Conductor Steel Reinforced) [29], (b) ACAR (Aluminum Conductor Aluminum alloy reinforced) [30], (c) ACCR (Aluminum Conductor Ceramic Reinforced) [31]

ACSR (Aluminum Conductor Steel Reinforced) conductor uses strong steel strands near the core to carry most of the stress and weak, highly conductive pure aluminum strands near the outer surface to carry most of the current. Steel is a poor conductor, but for $\mathrm{AC}$ power, the skin effect moves most of the current near the outer surface where the highly conductive aluminum lies. Steel is inexpensive and holds strength well when hot, but steel is heavy $\left(7.9 \mathrm{~g} / \mathrm{cm}^{3}\right)$; ACSR is considerably heavier than all-Al conductors. $\mathrm{Al}$ and Fe have greatly differing coefficients of thermal expansion and elastic moduli, which cause a number of difficulties in manufacture, spooling, erection, and service performance of ACSR conductors. .

ACAR (Aluminum Conductor Aluminum alloy Reinforced) conductor uses strong $\mathrm{Al}$ alloy strands near the core to carry most of the stress, and weak, highly conductive pure aluminum strands near the outer surface to carry most of the current. Aluminum alloy is a mediocre conductor, but for AC power, the skin effect moves most of the 
current near the outer surface where the more conductive pure aluminum lies. Aluminum alloy costs more than steel, and it weakens when hot, but the alloys are light $\left(2.7 \mathrm{~g} / \mathrm{cm}^{3}\right)$, and the two metals' thermal expansion coefficients and elastic moduli are nearly identical. ACCR (Aluminum Conductor Ceramic Reinforced) conductor uses strong composite (Al oxide $+\mathrm{Al}$ metal) strands near the core to carry most of the stress, and weaker, highly conductive $\mathrm{Al}-\mathrm{Zr}$ alloy strands near the outer surface to carry most of the current. $\mathrm{Al}$ oxide $+\mathrm{Al}$ metal composite is heavier $\left(3.4 \mathrm{~g} / \mathrm{cm}^{3}\right)$ than $\mathrm{Al}$ and a mediocre conductor, but its sag resistance at high temperature is outstanding. ACCR costs about five times more than ACSR, but for high-ampacity, restricted right-of-way situations, it can be an excellent option.

\subsubsection{Aluminum-Iron composite conductor}

Previous results of DMMCs $[4-5,7-11,13-19,21-23,27-28,32-34]$ indicate that heavily deformation-processed composite wire made with an fcc $\mathrm{Al}$ matrix and bcc $\mathrm{Fe}$ reinforcement ribbons should have combined strength and electrical conductivity better than ACCR. Note: conductivity of ACCR is $0.349(\mu \Omega \cdot c m)^{-1}$ at Al-Zr alloy and 0.134 $(\mu \Omega \cdot \mathrm{cm})^{-1}$ at $\mathrm{Al}$ oxide [31]. Al-Fe composite is also expected to have superior resistance to microstructure coarsening and strength degradation at high temperature. ACCR cable starts to degrade irreversibly at about $240^{\circ} \mathrm{C}[31]$, while $\mathrm{Al}-\mathrm{Fe}$ interface and morphology are expected to remain stable to $300^{\circ} \mathrm{C}$ or above. 


\subsubsection{Aluminum-Calcium composite conductor}

Aluminum is almost universally accepted as the best material for overhead conductors when all factors are considered. Calcium has several desirable properties for a reinforcement phase in aluminum:

- Good conductivity: $0.294(\mu \Omega \cdot \mathrm{cm})^{-1}$

- Strength similar to Al

- Exceptionally low density: $1.55 \mathrm{~g} / \mathrm{cm}^{3}$

- Abundant and inexpensive

- Near zero Ca solubility in Al and vice versa

- Non-toxic

- Thermal expansion coefficient nearly identical to Al's

Aluminum and calcium provide a desirable combination of high conductivity, low cost, and low density. Aluminum and calcium are both highly ductile metals that tolerate extensive deformation without fracture. Aluminum and calcium are the $4^{\text {th }}$ and $6^{\text {th }}$ best conducting elements. The $1^{\text {st }}, 2^{\text {nd }}, 3^{\text {rd }}$, and $5^{\text {th }}$ best conductors $(\mathrm{Ag}, \mathrm{Cu}, \mathrm{Au}$, and $\mathrm{Be}$, respectively) are all considerably more expensive and less abundant than $\mathrm{Al}$ and $\mathrm{Ca} . \mathrm{Al}$ and $\mathrm{Ca}$ densities are also low $\left(\mathrm{Al}: 2.70 \mathrm{~g} / \mathrm{cm}^{3}\right.$ and $\left.\mathrm{Ca}: 1.557 \mathrm{~g} / \mathrm{cm}^{3}\right)$.

The purpose of the research proposed for this project is to characterize a deformation-processed metal/metal composite for high-conductivity, high-strength, lowdensity conductor wire for electric power transmission. To achieve this purpose, an Al-Ca DMMC was chosen for study. 


\subsection{References}

1. Callister, W.D., Materials science and engineering : an introduction. 7th ed. 2007, New York: John Wiley \& Sons. xxv, 721, A41, G14, S5, I22 p.

2. Kelly, A. and W.R. Tyson, Tensile Properties of Fibre-Reinforced Metals Copper/Tungsten and Copper/Molybdenum. Journal of the Mechanics and Physics of Solids, 1965. 13(6): p. 329-\&.

3. Nielsen, L.F., Composite materials : properties as influenced by phase geometry. 2005, Berlin: Springer-Verlag. xv, 259 p.

4. $\mathrm{Xu}, \mathrm{K} ., \mathrm{K}$. Wongpreedee, and A.M. Russell, Microstructure and strength of a deformation processed Al-20\%Sn in situ composite. Journal of Materials Science, 2002. 37(24): p. 5209-5214.

5. $\mathrm{Xu}, \mathrm{K}$. , et al., Characterization of strength and microstructure in deformation processed Al-Mg composites. Journal of Materials Science, 1999. 34(24): p. 59555959.

6. Russell, A.M., et al., In-Situ Strengthening of Titanium with Yttrium - Texture Analysis. Journal of Materials Science, 1995. 30(17): p. 4249-4262.

7. Verhoeven, J.D., et al., Copper-Refractory Metal-Alloys. Journal of Metals, 1986. 38(9): p. 20-24.

8. Verhoeven, J.D., et al., Measurement of Filament Spacing in Deformation Processed Cu-Nb Alloys. Acta Metallurgica Et Materialia, 1991. 39(11): p. 28252834.

9. Pourrahimi, S., H. Nayebhashemi, and S. Foner, Strength and Microstructure of 
Powder-Metallurgy Processed Restacked $\mathrm{Cu}-\mathrm{Nb}$ Microcomposites. Metallurgical Transactions a-Physical Metallurgy and Materials Science, 1992. 23(2): p. 573586.

10. Pourrahimi, S., H.N. Hashemi, and S. Foner, High-Strength High-Conductivity Cu-Nb Microcomposite Wire by Powder-Metallurgy. Journal of Materials Science Letters, 1990. 9(12): p. 1484-1487.

11. Spitzig, W.A., A.R. Pelton, and F.C. Laabs, Characterization of the Strength and Microstructure of Heavily Cold-Worked $\mathrm{Cu}$-Nb Composites. Acta Metallurgica, 1987. 35(10): p. 2427-2442.

12. Kelly, A., High Strength Materials. Contemporary Physics, 1967. 8(4): p. 313-\&.

13. Thieme, C.L.H., S. Pourrahimi, and S. Foner, High-Strength Al Metal-Matrix Microcomposite Wire with 20 Vol-Percent Nb and Ultimate Tensile Strengths up to 1030 Mpa. Scripta Metallurgica Et Materialia, 1993. 28(8): p. 913-918.

14. Spitzig, W.A., C.L. Trybus, and F.C. Laabs, Structure Properties of Heavily Cold-Drawn Niobium. Materials Science and Engineering a-Structural Materials Properties Microstructure and Processing, 1991. 145(2): p. 179-187.

15. Bevk, J., J.P. Harbison, and J.L. Bell, Anomalous increase in strength of in situ formed $\mathrm{Cu}-\mathrm{Nb}$ multifilamentary composites. Journal of Applied Physics, 1978. 49(12): p. 6031 - 6038.

16. Russell, A.M., T.W. Ellis, and L.S. Chumbley, In-Situ Strengthening of Titanium with Yttrium. Journal of Materials Science, 1995. 30(8): p. 2070-2076.

17. Russell, A.M., et al., A high-strength, high-conductivity Al-Ti deformation processed metal metal matrix composite. Composites Part A-Applied Science and 
Manufacturing, 1999. 30(3): p. 239-247.

18. Funkenbusch, P.D. and T.H. Courtney, On the Strength of Heavily Cold-Worked In-situ Composites. Acta Metallurgica, 1985. 33(5): p. 913-922.

19. Russell, A., et al., A new method for strengthening gold. Gold Bulletin, 1998. 31(3): p. 88-92.

20. Agarwal, B.D., L.J. Broutman, and K. Chandrashekhara, Analysis and performance of fiber composites. 3rd ed. 2006, Hoboken, N.J.: John Wiley. xiv, $562 \mathrm{p}$.

21. Jensen, J.A., et al., Hcp Matrix In-situ Composites. Light Metals 1995, 1995: p. 1367-1374.

22. $\mathrm{Xu}, \mathrm{K}$., et al., A deformation processed Al-20\%Sn in-situ composite. Scripta Materialia, 2001. 44(6): p. 935-940.

23. Embury, J.D., A.S. Keh, and R.M. Fisher, Substructure Strengthening in Mechanical Working Processes. Journal of Metals, 1965. 17(9): p. 1016-\&.

24. Everett, R.K., Strengthening Mechanisms in Deformation Processed CompositeMaterials. Scripta Metallurgica, 1988. 22(8): p. 1227-1230.

25. Raabe, D. and U. Hangen, Simulation of the yield strength of wire drawn Cubased in-situ composites. Computational Materials Science, 1996. 5(1-3): p. 195202.

26. Sevillano, J.G., Substructure and Strengthening of Heavily Deformed Single and 2-Phase Metallic Materials. Journal De Physique Iii, 1991. 1(6): p. 967-988.

27. Kim, S.T., P.M. Berge, and J.D. Verhoeven, Deformation-Processed CopperChromium Alloys - Optimizing Strength and Conductivity. Journal of Materials 
Engineering and Performance, 1995. 4(5): p. 573-580.

28. Gantovnik, V., et al., Advances in deformation processed gold composites. Gold Bulletin, 2000. 33(4): p. 128-+.

29. http://www.southwire.com/products/ACSR.htm.

30. http://www.cable.alcan.com.

31. http://multimedia.3m.com.

32. Thieme, C.L.H., S. Pourrahimi, and S. Foner, High strength Al metal-matrix microcomposite wire with $20 \mathrm{vol} \% \mathrm{Nb}$ and ultimate tensile strengths up to 1030 MPa. Journal Name: Scripta Metallurgica et Materialia; (United States); Journal Volume: 28:8, 1993: p. Medium: X; Size: Pages: 913-918.

33. Chumbley, L.S., et al., Electron-Microscopy Observation of an Insitu $\mathrm{Cu}-\mathrm{Nb}$ Composite. Materials Science and Engineering a-Structural Materials Properties Microstructure and Processing, 1989. 117: p. 59-65.

34. Ellis, T.W. and E.D. Gibson, New Extensions in the Development of Deformation Processed Metal-Metal Matrix Composites. First International Conference on Processing Materials for Properties, 1993: p. 19-22. 


\section{CHAPTER 2. EXPERIMENTAL PROCEDURES}

\subsection{Material preparation}

In this study, powder metallurgy and deformation processing were used to produce Al-Ca composites. Powder metallurgy is the process of blending fine powdered materials, pressing (compacting), and heating (sintering) or co-deforming them[1]. In powder metallurgy, all considerations of solid-liquid phase changes can be ignored, so powder processes can be used to produce DMMCs of metals that could not be processed by comelting (i.e., $\mathrm{Al}$ and $\mathrm{Fe}, \mathrm{Al}$ and $\mathrm{Ca}$ ).

\subsubsection{Al-Fe DMMCs}

The commercial-purity of A1000C Fe powder from Hoeganaes Corp. was used for this study. This powder size is $<63 \mu \mathrm{m}$. High-purity (99.99\%) Al powder produced by the gas atomized rapid solidification (GARS) method at Ames Laboratory. The Al powder was selected by size range of $20-45 \mu \mathrm{m}$ and $45-75 \mu \mathrm{m}$. The two powders were blended together with two composition ratios and two powder size ranges:

- $\quad 93 \mathrm{vol} \% \mathrm{Al}(20-45 \mu \mathrm{m})-7 \mathrm{vol} \% \mathrm{Fe}(20-45 \mu \mathrm{m})$

- $\quad 93 \mathrm{vol} \% \mathrm{Al}(45-75 \mu \mathrm{m})-7 \mathrm{vol} \% \mathrm{Fe}(<20 \mu \mathrm{m})$

- $\quad 90 \mathrm{vol} \% \mathrm{Al}(45-75 \mu \mathrm{m})-10 \mathrm{vol} \% \mathrm{Fe}(<20 \mu \mathrm{m})$

- $80 \mathrm{vol} \% \mathrm{Al}(45-75 \mu \mathrm{m})-20 \mathrm{vol} \% \mathrm{Fe}(45-63 \mu \mathrm{m})$ 
The blended Al-Fe powders were poured into a $\mathrm{Cu}$ tube (inner diameter $=25.4 \mathrm{~mm}$, wall thickness $=1.588 \mathrm{~mm}$, height $=101.75 \mathrm{~mm}$ ). The specimen and $\mathrm{Cu}$ tube were extruded at $227^{\circ} \mathrm{C}$ with $27.5 \mathrm{MPa}$ pressure through a back extrusion die with an 11.68 $\mathrm{mm}$ inlet diameter and a $5.69 \mathrm{~mm}$ outlet diameter. The yield strengths of pure $\mathrm{Fe}$ and pure $\mathrm{Al}$ (1060-O aluminum alloy) by elevated temperature from $-200^{\circ} \mathrm{C}$ to $200^{\circ} \mathrm{C}$ were drawn in Figure 2.1. The yield strength of pure Fe is higher than pure Al by $84 \mathrm{MPa}$ at room temperature. This gap can be reduced by increasing temperature. In $200^{\circ} \mathrm{C}$, the gap is $73 \mathrm{MPa}$.

The extruded specimen and $\mathrm{Cu}$ tube assembly was swaged to true strain deformation of $\eta=7.6($ diameter $=0.635 \mathrm{~mm})$. 


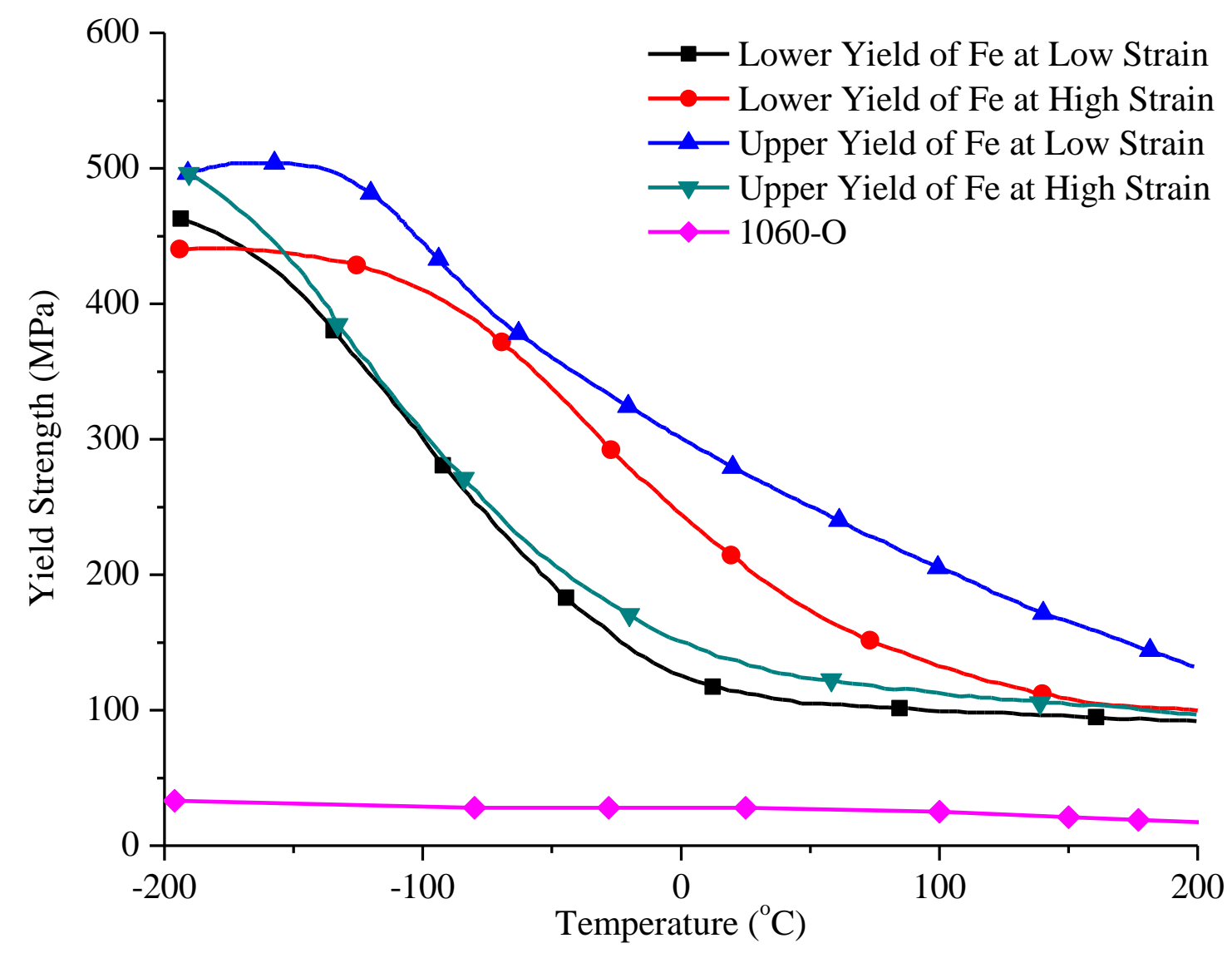

Figure 2.1 Plots of yield Strength of High-purity Iron and 1060-O Aluminum Alloy [2-3]

\subsubsection{Preceding experiment for Al-Ca DMMCs}

A proof of concept trial to demonstrate that DMMCs of $\mathrm{Al}$ and alkaline earth metal could be made was performed with GARS Al power $(21-54 \mu \mathrm{m})$ and $\mathrm{Ca}$ granules (technical grade purity, 2-10 mm). The Ca granules were cut into $\sim 1 \mathrm{~mm}$ with chopping with a hand knife. Al powders and Ca granules were blended with 0.9 volume fraction of $\mathrm{Al}$ and 0.1 volume fraction of $\mathrm{Ca}$. The blended $\mathrm{Al}-10 \mathrm{vol} \% \mathrm{Ca}$ was poured into a $\mathrm{Cu}$ tube (inner diameter $=25.4 \mathrm{~mm}$, wall thickness $=1 \mathrm{~mm}$ ) and two $1100 \mathrm{Al}$ alloy plugs $($ diameter $=25.4 \mathrm{~mm}$, height $=12.7 \mathrm{~mm})$ were placed at each end of the tube to prevent 
the blended Al-10vol\%Ca from plastically flowing out the ends of the tube. The specimen was pressed in a hand press machine, model 9312 of Carver Inc., with 3.95MPa for 2 hours. The pressed specimen and $\mathrm{Cu}$ tube assembly was swaged to a true strain deformation strain of $\eta=7.18$ (diameter $=0.72 \mathrm{~mm}$ ). All deformation was done at room temperature.

\subsubsection{Al-Ca DMMCs}

High-purity (99.99\%) Al powder produced by the GARS method was obtained from Iver Anderson's group at Ames Laboratory. This powder had a particle size range of 20$45 \mu \mathrm{m}$. The Ca powder used was $99.5 \%$ purity, and the $\mathrm{Ca}$ average particle size was quite large $(\sim 1.2 \mathrm{~mm})$. Finer particle size Ca powder is not commercially available. The two powders were blended together with three composition ratios:

- $97 \mathrm{vol} \% \mathrm{Al}-3 \mathrm{vol} \% \mathrm{Ca}$

- $94 \mathrm{vol} \% \mathrm{Al}-6 \mathrm{vol} \% \mathrm{Ca}$

- $91 \mathrm{vol} \% \mathrm{Al}-9 \mathrm{vol} \% \mathrm{Ca}$

A commercial-purity $1100 \mathrm{Al}$ alloy can (outside diameter $88.9 \mathrm{~mm}$, inside diameter $81.2 \mathrm{~mm}$ ) was prepared to hold the three $\mathrm{Al}+\mathrm{Ca}$ powder compacts for extrusion along with a pure $\mathrm{Al}$ powder compact control specimen. The mixed powders were pressed into the extrusion can with a pressure of 6.55 to $8.73 \mathrm{MPa}$. Unfilled volume was filled with a solid MIC-6 Al alloy plug which has a yield strength (105MPa) close to that of $1100 \mathrm{Al}$ 
alloy (103MPa) [4]. To separate the compositions, thin Fe sheets were placed between the different compositions (Figure 2.2). The pressed can was sealed by e-beam welding in a vacuum chamber at a pressure of $3.2 \times 10^{-5} \mathrm{~Pa}$.
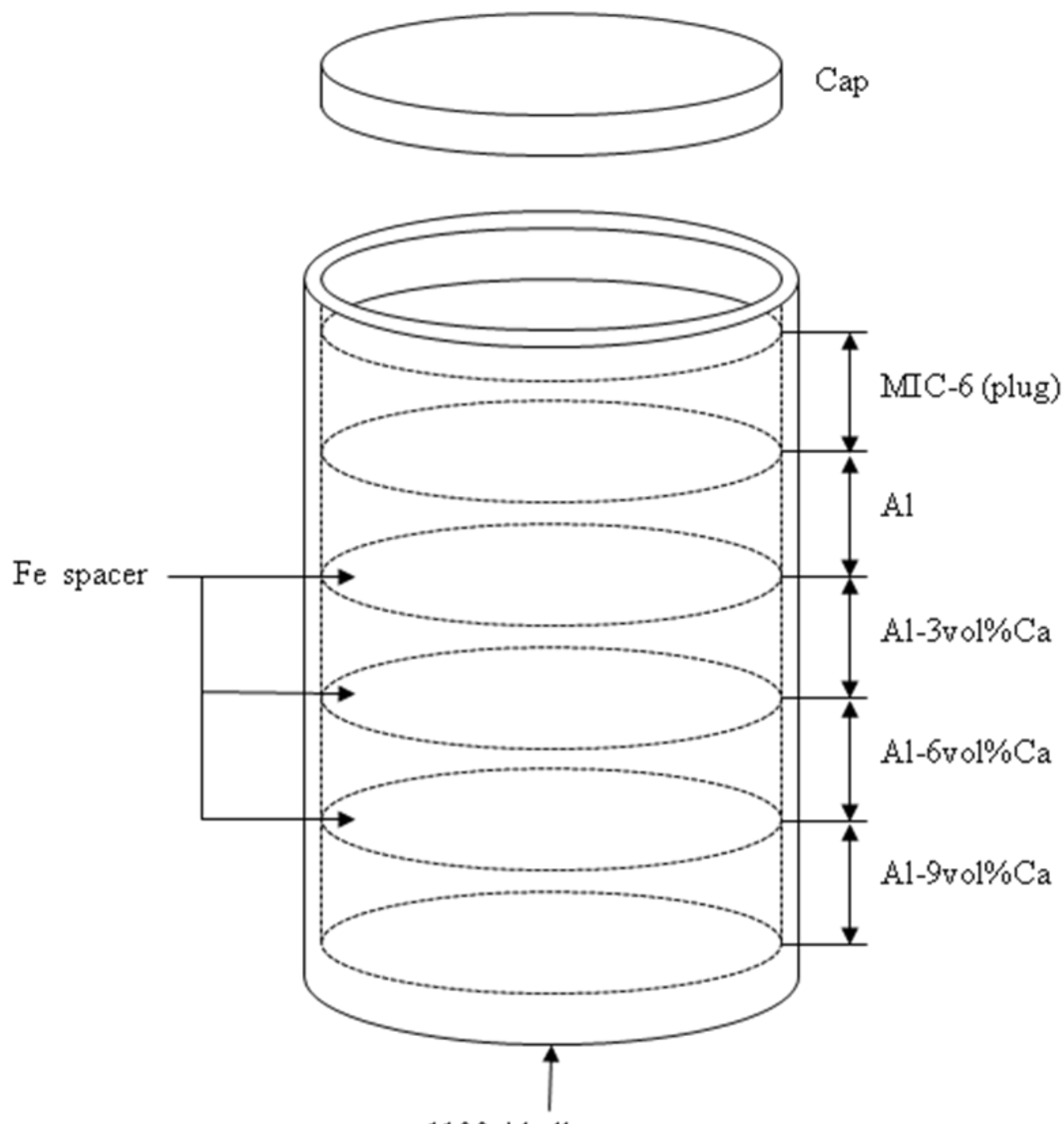

1100 Al alloy can

Figure 2.2 Schematic drawing of preparation $1100 \mathrm{Al}$ alloy can and specimens 


\subsection{Mechanical deformation}

Extrusion was performed at the SAPA, Inc. facility in Portland, OR. The extrusion can and its contents were extruded at approximately $287^{\circ} \mathrm{C}$ with $26.2 \mathrm{MPa}$ pressure through a conical extrusion die with an $81.23 \mathrm{~mm}$ inlet diameter and a $22.1 \mathrm{~mm}$ outlet diameter. During extrusion, the temperature was not monitored precisely since it was not possible to insert a thermocouple inside the extrusion can. The extrusion die was preheated by a torch, but its exact temperature at the time of extrusion is unknown. Heat generated from deformation work can be calculated by the following equation [5]:

$$
\Delta T=\frac{\alpha \cdot \bar{\sigma} \cdot \bar{\varepsilon}}{\rho \cdot C}
$$

where $\bar{\sigma}$ is the average flow stress, $\bar{\varepsilon}$ is the effective strain, $\rho$ is the density, $C$ is the heat capacity, and $\alpha$ is the fraction of energy stored. For metal the value of fraction of energy stored is " 1 " [5]. Because the $1100 \mathrm{Al}$ alloy has a higher value of yield strength than pure $\mathrm{Al}$ and pure $\mathrm{Ca}$, the amount of temperature increase of the extrusion can and specimens should be less than the amount of the temperature increase of $1100 \mathrm{Al}$ alloy. For $1100 \mathrm{Al}$ alloy with the same shape and size as the extrusion can, the temperature increase can be calculated as:

$$
\Delta T=\frac{\alpha \cdot \bar{\sigma} \cdot \bar{\varepsilon}}{\rho \cdot C}=\frac{1 \times 26.2 \mathrm{MPa} \times 2.25}{2.71 \mathrm{~g} / \mathrm{cm}^{3} \times 0.904 \mathrm{~J} /(\mathrm{g} \cdot \mathrm{K})}=24.1 \mathrm{~K}
$$


The actual temperature increase during extrusion of the Al-Ca powder compacts with their extrusion can would be expected to be lower than $24.1 \mathrm{~K}$. According to the $\mathrm{Al}-\mathrm{Ca}$ phase diagram, no solid-liquid phase transformations occur under $829 \mathrm{~K}$, so assuming a $24 \mathrm{~K}$ temperature increase from the deformation itself, the composite should have been entirely solid throughout the extrusion process. According to the Al-Ca phase diagram, the lowest transformation or formation temperature in the $\mathrm{Al}-\mathrm{Ca}$ system is $728 \mathrm{~K}$ for the fcc-to-bcc transformation in Ca. It is also worth noting that an fcc-to-bcc phase transformation occurs at room temperature in $\mathrm{Ca}$ at pressures above $19.5 \mathrm{GPa}$. Although no pressure-temperature phase diagram for $\mathrm{Ca}$ was found in the literature, the pressure during extrusion was almost certainly below $1 \mathrm{GPa}$, so no fcc-bcc phase transformation of $\mathrm{Ca}$ would be expected if one assumes a linear relationship between the two aforementioned fcc-bcc transformation values. The extrudate was cooled with room temperature water immediately after extrusion. A magnet was used to detect the locations of the Fe spacers, so the extruded specimens of various compositions within the $1100 \mathrm{Al}$ alloy sleeve could be cut into rods of each composition. 


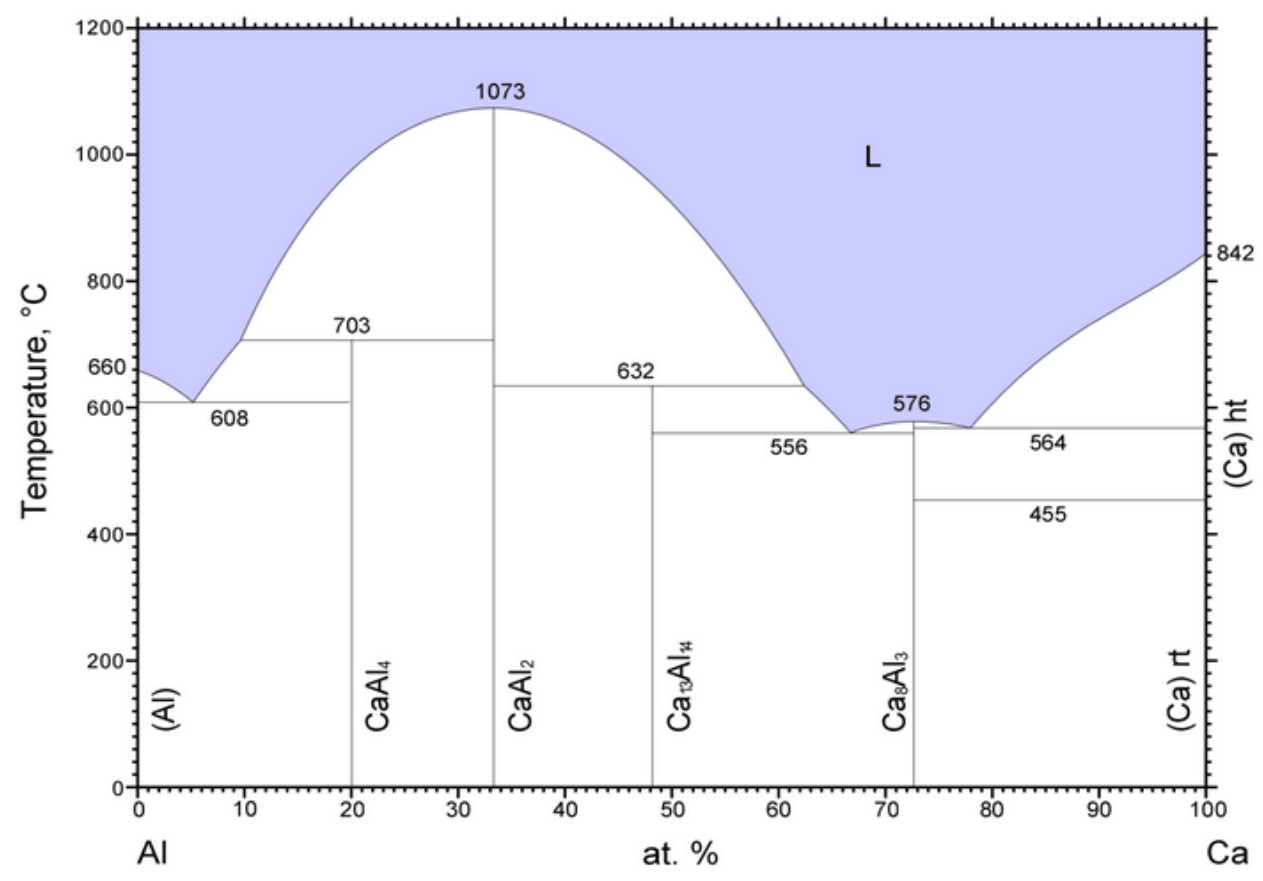

Figure 2.3 Al-Ca equilibrium phase diagram [6]

The deformation true strain, $\eta$, is defined as $\eta=2 \ln \left(\mathrm{d}_{0} / \mathrm{d}_{\mathrm{f}}\right)$, where $\mathrm{d}_{0}$ and $\mathrm{d}_{\mathrm{f}}$ are the initial and final specimen diameters, respectively. The extruded rod specimens were swaged to a diameter of $6.35 \mathrm{~mm}(\eta=4.86)$ then wire drawn to a diameter of $1 \mathrm{~mm}$ $(\eta=8.55)$. In an effort to develop finer, more closely spaced Ca filaments [7], the wires at $\eta=8.55$ were cut to $35 \mathrm{~mm}$ long and bundled/packed into a fully annealed $\mathrm{Cu}$ tube (inside diameter $=25.4 \mathrm{~mm}$ ) then swaged to a diameter of $6.8 \mathrm{~mm}$ and wire drawn to a diameter of $1.7 \mathrm{~mm}(\eta=13.76)$. The true strains of the bundled specimens were calculated by measuring images of a transverse cross section with a JEOL JSM-606LV scanning electron microscope (SEM) (Figure 2.4). The specimens were cut and set aside for later analysis at deformation true strains of $\eta=6.27,8.55,10.34,12.45$ and 13.76 . 


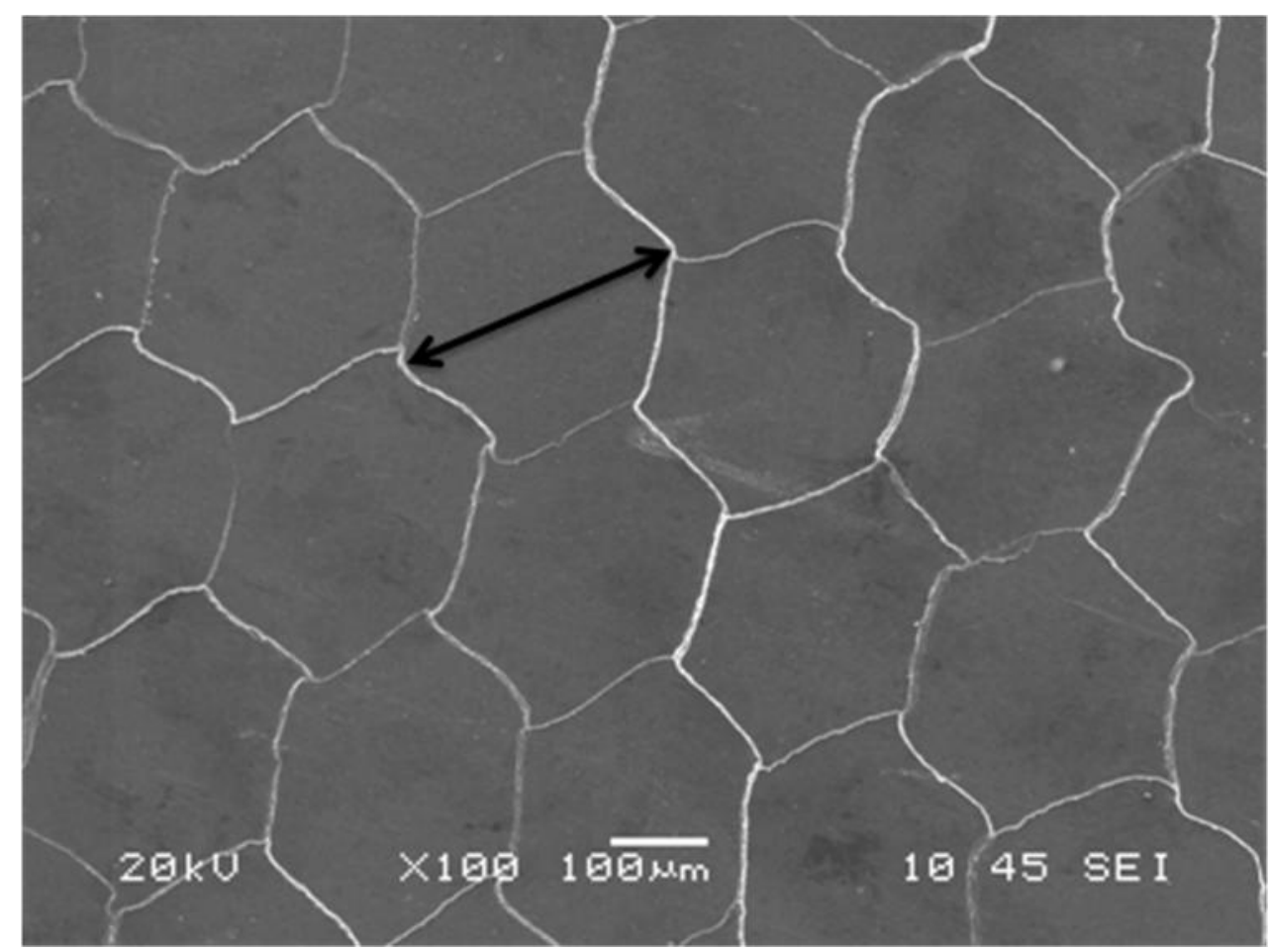

Figure 2.4 SEM image of transverse cross section of the bundled-wire specimen for measuring the true strain of $\eta=12.45$

\subsection{Mechanical testing}

Tensile tests were performed for specimens with $\eta=6.27,8.55,12.45$ and 13.76 for Al-9vol\%Ca. The pure Al, Al-3vol\%Ca, and Al-6vol\%Ca specimens were tested at $\eta=6.27$. Heat treatments at $200^{\circ} \mathrm{C}$ and $350^{\circ} \mathrm{C}$ for 4 hours were performed on tensile specimens with $\eta=6.27$. Non-standard tensile specimens were used for small-diameter specimens. Ultimate tensile strength (UTS) of every specimen was averaged from at least two tensile tests (UTS=F/A, where F and A are the applied maximum load and the initial cross sectional area of the specimen). The UTS of a material is generally a less useful metric than yield strength in static design for ductile metals [8]; however, the 
measurement of UTS is highly reproducible and more easily obtained in small tensile specimens [8]. In this study, the small specimen size of the Al-Ca composites made UTS the only strength value that could be reliably measured in tensile tests performed without an extensometer. UTS For the bundled specimen with $\eta=10.34$, an approximate UTS value was estimated from Vickers microhardness test data taken with a $100 \mathrm{~g}$ load; microhardness data were used because the bundled wires were not yet sufficiently well consolidated to allow tensile testing.

\subsection{Microstructure analysis}

Microstructure images of specimens with $\eta=2.25,4.89,6.27,8.55,12.45$ and 13.76 were taken with a JEOL JSM-606LV scanning electron microscope (SEM). Every specimen was prepared with transverse and longitudinal polished cross sections. SEM specimens were made by dry polishing with silicon carbide grinding papers only. Ca's rapid reaction with water and oxygen prevented use of all conventional polishing fluids.

In this study, the average Ca filament thickness, $t$, and the mean free path, $\lambda$ (or uninterrupted distance between Ca filaments), were determined by quantitative stereology [9]. The number of interceptions with Ca filaments per unit length, $\mathrm{N}_{\mathrm{L}}$, is the same as the number of interceptions with Al matrix per unit length. Mean free path, $\lambda$, is calculated with the equation $\lambda=\left(1-\mathrm{V}_{\mathrm{f}}\right) / \mathrm{N}_{\mathrm{L}}=\mathrm{V}_{\mathrm{m}} / \mathrm{N}_{\mathrm{L}}$, where $\mathrm{V}_{\mathrm{f}}$ is the volume fraction of Ca filaments and $\mathrm{V}_{\mathrm{m}}$ is the volume fraction of $\mathrm{Al}$ matrix. The average Ca filament thickness, $\mathrm{t}$, is given by $t=\left(1-V_{m}\right) / N_{L}=V_{f} / N_{L}$.

X-ray diffraction (XRD) patterns were obtained from Al-9vol\%Ca with a Scintag X- 
ray diffractometer with a $\mathrm{Cu}$ anode (wavelength $=1.54187 \AA$ ) at a scan rate of 0.1 degree per minute. As-extruded rod $(\eta=2.25)$ and bundled wire $(\eta=13.76)$ were analyzed by XRD. In addition, a specimen with $\eta=13.76$ was cut into 3 pieces, then heat treated at $200^{\circ} \mathrm{C}$ for 16 hours and $300^{\circ} \mathrm{C}$ for 2 hours, respectively. The third piece was given no heat treatment. For more precise XRD analysis, 3 specimens with $\eta=13.76$ were reduced to powder $(<200 \mu \mathrm{m})$ in a glove box with a dry nitrogen atmosphere.

Specimens with $\eta=6.27$ were prepared with the various heat treatments shown in

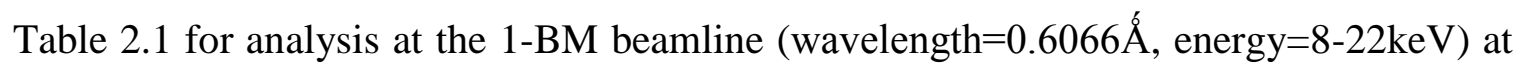
the Advanced Photon Source (APS) at Argonne National Laboratory [10]. The specimens were exposed to X-rays at room temperature for $200 \mathrm{sec}(\mathrm{dwell}=0.5 \mathrm{sec}$, repeat $=400)$. 
Table 2.1 Heat treatment conditions of $\mathrm{Al}-9 \mathrm{vol} \% \mathrm{Ca}(\eta=6.27)$ for $\mathrm{XRD}$ analysis at $1-\mathrm{BM}$ beamline at APS

\begin{tabular}{ccl}
\hline \multirow{2}{*}{ Specimen Designation } & \multicolumn{2}{c}{ Heat Treatment } \\
\cline { 2 - 3 } noHT & Temperature $\left({ }^{\circ} \mathrm{C}\right)$ & Time \\
\hline $225 \_05 \mathrm{~m}$ & 225 & none \\
\hline $225 \_20 \mathrm{~m}$ & 225 & $5 \mathrm{~min}$ \\
$225 \_01 \mathrm{~h}$ & 225 & $20 \mathrm{~min}$ \\
$225 \_04 \mathrm{~h}$ & 225 & 1 hour \\
$275 \_01 \mathrm{~m}$ & 275 & 4 hours \\
$275 \_05 \mathrm{~m}$ & 275 & $1 \mathrm{~min}$ \\
$275 \_10 \mathrm{~m}$ & 275 & $5 \mathrm{~min}$ \\
$275 \_01 \mathrm{~h}$ & 275 & $10 \mathrm{~min}$ \\
$275 \_04 \mathrm{~h}$ & 275 & 1 hour \\
\hline
\end{tabular}

Al-9vol\%Ca specimens with diameter of $1 \mathrm{~mm}(\eta=8.55$ and 13.76 (bundled)) were prepared with the various heat treatments shown in Table 2.2 for XRD analysis during tensile tests at room temperature and high temperature $\left(325,350,375,400,430^{\circ} \mathrm{C}\right)$ annealing for kinetics experiments at the 1-ID-C beamline (wavelength=0.117 energy $=70 \mathrm{keV}, \mathrm{Ge} \& \mathrm{Si}$ solid state detectors) at the Advanced Photon Source (APS) at Argonne National Laboratory [11]. 
Table 2.2 Heat treatment conditions of Al-9vol\%Ca $(\eta=8.55,13.76)$ for XRD analysis at 1-ID-C beamline at APS

\begin{tabular}{|c|c|c|c|}
\hline \multirow{2}{*}{$\begin{array}{c}\text { Specimen } \\
\text { Designation }\end{array}$} & \multirow{2}{*}{$\begin{array}{c}\text { Deformation } \\
\text { True Strain }(\eta)\end{array}$} & \multicolumn{2}{|c|}{ Heat Treatment } \\
\hline & & Temperature $\left({ }^{\circ} \mathrm{C}\right)$ & Time (hour) \\
\hline 100 & 8.55 & none & none \\
\hline 111 & 8.55 & 240 & 1 \\
\hline 112 & 8.55 & 240 & 4 \\
\hline 113 & 8.55 & 240 & 12 \\
\hline 114 & 8.55 & 240 & 24 \\
\hline 115 & 8.55 & 240 & 48 \\
\hline 121 & 8.55 & 300 & 1 \\
\hline 122 & 8.55 & 300 & 4 \\
\hline 123 & 8.55 & 300 & 12 \\
\hline 124 & 8.55 & 300 & 24 \\
\hline 125 & 8.55 & 300 & 48 \\
\hline 200 & 13.76 & none & none \\
\hline 211 & 13.76 & 240 & 1 \\
\hline 212 & 13.76 & 240 & 4 \\
\hline 213 & 13.76 & 240 & 12 \\
\hline 214 & 13.76 & 240 & 24 \\
\hline 215 & 13.76 & 240 & 48 \\
\hline 221 & 13.76 & 300 & 1 \\
\hline 222 & 13.76 & 300 & 4 \\
\hline 223 & 13.76 & 300 & 12 \\
\hline 224 & 13.76 & 300 & 24 \\
\hline 225 & 13.76 & 300 & 48 \\
\hline
\end{tabular}


For tensile tests with small diameter specimens $(1 \mathrm{~mm})$, pin vice grips were used (Figure 2.5). Due to insufficient gauge length for attaching extensometers, two Molybdenum (Mo) strips ( $0.125 \mathrm{~mm}$ thick) were attached at the both ends of a gauge section for measurement of elongation (Figure 2.6).

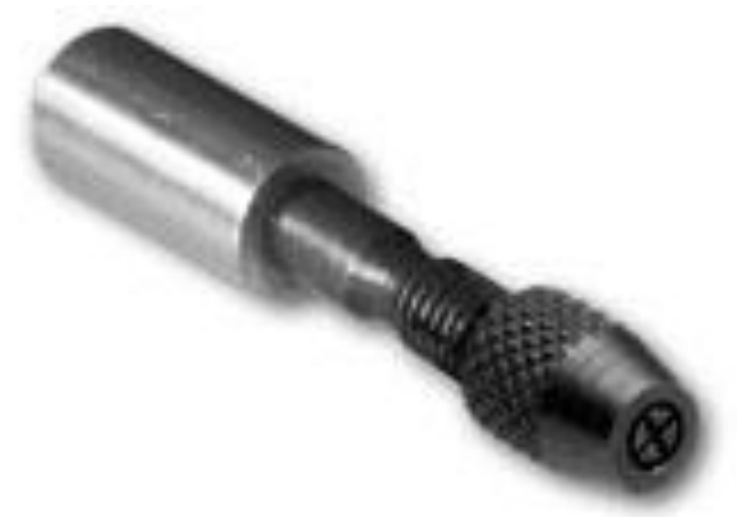

Figure 2.5 Photograph of pin vice grip used for tensile tests for small diameter specimens [12].

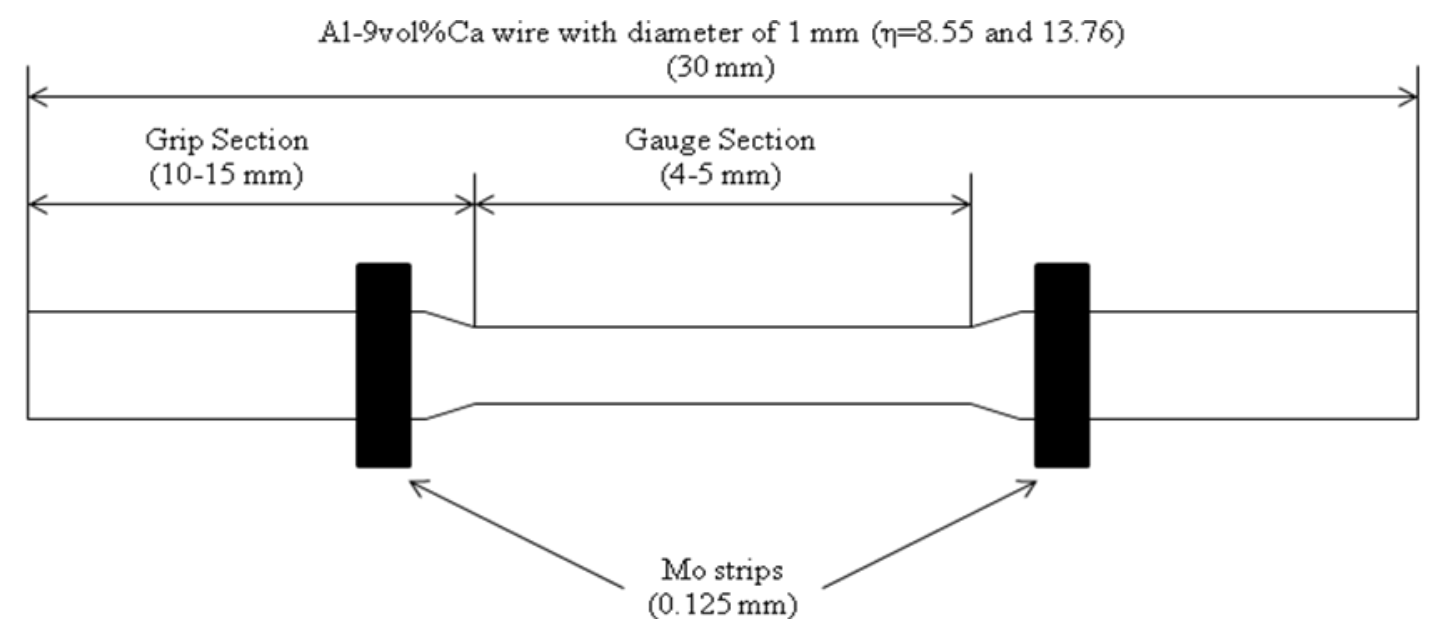

Figure 2.6 Schematic drawing of specimen with Mo strips for tensile tests. 
An infrared (IR) furnace (model 5705, Research Inc.) was used for high temperature $\left(325,350,375,400,430^{\circ} \mathrm{C}\right)$ annealing for kinetics experiments. Two K-type thermocouples for control temperature were mounted near the specimen. For precise control of temperature during experiments, two thermocouples were located at $2 \mathrm{~mm}$ under the X-ray spot of specimens (Figure 2.7).

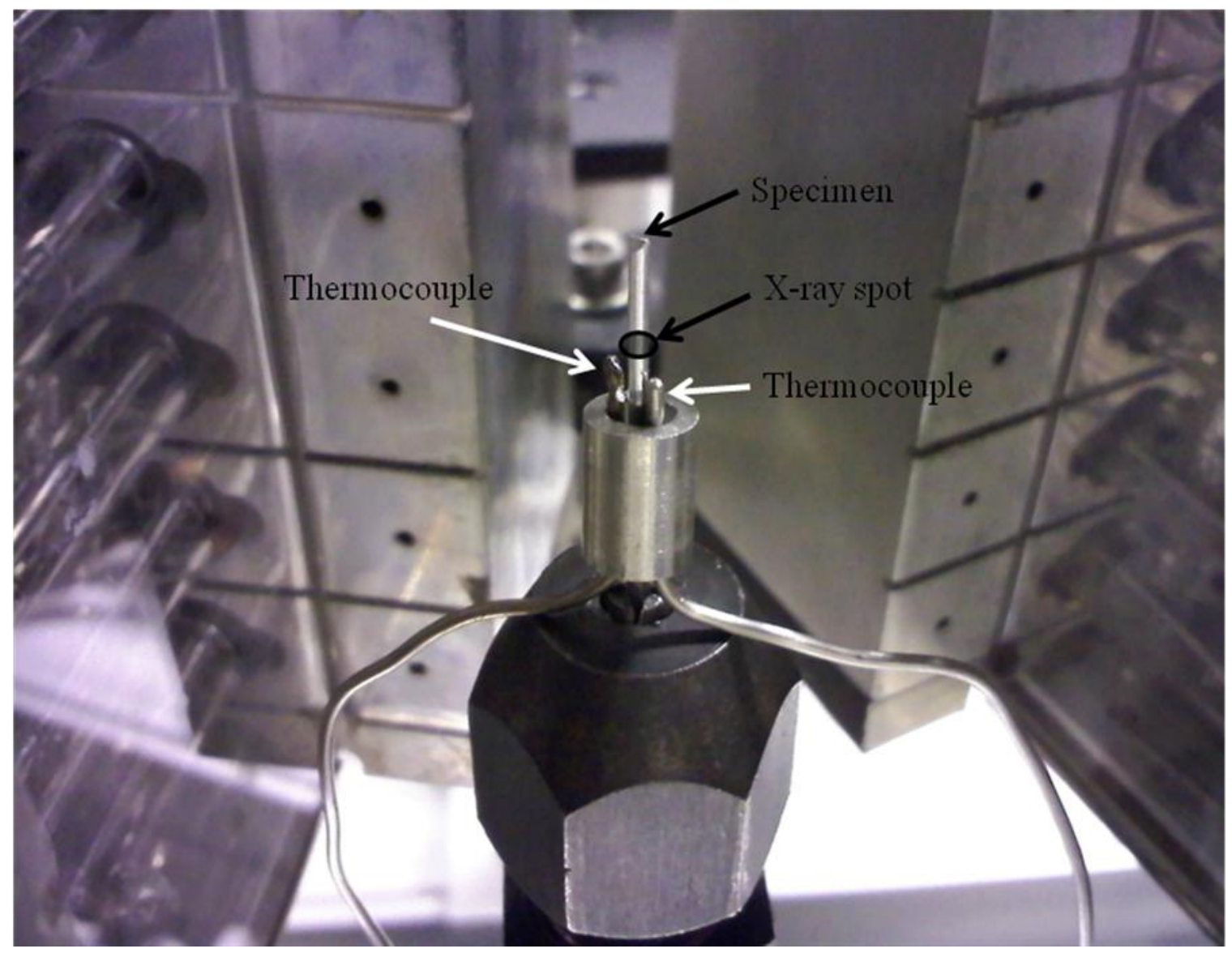

Figure 2.7 Photograph of specimen for kinetics 


\subsection{References}

1. DeGarmo, E.P., J.T. Black, and R.A. Kohser, Materials and processes in manufacturing. 6th ed. 1984, New York: Macmillan Pub. Co. xi, 1038 p.

2. Kaufman, J.G., Properties of aluminum alloys : fatigue data and the effects of temperature, product form, and processing. 2008, Materials Park, Ohio: ASM International. vii, $559 \mathrm{p}$.

3. Ll, H., S.S. Chang, and D. Pugh, Tensile Properties of a High-Purity Iron from 196 Degrees C to 200 Degrees at 2 Rates of Strain. Philosophical Magazine, 1963. 8(89): p. 753-\&.

4. https://www.matweb.com.

5. Hosford, W.F. and R.M. Caddell, Metal forming : mechanics and metallurgy. 2nd ed. 1993, Englewood Cliffs, N.J.: Prentice Hall. xvi, 364 p.

6. Ozturk, K., L.Q. Chen, and Z.K. Liu, Thermodynamic assessment of the Al-Ca binary system using random solution and associate models. Journal of Alloys and Compounds, 2002. 340(1-2): p. 199-206.

7. Klein, J.L. and C.H. Zenuk, Method of preparation of fibers having high aspect ratios, in United States Patent 1968.

8. Dieter, G.E., Mechanical metallurgy. 3rd ed. McGraw-Hill series in materials science and engineering. 1986, New York: McGraw-Hill. xxiii, 751 p.

9. Underwood, E.E., Quantitative stereology. Addison-Wesley series in metallurgy and materials. 1970, Reading, Mass.,: Addison-Wesley Pub. Co. x, 274 p. 
10. https://www.aps.anl.gov/Beamlines/Directory/beamline.php?beamline $i d=1$.

11. https://beam.aps.anl.gov/pls/apsweb/beamline_display_pkg.display_beamline.

12. https://www.wagnerinstruments.com/images/jpg/gp20_small.jpg. 


\section{CHAPTER 3. RESULTS AND DISCUSSIONS}

\subsection{Microstructure}

\subsubsection{DMMC of Al-Fe}

Figure 3.1 shows the microstructure in transverse and longitudinal sections of Al$20 \mathrm{vol} \% \mathrm{Fe}$ with $\eta=2.6$ (as-extruded). The $\mathrm{Al}$ matrix is dark gray, and the Fe second phase is light gray. The initial size of Fe powders was $45-63 \mu \mathrm{m}$, and deformation of the composite failed to cause extensive deformation of the Fe particles. Longitudinal sections (Fig. 3.1b) showed that most Fe particles deformed only slightly, but a few of the Fe particles had elongated to well over $100 \mu \mathrm{m}$.

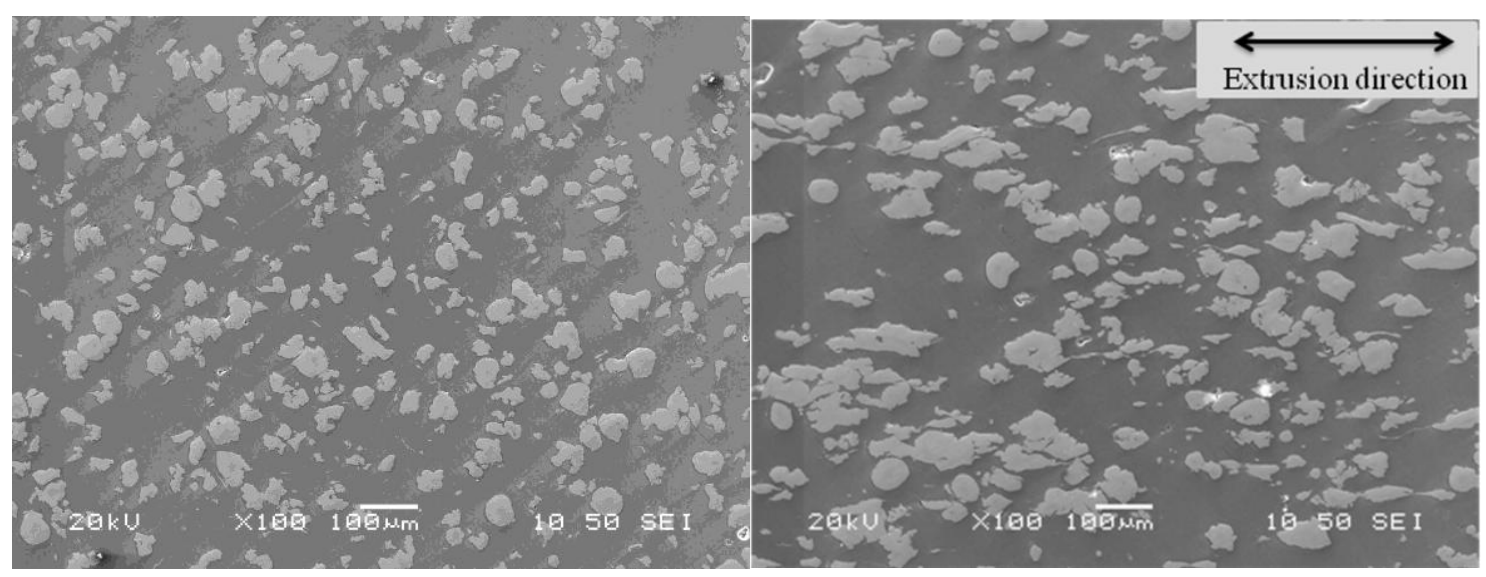

(a)

(b)

Figure 3.1 Transverse (a) and longitudinal (b) section SEM micrographs of as-extruded $\mathrm{Al}-20 \mathrm{Vol} \% \mathrm{Fe}(\eta=2.6)$. Fe phase appears light gray; the $\mathrm{Al}$ matrix is a darker gray. 
Figure 3.2 shows a longitudinal section of $\mathrm{Al}-20 \mathrm{vol} \% \mathrm{Fe}$ at $\eta=7.18$. The specimen was heavily deformed. A true strain of 7.18 corresponds to a 36 -fold reduction of diameter, which would render a freely deforming second phase particle with an initial diameter of $50 \mu \mathrm{m}$ into a thin fiber several millimeters long. However, Fig. 3.2 shows that most of the Fe powder particles had elongated to less than $200 \mu \mathrm{m}$. The failure of the Fe particles to deform extensively is probably attributable to the large difference between the critical resolved shear stress for high-purity $\mathrm{Al}$ (1.0 MPa for 99.996\% purity) and the critical resolved shear stress for high-purity Fe (aprox. $28 \mathrm{MPa}$ ) [1]. Due to the poor deformation response of the Fe particles, work on the Al-Fe composites was abandoned.

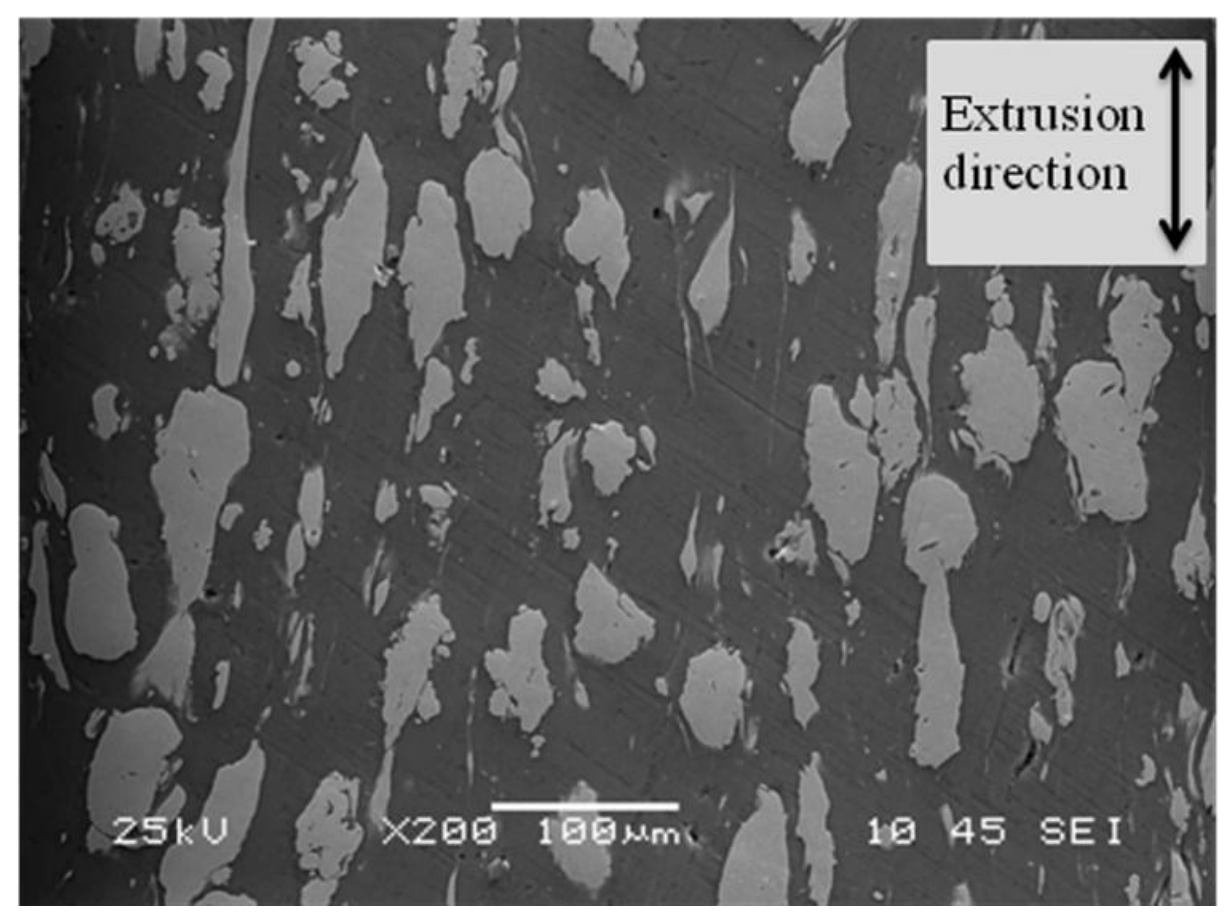

Figure 3.2 Longitudinal section SEM micrographs of $\mathrm{Al}-20 \mathrm{Vol} \% \mathrm{Fe}$ at $\eta=7.18$. Fe phase appears lighter gray than the $\mathrm{Al}$ matrix. 
Figure 3.3 shows an XRD pattern taken from Al-20vol\%Fe at true strain deformation, $\eta=2.60$ (as extruded). The XRD pattern shows only $\mathrm{Al}$ and Fe. The intermetallic phase, FeAl, was not detected.

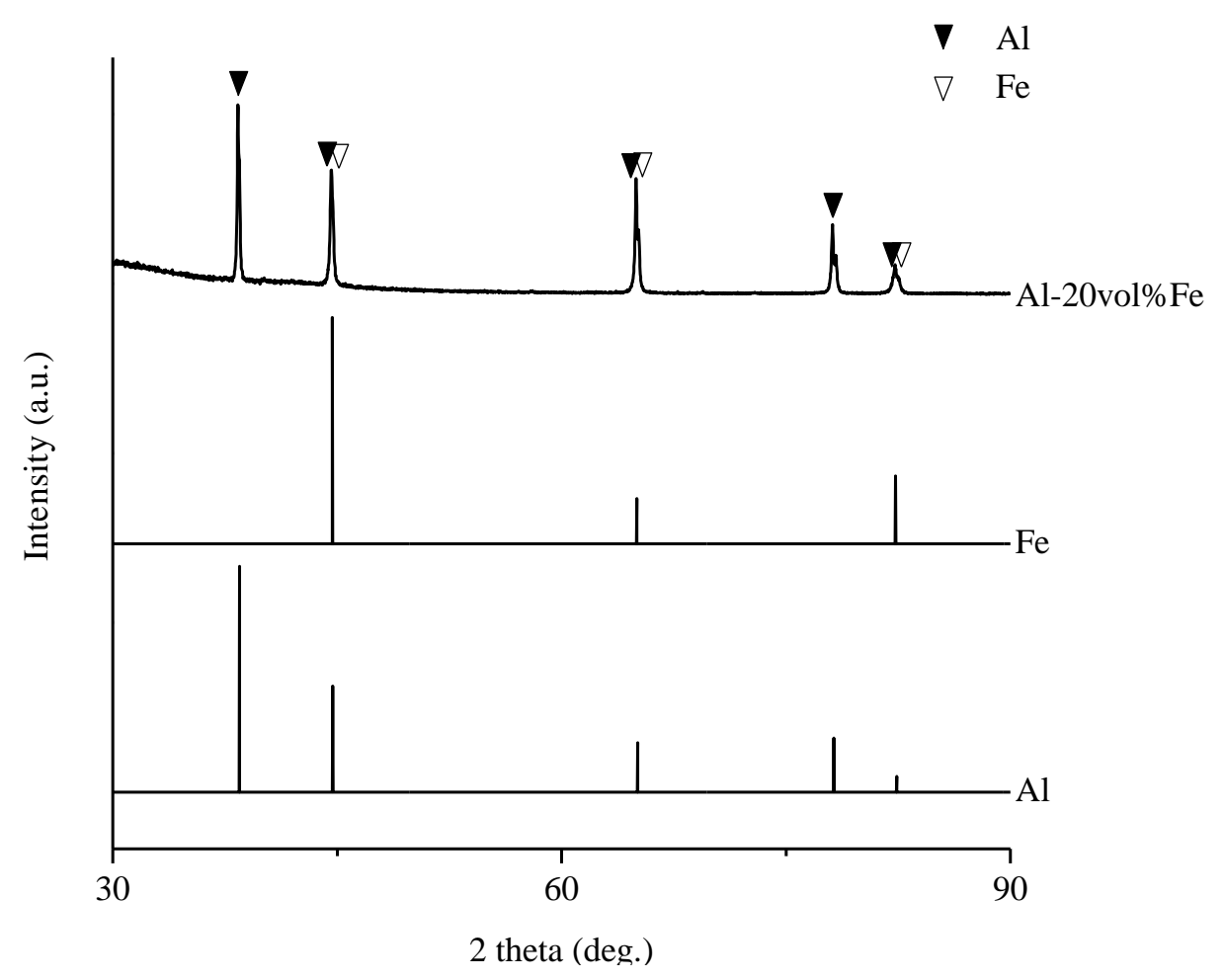

Figure 3.3 XRD pattern of Al-20vol\%Fe compared to reference patterns of $\mathrm{Al}$ and $\mathrm{Fe}$.

\subsubsection{DMMC of 90 vol\% Al powders and 10vol\% Ca granules}

Low-magnification images taken with an Olympus GX51 optical microscope were taken at $\eta=7.18$. Figure 3.4 shows the longitudinal sections of Al-10vol\%Ca. Polishing 
on this specimen was done with water, and the elongated $\mathrm{Ca}$ granules were dissolved by the water, leaving black lines in Figure 3.1 as the traces of the elongated Ca granules.

To provide qualitative analysis, an XRD pattern was taken from $\mathrm{Al}-10 \mathrm{vol} \% \mathrm{Ca}$ at true strain deformation, $\eta=7.18$. Since low-purity $\mathrm{Ca}$ granules were used and polishing was performed with water, the XRD pattern shows only $\mathrm{Al}$ and $\mathrm{CaO}$ (Figure 3.5). Pure $\mathrm{Ca}$ and the inter-metallic phases, $\mathrm{Al}_{2} \mathrm{Ca}$ and $\mathrm{Al}_{4} \mathrm{Ca}$, were not detected.

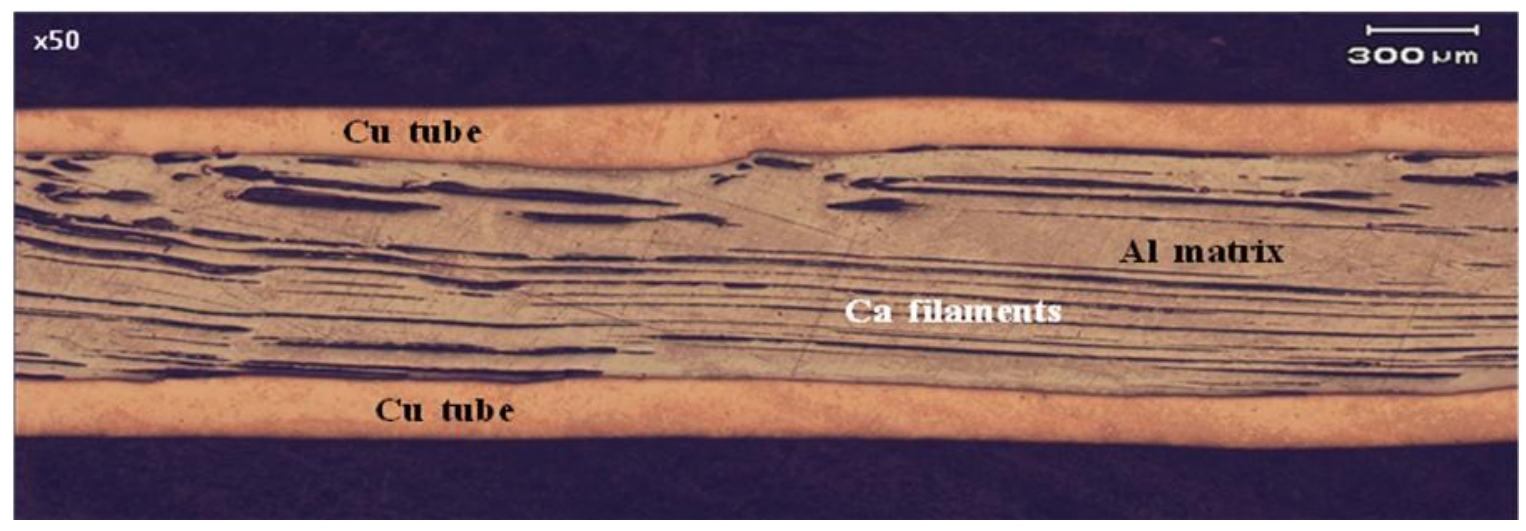

Figure 3.4 Longitudinal section optical microscopy image of Al-10vol\%Ca 


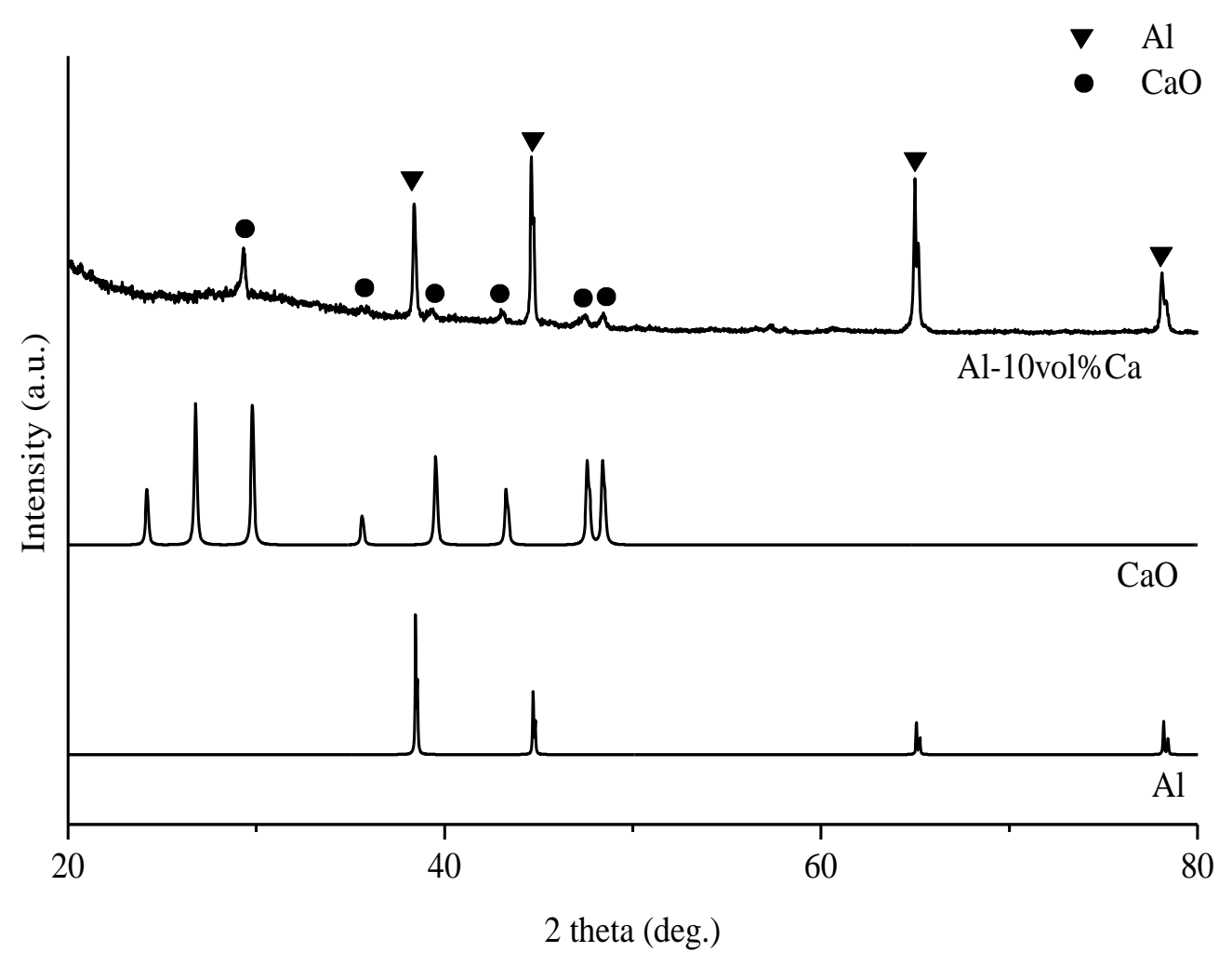

Figure 3.5 XRD pattern of $\mathrm{Al}-10 \mathrm{vol} \% \mathrm{Ca}$ compared to reference patterns of $\mathrm{Al}$ and $\mathrm{CaO}$.

\subsubsection{Extruded Al-Ca DMMCs}

Figure 3.6 shows the microstructure in longitudinal and transverse sections of Al9vol\%Ca with $\eta=2.25$ (as-extruded). The $\mathrm{Al}$ matrix is dark gray, and $\mathrm{Ca}$ filaments are light gray. The Ca particles were initially equiaxed and about $1.2 \mathrm{~mm}$ in diameter; these were reduced to cross sections less than $0.5 \mathrm{~mm}$, as shown in the transverse section SEM micrograph on the left.

In the longitudinal section SEM micrograph, Ca particles were elongated to form filaments more than $2 \mathrm{~mm}$ long. 


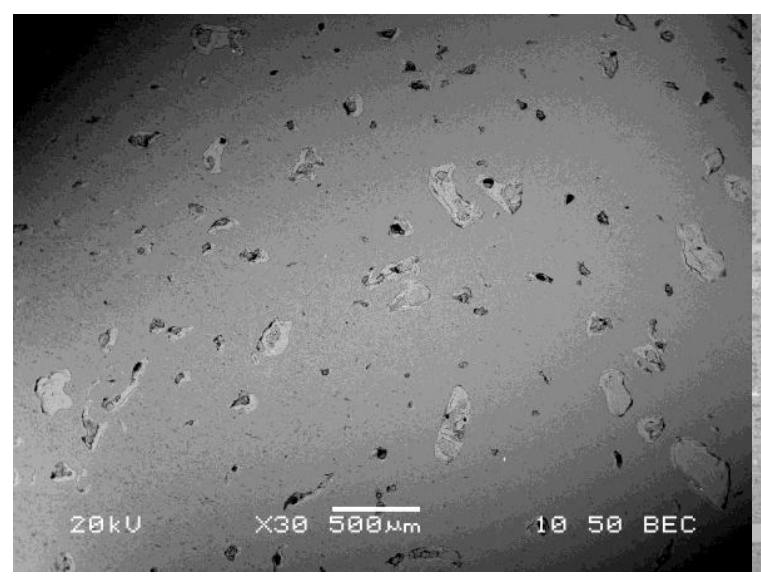

(a)

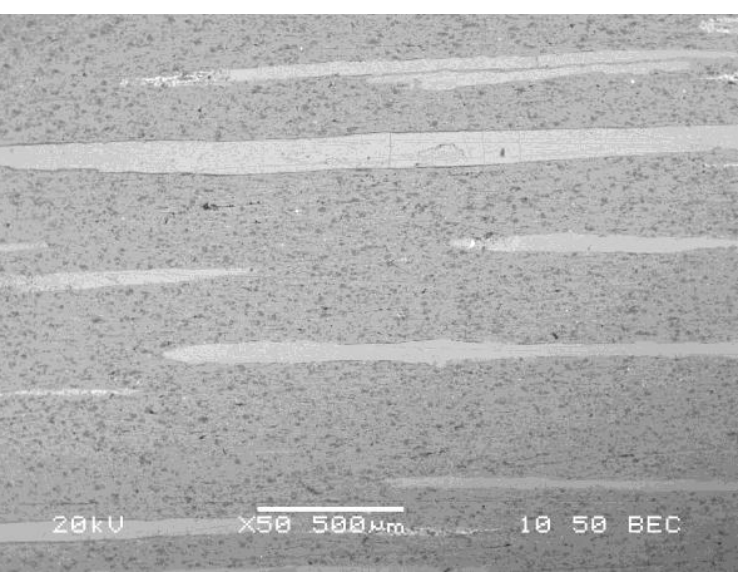

(b)

Figure 3.6 Transverse (a) and longitudinal (b) section SEM micrographs of as-extruded Al-9Vol\%Ca $(\eta=2.25)$. Ca filaments appear lighter gray than the Al matrix in these back-scattered-electron images. Black regions are voids, which are common in P/M metals.

Figure 3.7 and Figure 3.8 show longitudinal-section SEM micrographs of Al9vol\%Ca with $\eta=4.89$ and 7.32 . The thicknesses of the Ca filaments are approximately $10 \mu \mathrm{m}$ and $5 \mu \mathrm{m}$, respectively. 


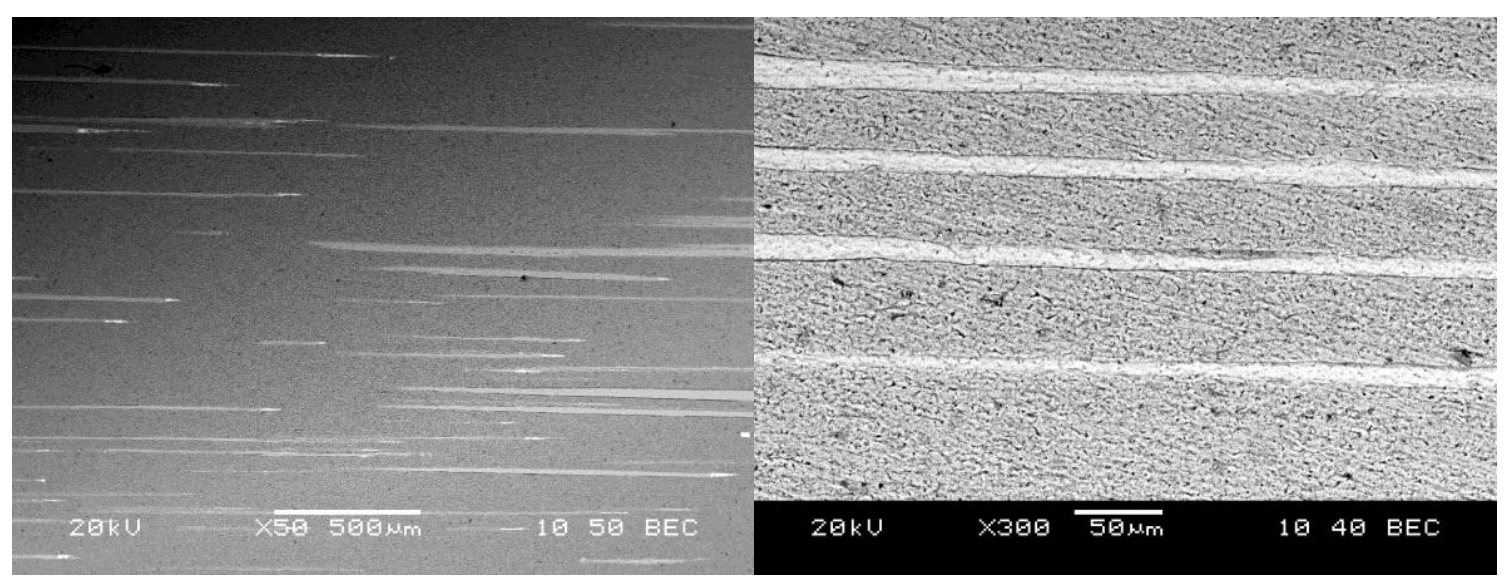

Figure 3.7 Longitudinal section SEM micrographs of Al-9Vol\%Ca $(\eta=4.89)$ at different magnifications. Ca filaments appear lighter gray than the Al matrix in these backscattered-electron images. Black regions are voids.

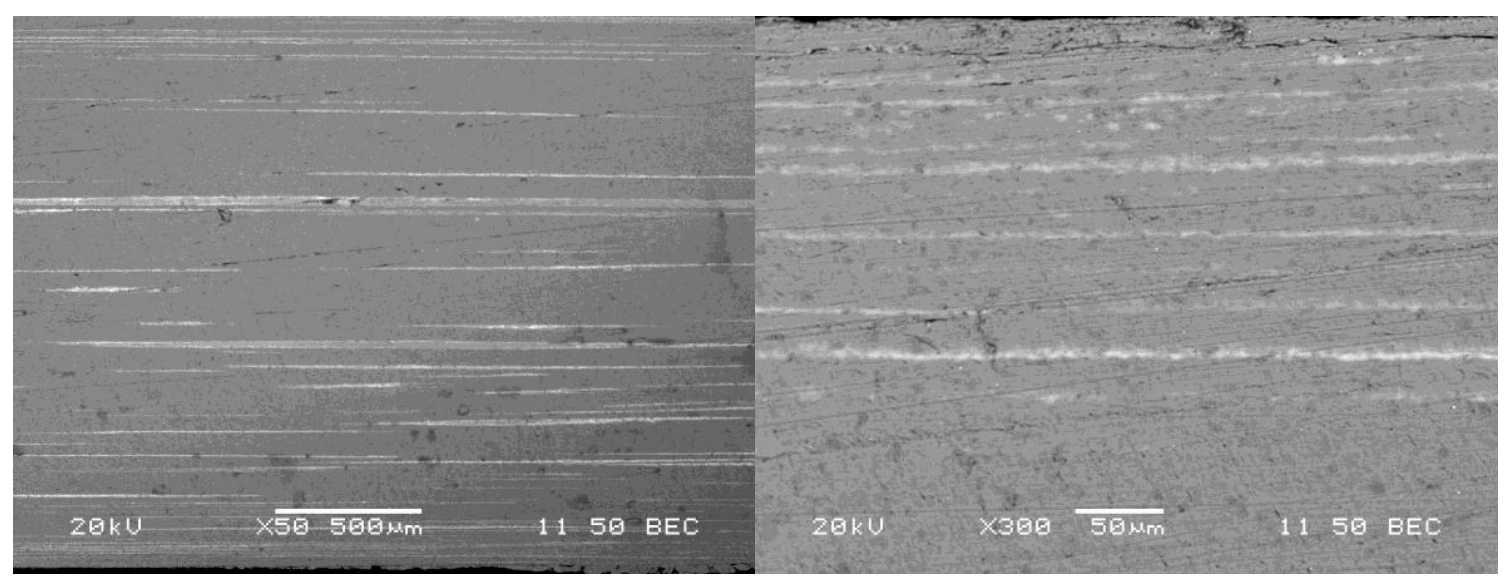

Figure 3.8 Longitudinal section SEM micrographs of $\mathrm{Al}-9 \mathrm{Vol} \% \mathrm{Ca}(\eta=7.32)$ at two different magnifications. Ca filaments appear lighter gray than the $\mathrm{Al}$ matrix in these back-scattered-electron images. Black regions are voids.

Figure 3.9 shows the microstructure in longitudinal and transverse sections of Al9vol\%Ca with $\eta=13.76$ (bundled). The Ca second phase was deformed to fine filaments about 1 to $3 \mu \mathrm{m}$ in diameter. 


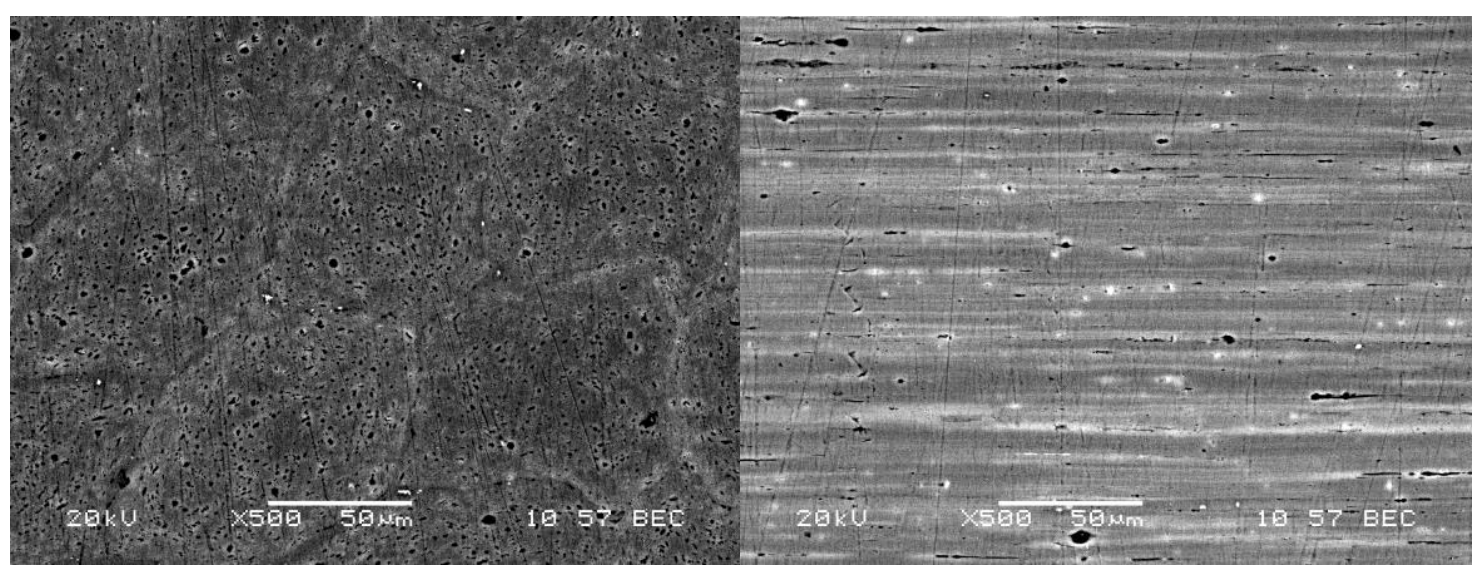

(a)

(b)

Figure 3.9 Transverse (a) and longitudinal (b) section SEM micrographs of Al-9Vol\%Ca $(\eta=13.76)$. Ca filaments appear lighter gray than the $\mathrm{Al}$ in these back-scattered-electron images. Black regions are voids, which are common in P/M metals.

Although the operating temperature of conductor wire used in high-voltage power transmission is usually below $90^{\circ} \mathrm{C}$, conductors occasionally run as hot as $200^{\circ} \mathrm{C}$ in highampacity situations, which makes the kinetics of these reactions relevant to their possible use in power transmission. To determine the temperature of intermetallic compound formation, thermal analysis was performed on $\mathrm{Al}-\mathrm{Ca}$ specimens using differential scanning calorimetry (DSC). Figure 3.10 shows the result of a thermal analysis measurement of a Al-9vol\% Ca wire that had been deformed to a true strain, $\eta=8.55$. The DSC device used was manufactured by PerkinElmer, Inc. The experiment was done with the following heating conditions:

- Hold for $10 \mathrm{~min}$ at $50^{\circ} \mathrm{C}$ 
- Heat from $50^{\circ} \mathrm{C}$ to $535^{\circ} \mathrm{C}$ at $10^{\circ} \mathrm{C} / \mathrm{min}$

- Hold for $5 \mathrm{~min}$ at $535^{\circ} \mathrm{C}$

- Cool from $535^{\circ} \mathrm{C}$ to $50^{\circ} \mathrm{C}$ at $500^{\circ} \mathrm{C} / \mathrm{min}$

Two transformations were detected by DSC, as shown by the event temperatures marked in Figure 3.10. Each event temperature can be matched with formation of a specific intermetallic compound. From results of XRD studies for various heat treatment specimens, each deflection in the curve can be matched to a specific intermetallic compound formation event. The lower temperature event occurred at $295^{\circ} \mathrm{C}$ and is attributed to formation of $\mathrm{Al}_{4} \mathrm{Ca}$. The higher temperature event occurred at $345^{\circ} \mathrm{C}$ and is attributed to formation of $\mathrm{Al}_{2} \mathrm{Ca}$. 


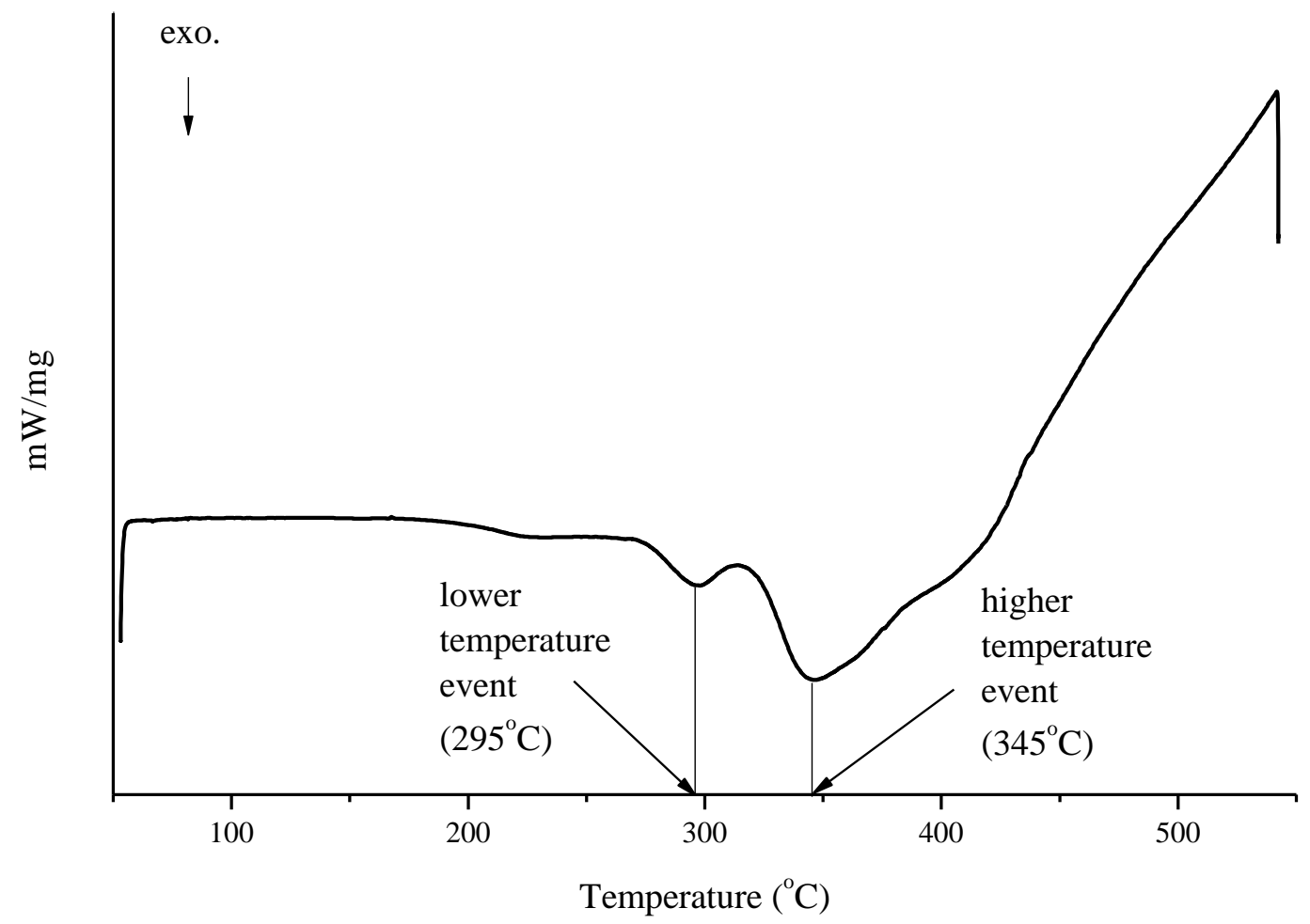

Figure 3.10 DSC measurement for $\mathrm{Al}-9 \mathrm{vol} \% \mathrm{Ca}$ at $\eta=8.55$

To confirm this conclusion about formation of $\mathrm{Al}_{\mathrm{x}} \mathrm{Ca}_{\mathrm{y}}$ intermetallic compounds in Al-Ca DMMCs, specimens were annealed at temperatures ranging between $200^{\circ} \mathrm{C}$ and $325^{\circ} \mathrm{C}$ for 1 hour. Specimens with $\eta=6.27$ were prepared with the various heat treatments shown in Table 3.1 for microstructure analysis. Selection of the heat treatment temperatures was guided by the results of DSC measurement. 
Table 3.1 Heat treatment conditions of Al-9vol\%Ca $(\eta=6.27)$ for microstructure analysis with SEM and EDS

\begin{tabular}{cccc}
\hline & & \multicolumn{2}{c}{ Heat treatment } \\
\cline { 3 - 4 } Specimen & $\eta$ & Temperature $\left({ }^{\circ} \mathrm{C}\right)$ & Time (hour) \\
\hline Al-9vol\%Ca & 6.27 & 200 & 1 \\
Al-9vol\%Ca & 6.27 & 225 & 1 \\
Al-9vol\%Ca & 6.27 & 250 & 1 \\
Al-9vol\%Ca & 6.27 & 300 & 1 \\
Al-9vol\%Ca & 6.27 & 325 & 1 \\
Al-9vol\%Ca & 6.27 & & 1 \\
\hline
\end{tabular}

Figures $3.11,3.12$ and 3.13 each show transverse sections of $\mathrm{Al}-9 \mathrm{vol} \% \mathrm{Ca}(\eta=6.27)$ after various heat treatments (i.e., $200^{\circ}, 225^{\circ}, 250^{\circ}, 275^{\circ}, 300^{\circ}$ and $325^{\circ} \mathrm{C}$ for 1 hour). The areas of the white regions around the $\mathrm{Ca}$ filaments are thought to be $\mathrm{Al}_{\mathrm{x}} \mathrm{Ca}_{\mathrm{y}}$ intermetallic compounds; these areas were larger after the higher temperature heat treatments. 


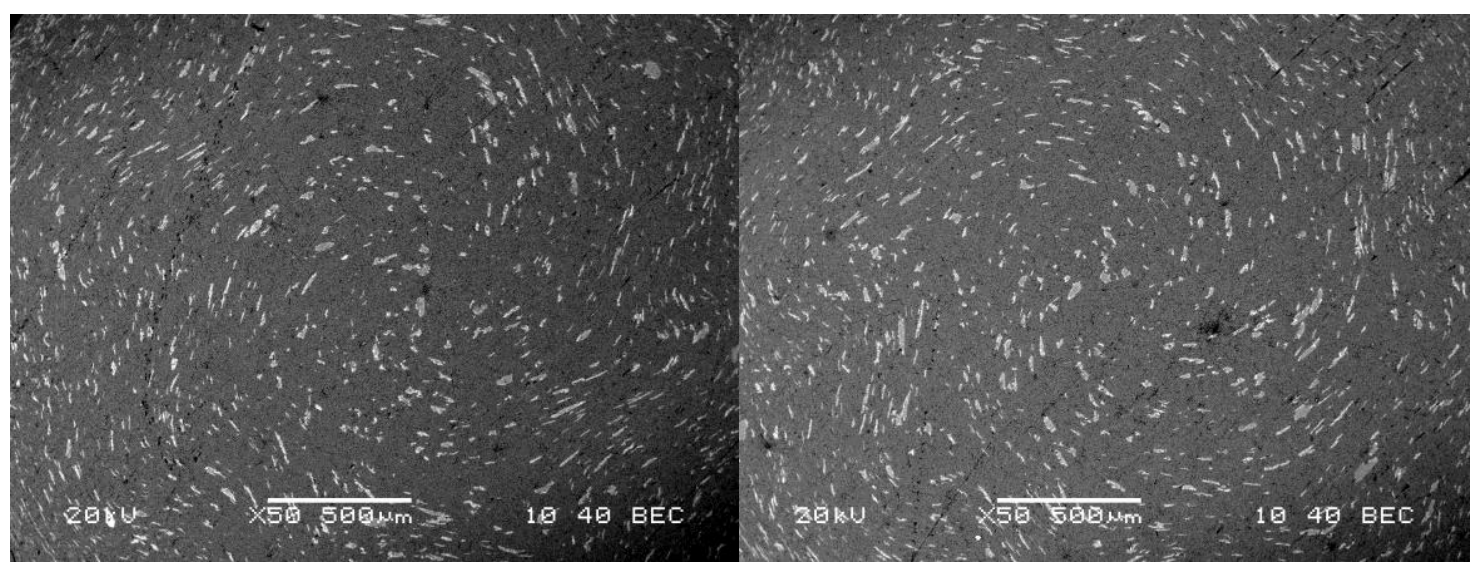

(a)

(b)

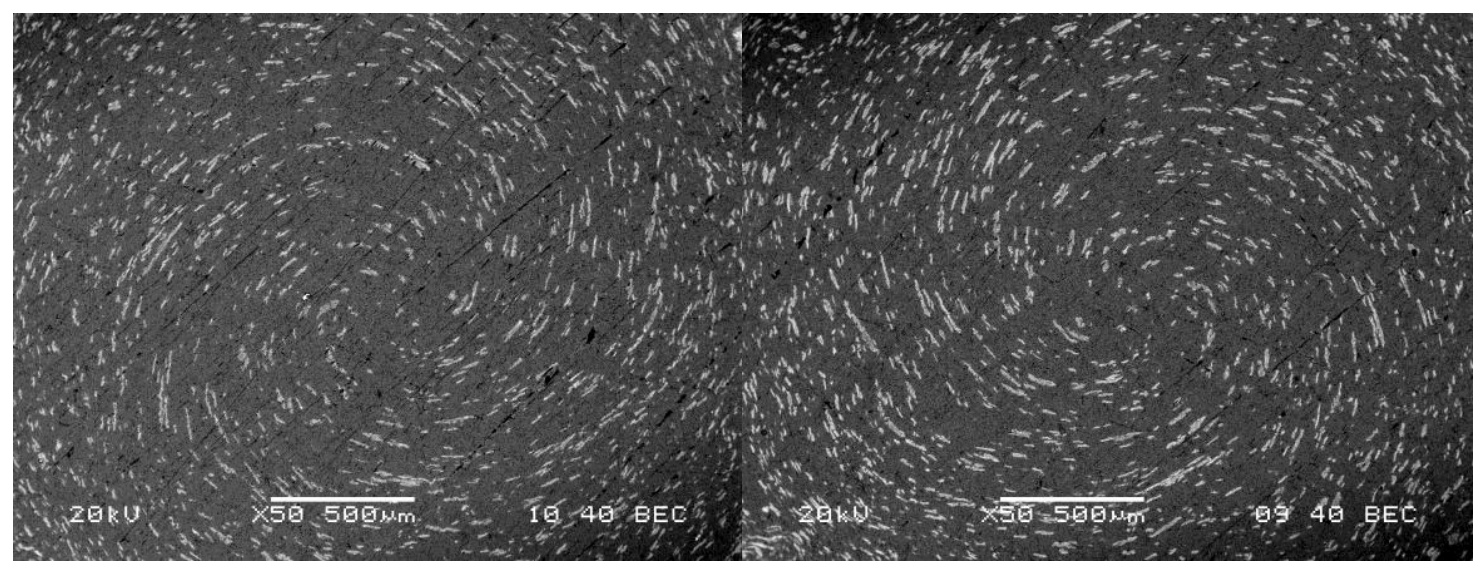

(c)

(d)

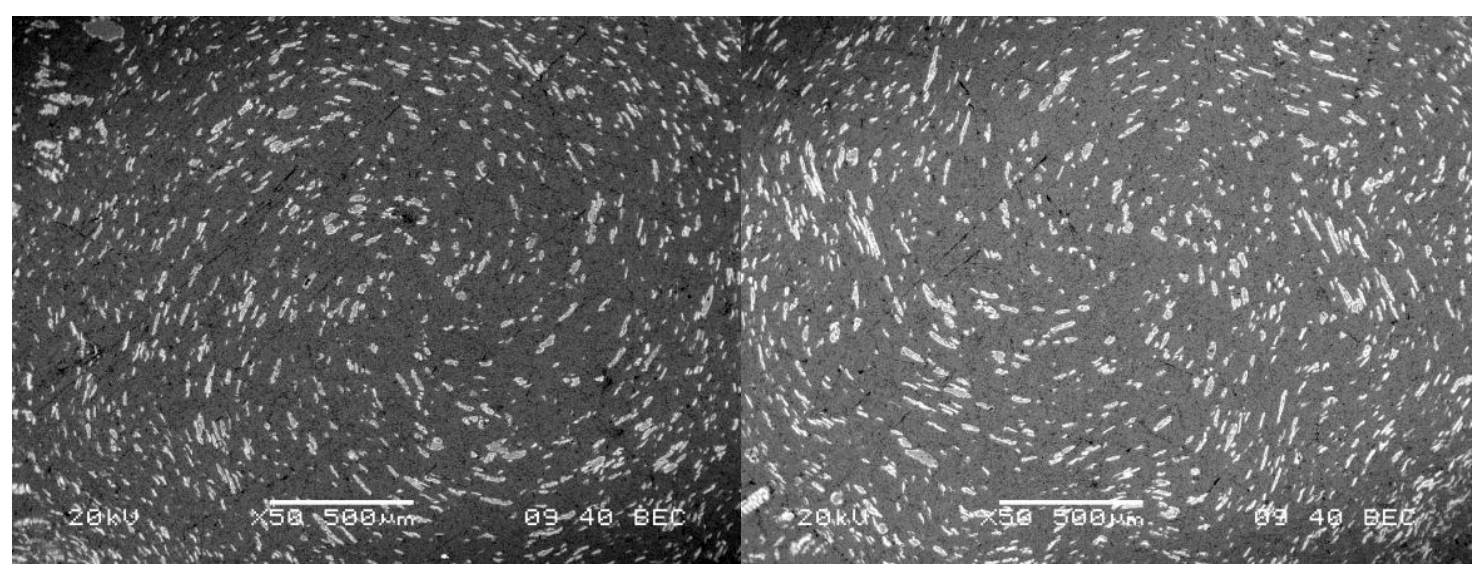

(e)

(f)

Figure 3.11 Transverse section SEM micrographs of $\mathrm{Al}-9 \mathrm{Vol} \% \mathrm{Ca}(\eta=6.27)$ with different temperature heat treatments for 1 hour. (a) $200^{\circ} \mathrm{C}$, (b) $225^{\circ} \mathrm{C} \mathrm{(c)} 250^{\circ} \mathrm{C} \mathrm{(d)} 275^{\circ} \mathrm{C}$ (e) $300^{\circ} \mathrm{C}$ (f) $325^{\circ} \mathrm{C}$. The $\mathrm{Al}$ matrix is dark gray; $\mathrm{Ca}$ filaments are light gray. 


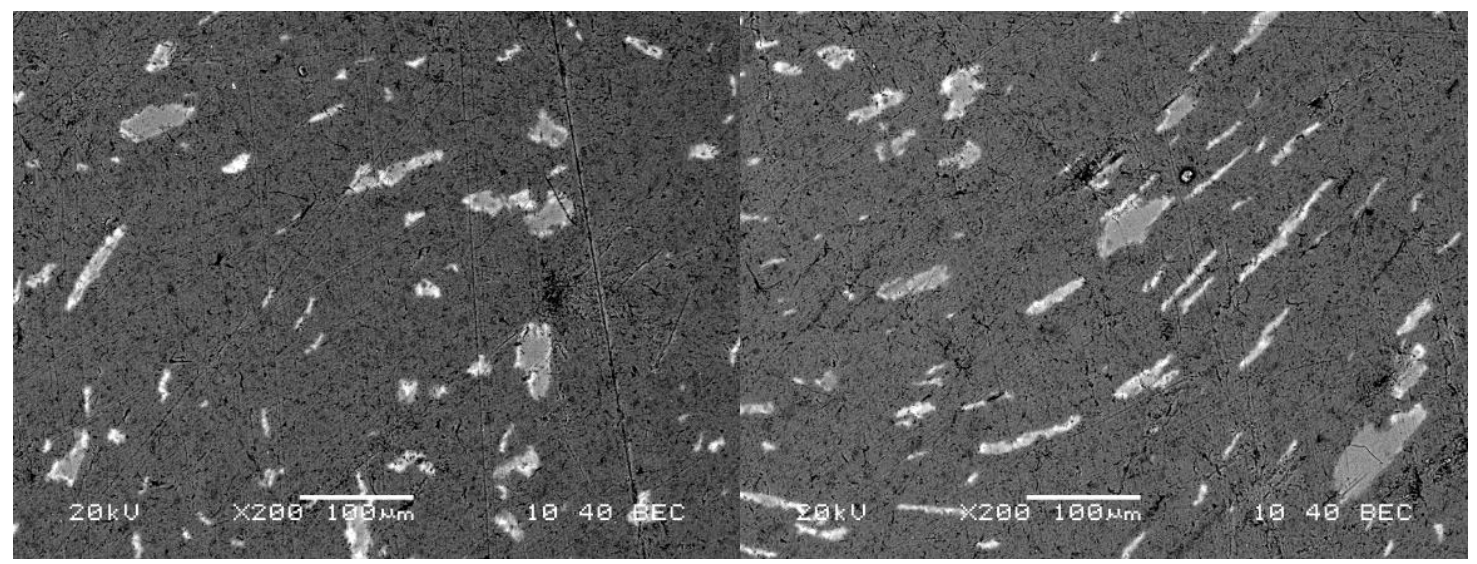

(a)

(b)

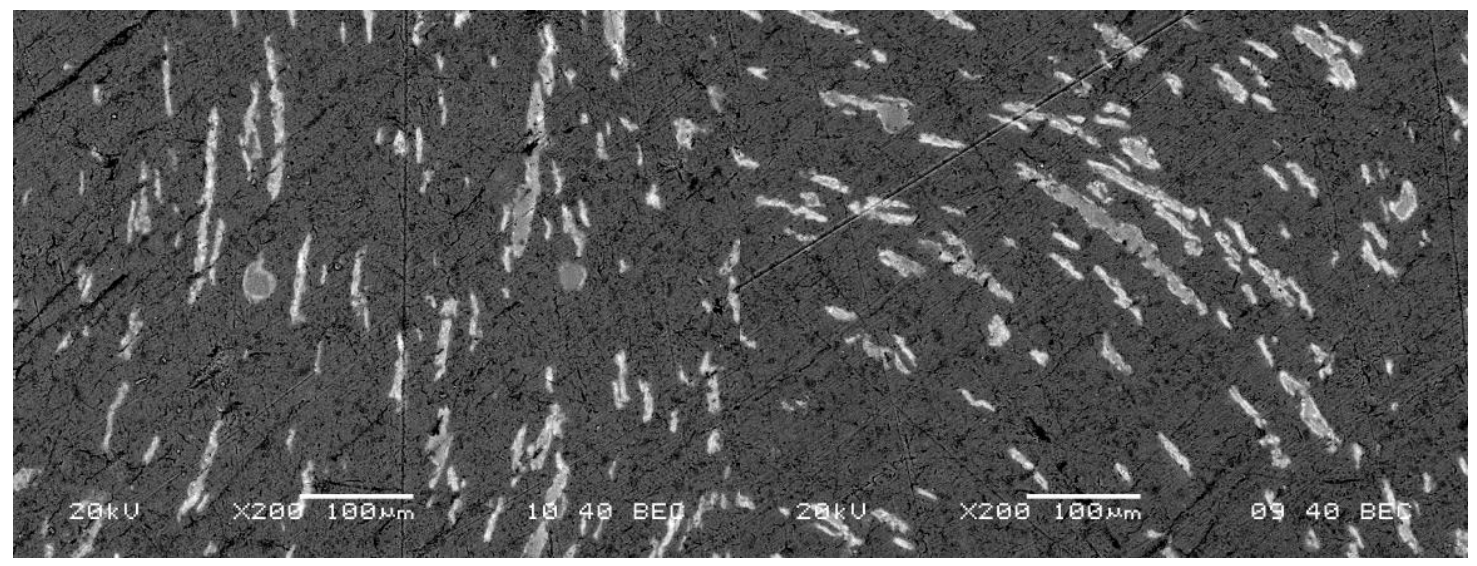

(c)

(d)

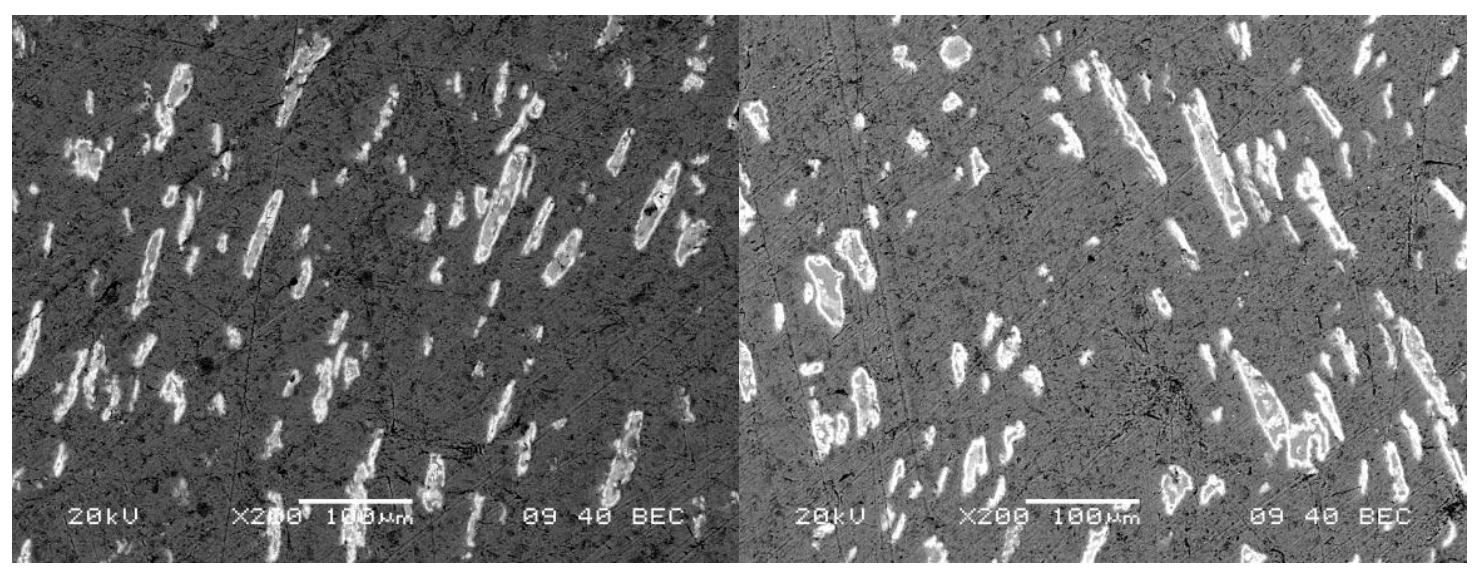

(e)

(f)

Figure 3.12 Transverse section SEM micrographs of Al-9Vol\%Ca $(\eta=6.27)$ after different one-hour heat treatments. . (a) $200^{\circ} \mathrm{C}$, (b) $225^{\circ} \mathrm{C}$ (c) $250^{\circ} \mathrm{C}$ (d) $275^{\circ} \mathrm{C}$ (e) $300^{\circ} \mathrm{C}$ (f) $325^{\circ} \mathrm{C}$. The $\mathrm{Al}$ matrix is dark gray; Ca filaments are light gray. 


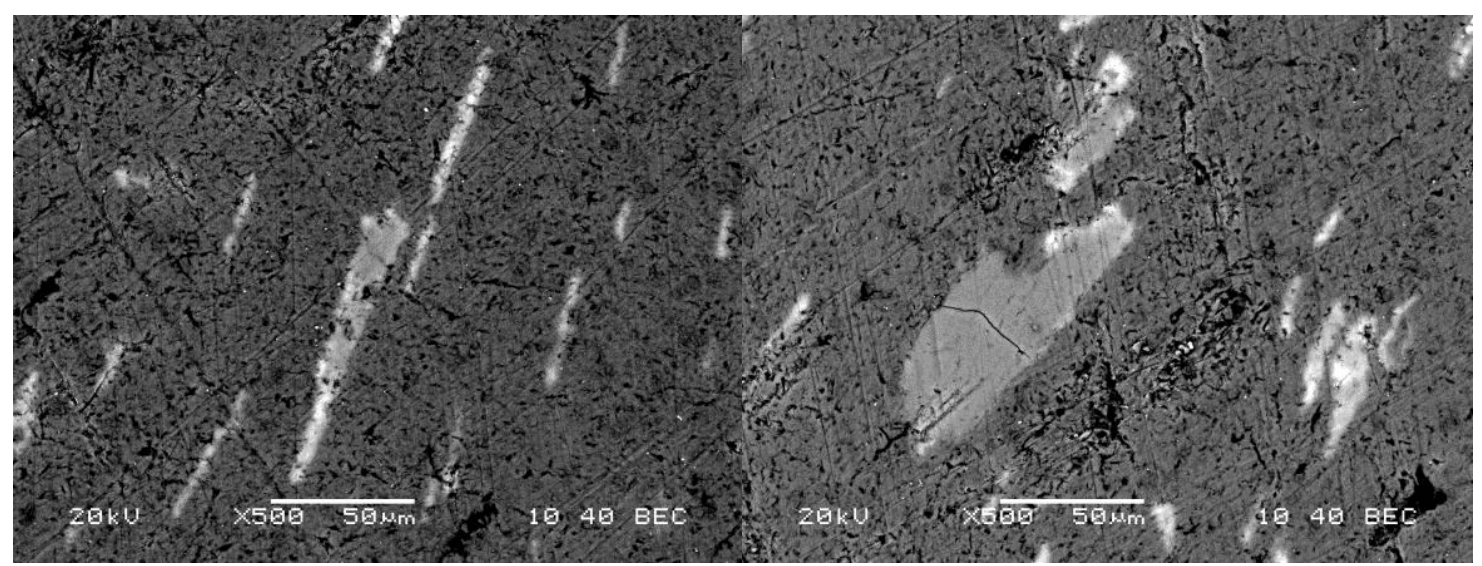

(a)

(b)

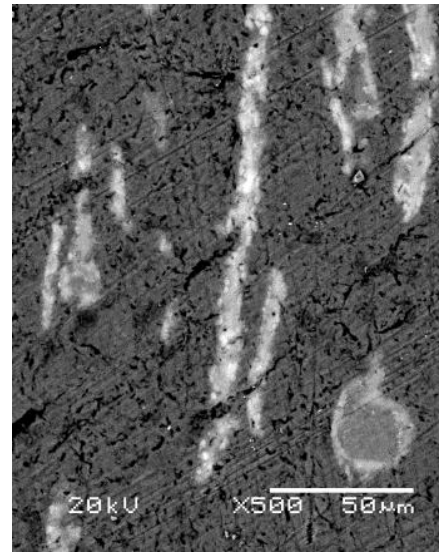

(c)

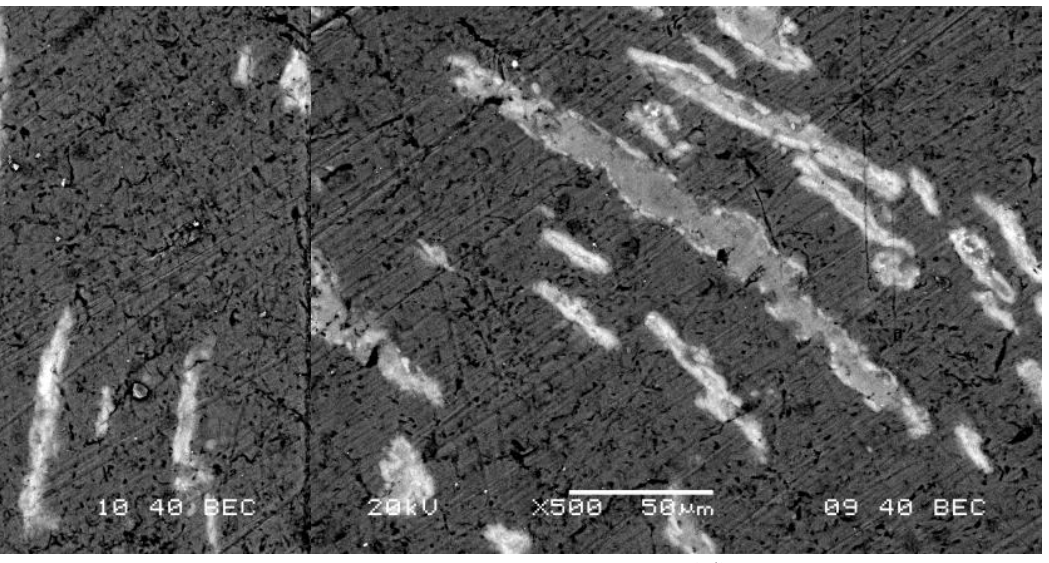

(d)

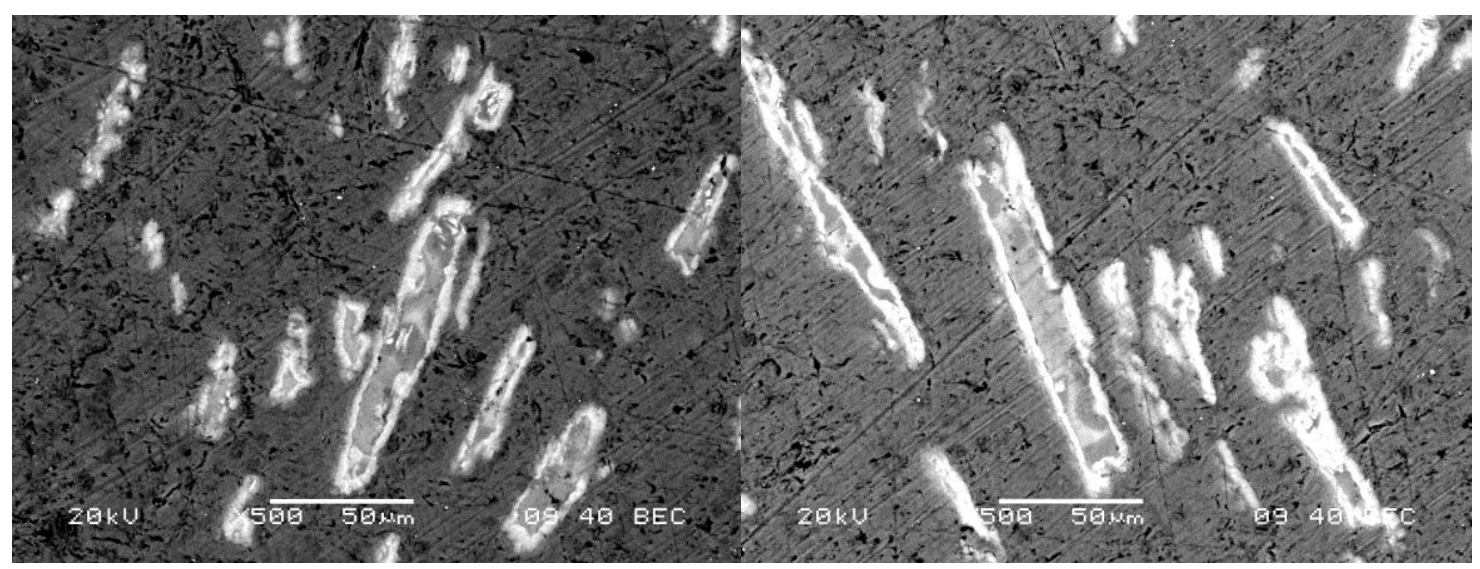

(e)

(f)

Figure 3.13 Transverse section SEM micrographs of Al-9Vol\%Ca $(\eta=6.27)$ with different one-hour heat treatments. (a) $200^{\circ} \mathrm{C}$, (b) $225^{\circ} \mathrm{C}$ (c) $250^{\circ} \mathrm{C}$ (d) $275^{\circ} \mathrm{C}$ (e) $300^{\circ} \mathrm{C}$ (f) $325^{\circ} \mathrm{C}$. The Al matrix is dark gray; Ca filaments are light gray. 
Table 3.1 shows an EDS analysis of specimens heat treated one hour at $325^{\circ} \mathrm{C}$. The at\% values given for $\mathrm{Al}$ and $\mathrm{Ca}$ do not account for any oxygen fraction that may be present. The dark gray region is $\mathrm{Al}$ matrix. The white region around the $\mathrm{Ca}$ filaments contains 30at\% Al. This suggests that this phase is not $\mathrm{Al}_{2} \mathrm{Ca}$, which has a ratio of 66.67at\% Al-33.33at\%Ca. Also, the light gray region is presumed to be not pure Ca but $\mathrm{CaO}$ or $\mathrm{Ca}(\mathrm{OH})_{2}$. To access $\mathrm{Al}$ and $\mathrm{Ca}$ fractions, the EDS software's internal standard subroutines were used. In EDS analysis, the interaction volume of X-ray generation is affected by the atomic number of the specimen materials, the accelerating voltage of the beam, and the angle of incidence of the beam. Due to the imperfections inevitable in a metallographically polished surface, the surface of the heat-treated Al-Ca DMMC is not perfectly even, potentially causing inaccuracies in the quantitative determination of elemental fractions. In addition the x-rays may have to travel through several micrometers of metal before reaching the surface, which can further degrade the accuracy of quantitative determinations. Therefore this method does not give highly accurate weight percentages, making the composition of the white region somewhat uncertain. As a cross-check of the accuracy of the EDS elemental analysis of the specimens' phases, XRD was performed on the heat-treated specimens. The 1-BM beamline with $\mathrm{LaB}_{6}$ (wavelength $=0.6066 \AA$ ) source at the Advanced Photon Source (APS) at Argonne National Laboratory was used to acquire these diffraction patterns. 
Table 3.2 Elemental analysis by standardless EDS for Al-9vol\%Ca $(\eta=6.27)$ with heat treatment at $325^{\circ} \mathrm{C}$ for 1 hour.

\begin{tabular}{ccc}
\hline & \multicolumn{2}{c}{ Atomic $\%$} \\
\cline { 2 - 3 } & $\mathrm{Al}$ & $\mathrm{Ca}$ \\
\hline Dark gray & 100 & 0 \\
Light gray & 3 & 97 \\
White & 30 & 70 \\
\hline
\end{tabular}

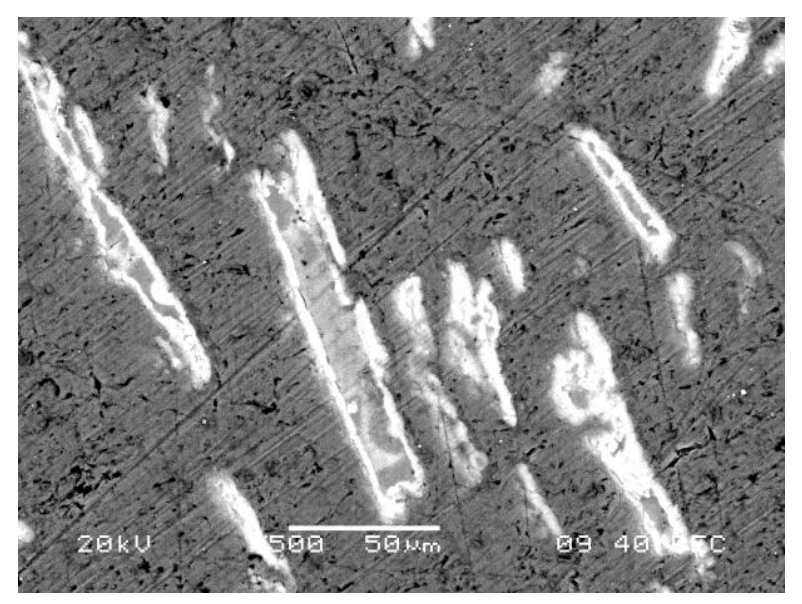

Figure 3.14 shows XRD patterns of a fully heat-treated specimen (275_04h) and a specimen given no heat treatment (noHT). These patterns indexed as $\mathrm{Al}, \mathrm{Ca}, \mathrm{Al}_{2} \mathrm{Ca}$, and $\mathrm{Al}_{4} \mathrm{Ca}$. The intensities of $\mathrm{Ca}$ peaks from specimen noHT were higher than in specimen 275_04h; presumably Ca peaks weaken as $\mathrm{Ca}$ is consumed by the reaction to form $\mathrm{Al}_{2} \mathrm{Ca}$. 


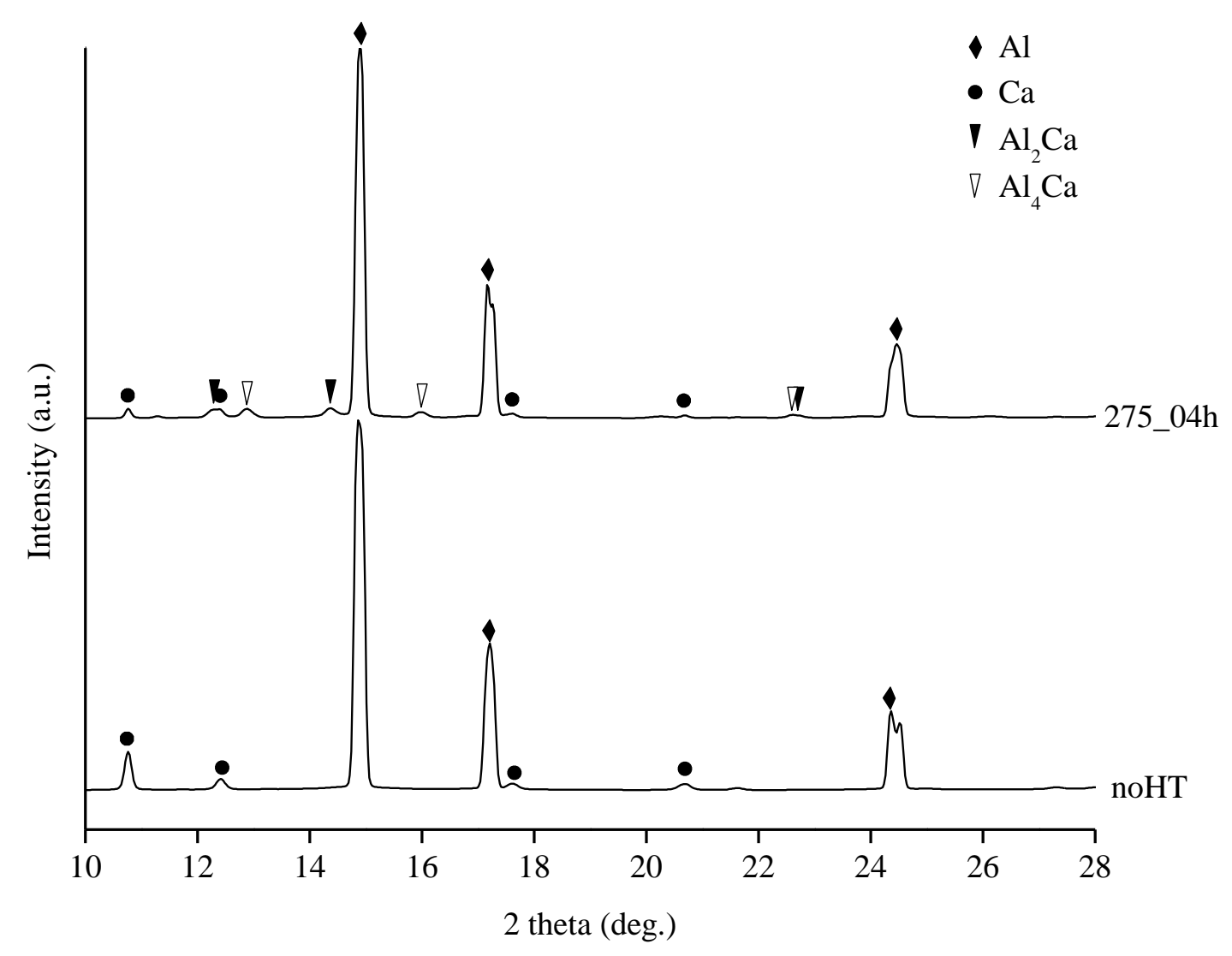

Figure 3.14 XRD patterns obtained at APS of two specimens $(\eta=6.27)$, one was a nonheat treated (noHT) specimen, and the other was heat treated at $275^{\circ} \mathrm{C}$ for 4 hours (275_04h).

Figure 3.15 shows a comparison of XRD patterns from specimens with two different temperatures for heat treatment. XRD patterns of noHT, 225_04h, and 275_04h are plotted in Figure 3.14. Figure 3.14 shows $\mathrm{Al}_{2} \mathrm{Ca}$ indexed in the specimen heat treated at high temperature $\left(275^{\circ} \mathrm{C}\right)$ only. This suggests that $\mathrm{Al}_{4} \mathrm{Ca}$ formed below $225^{\circ} \mathrm{C}$ and $\mathrm{Al}_{2} \mathrm{Ca}$ formed above $275^{\circ} \mathrm{C}$. The XRD pattern of 275_04h has the lowest intensity of Ca peaks and the greatest intensity of $\mathrm{Al}_{4} \mathrm{Ca}$ peaks. 


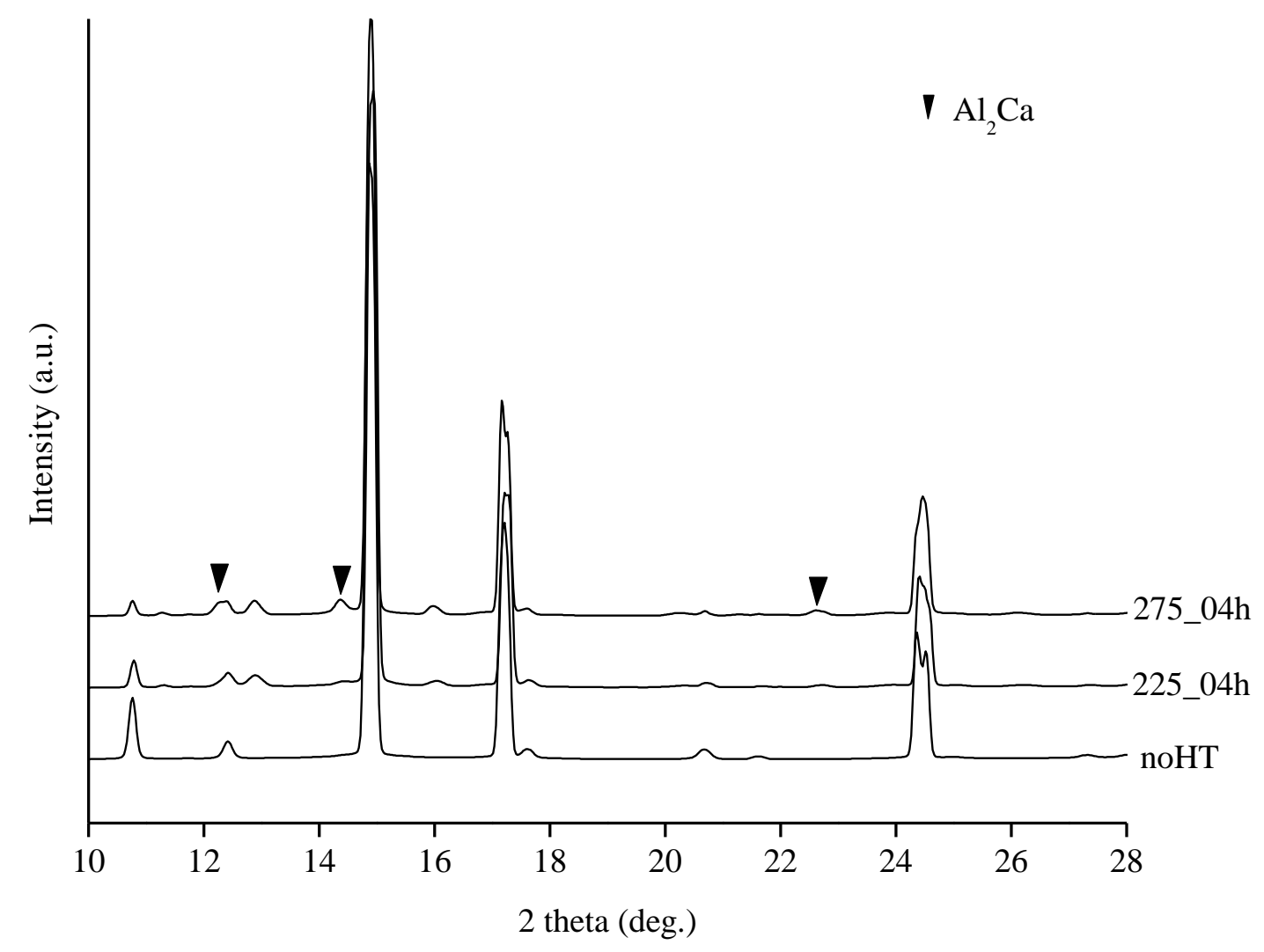

Figure 3.15 XRD patterns of three specimens $(\eta=6.27)$ of non-heat treated (noHT), heat treated at $225^{\circ} \mathrm{C}$ for 4 hours $\left(225 \_04 \mathrm{~h}\right)$ and $275^{\circ} \mathrm{C}$ for 4 hours (275_04h).

Figure 3.16 shows XRD patterns from specimens heat treated at high temperature $\left(275^{\circ} \mathrm{C}\right)$ for various times. Peaks of $\mathrm{Al}_{2} \mathrm{Ca}$ appeared on 275_01h and 275_04h. Short time ( $<10 \mathrm{~min}$ ) heat treatment is insufficient to form $\mathrm{Al}_{2} \mathrm{Ca}$. $\mathrm{Al}_{4} \mathrm{Ca}$ peaks were detected in the 275_05m and longer time heat-treated specimens. 


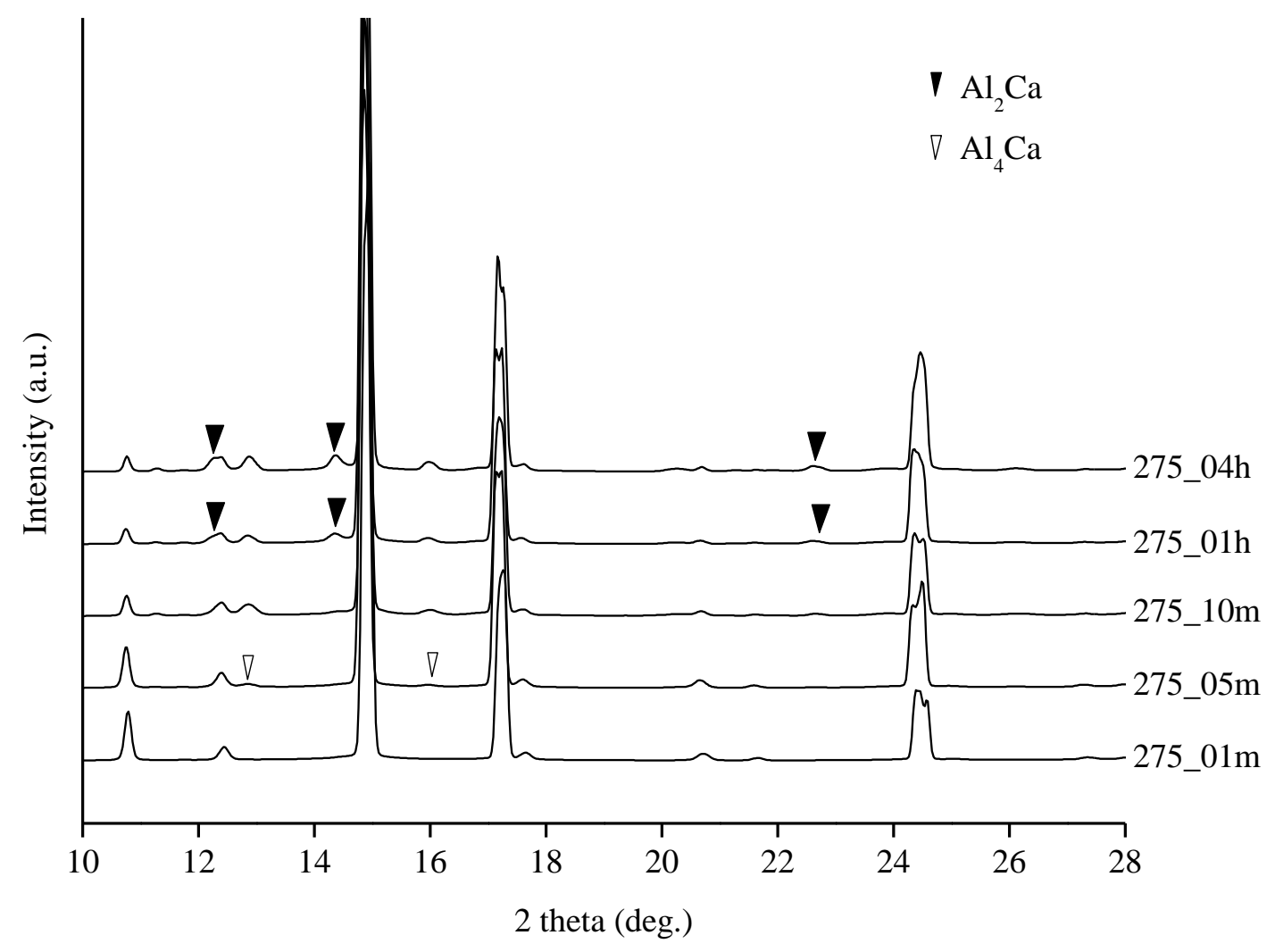

Figure 3.16 XRD patterns of specimens heat treated at $275^{\circ} \mathrm{C}$ for 1 minute, 5 minutes, 10 minutes, 1 hour and 4 hours $\left(275 \_01 \mathrm{~m}, 275 \_05 \mathrm{~m}, 275 \_10 \mathrm{~m}, 275 \_01 \mathrm{~h}\right.$, and 275_04h).

\subsubsection{Substitutional diffusion in Al-Ca}

Previous XRD results showed that the intermetallic phases formed during heat treatments. The relative sizes of the $\mathrm{Ca}$ and $\mathrm{Al}$ atoms strongly suggest that the phases were formed as a result of substitutional diffusion rather than interstitial diffusion in the Al-Ca composites. The atomic jumps can occur when enough thermal energy is available 
to overcome the activation energy barrier to migration [2]. Therefore, the probability that any attempt at jumping is affected by the activation energy of $\mathrm{Al}$ and $\mathrm{Ca}$. Unfortunately, the activation energy of $\mathrm{Ca}$ for diffusion into $\mathrm{Al}$ has not been published. The activation energy self diffusion in $\mathrm{Ca}$ is $161.2 \mathrm{~kJ} / \mathrm{mol}$ [3], and the activation energy for self diffusion in $\mathrm{Al}$ is $142.4 \mathrm{~kJ} / \mathrm{mol}$. [3] However, these values provide no direct guidance on predicting how readily the two elements would intermix by diffusion. The activation energy for self-diffusion is lower in $\mathrm{Al}$ than in $\mathrm{Ca}$, which is consistent with the generally observed trend that self-diffusion activation energies scale with melting temperature. Al melts at $660^{\circ} \mathrm{C}$, and $\mathrm{Ca}$ melts about $180 \mathrm{C}^{\circ}$ higher. Perhaps the best insight into predicting the relative rates of self-diffusion of $\mathrm{Al}$ in $\mathrm{Ca}$ and vice versa is their relative sizes. The atomic radius of $\mathrm{Al}(0.143 \mathrm{~nm})$ is smaller than $\mathrm{Ca}(0.197 \mathrm{~nm})$, which suggests that the smaller $\mathrm{Al}$ atoms could diffuse into $\mathrm{Ca}$ much more readily than $\mathrm{Ca}$ atoms could diffuse into $\mathrm{Al}$.

\subsection{Tensile testing}

\subsubsection{Tensile tests with heat treated Al-Ca DMMCs at $\eta=6.27$}

Tensile tests were performed with pure $\mathrm{Al}, \mathrm{Al}-3 \mathrm{vol} \% \mathrm{Ca}, \mathrm{Al}-6 \mathrm{vol} \% \mathrm{Ca}, \mathrm{Al}-9 \mathrm{vol} \% \mathrm{Ca}$ wires at deformation true strain, $\eta=6.27$ (diameter $=3.175 \mathrm{~mm}$ ). These tests were performed at a strain rate of $8.3 \times 10^{-4} s^{-1}$ at room temperature. The samples were too small to allow use of an extensometer, so the slopes of the elastic portions of the plots do not accurately represent elastic modulus. The specimens of each type consist of two non- 
heat treated specimens and two or three heat-treated specimens. Table 3.2 shows conditions of heat treatment and tensile test results. Stress-strain curves of each series of specimen are shown in Figures 3.17-20. Figures 3.20-21 show stress-strain curves of the specimens sorted into non-heat-treated and heat-treated groups of specimens, respectively. According to Figure 3.21, the highest ultimate tensile strength was observed in the pure Al specimen. This finding indicates that a deformation true strain of $\eta=6.27$ is not enough to produce meaningful strengthening in these DMMCs. Also, in Figure 3.22, the highest ultimate tensile strength occurred in the pure $\mathrm{Al}$ specimen. As a result of Figure 3.22 , it can be inferred that heat-treatment at $200^{\circ} \mathrm{C}$ has little effect on the strength of $\mathrm{Al}-$ Ca DMMCs and does not form significant amounts of $\mathrm{Al}_{2} \mathrm{Ca}$ or $\mathrm{Al}_{4} \mathrm{Ca}$. The $350^{\circ} \mathrm{C}$ heat treatment, however, did substantially lower strength. 
Table 3.3 Heat treatment conditions and results of tensile tests of Al-Ca wires at $\eta=6.27$

\begin{tabular}{|c|c|c|c|}
\hline Specimen & Heat treatment & $\begin{array}{l}\text { Ultimate tensile } \\
\text { strength }(\mathrm{MPa})\end{array}$ & $\begin{array}{c}\text { Maximum strain } \\
(\%)\end{array}$ \\
\hline \multirow[t]{4}{*}{ Pure Al } & - & 90 & 19 \\
\hline & - & 94 & 19 \\
\hline & $200^{\circ} \mathrm{C}, 4$ hours & 90 & 17 \\
\hline & $200^{\circ} \mathrm{C}, 4$ hours & 93 & 21 \\
\hline \multirow[t]{4}{*}{ Al-3vol\%Ca } & - & 81 & 12 \\
\hline & - & 88 & 11 \\
\hline & $200^{\circ} \mathrm{C}, 4$ hours & 91 & 9 \\
\hline & $200^{\circ} \mathrm{C}, 4$ hours & 91 & 8 \\
\hline \multirow[t]{4}{*}{ Al-6vol\%Ca } & - & 91 & 11 \\
\hline & - & 91 & 13 \\
\hline & $200^{\circ} \mathrm{C}, 4$ hours & 87 & 13 \\
\hline & $200^{\circ} \mathrm{C}, 4$ hours & 87 & 11 \\
\hline \multirow[t]{5}{*}{ Al-9vol\% Ca } & - & 86 & 14 \\
\hline & - & 93 & 13 \\
\hline & $200^{\circ} \mathrm{C}, 4$ hours & 87 & 15 \\
\hline & $200^{\circ} \mathrm{C}, 4$ hours & 90 & 15 \\
\hline & $350^{\circ} \mathrm{C}, 4$ hours & 66 & 15 \\
\hline
\end{tabular}




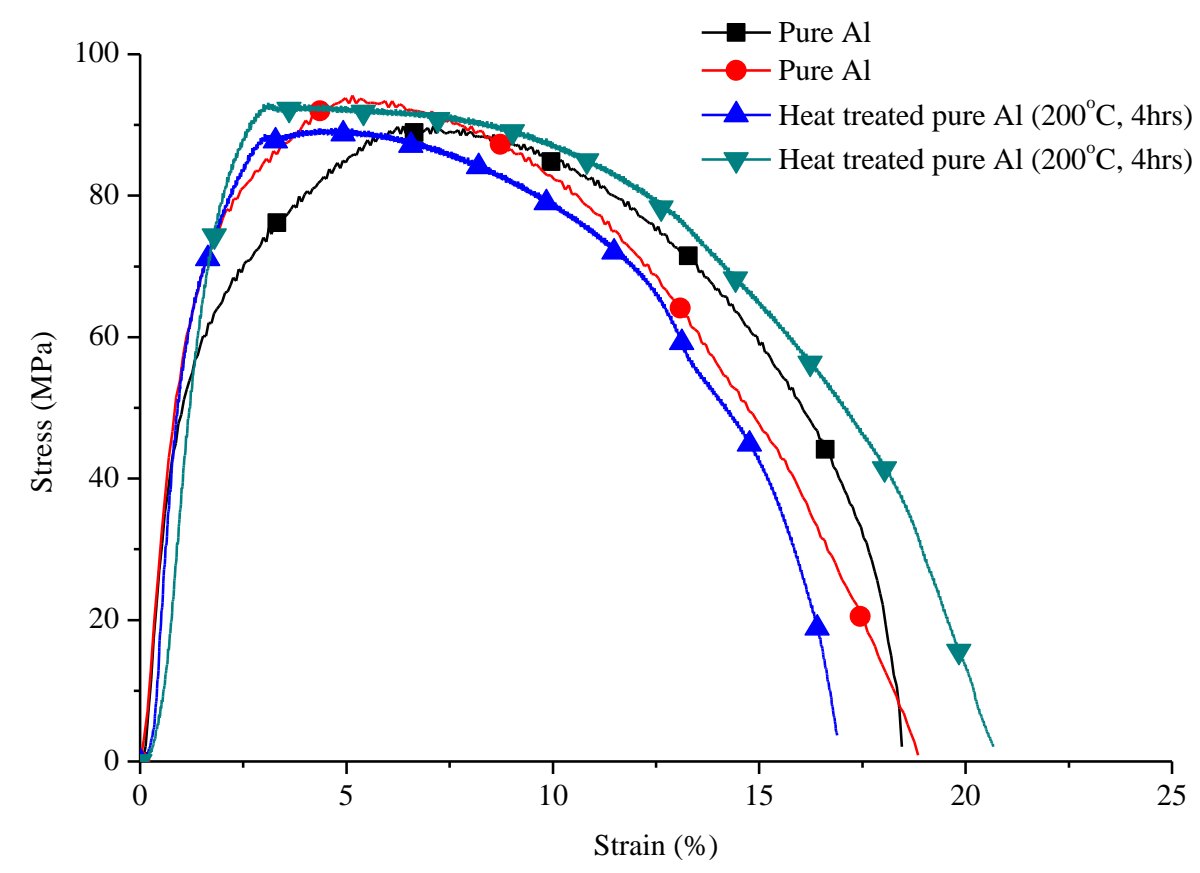

Figure 3.17 Stress-strain plots of pure Al specimens with $\eta=6.27$.

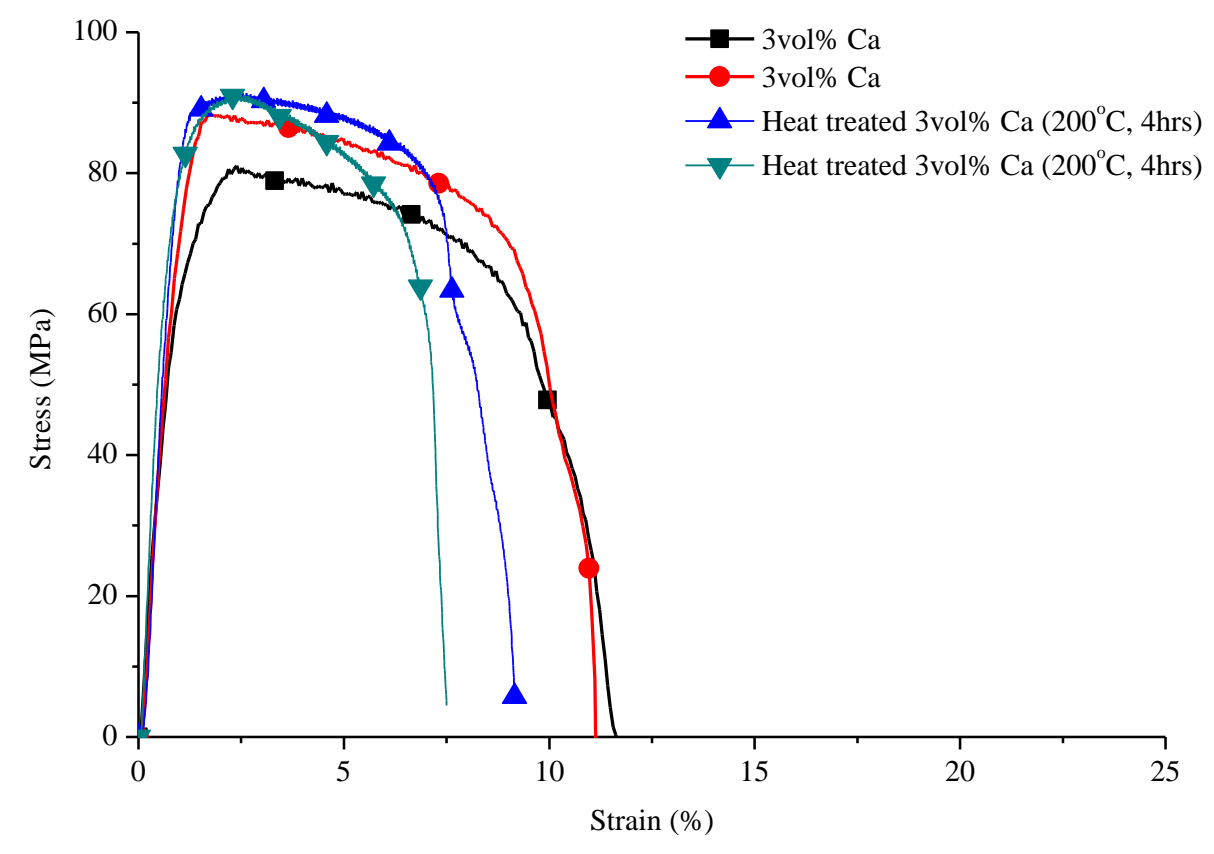

Figure 3.18 Stress-strain plots of Al-3vol\%Ca specimens with $\eta=6.27$. 


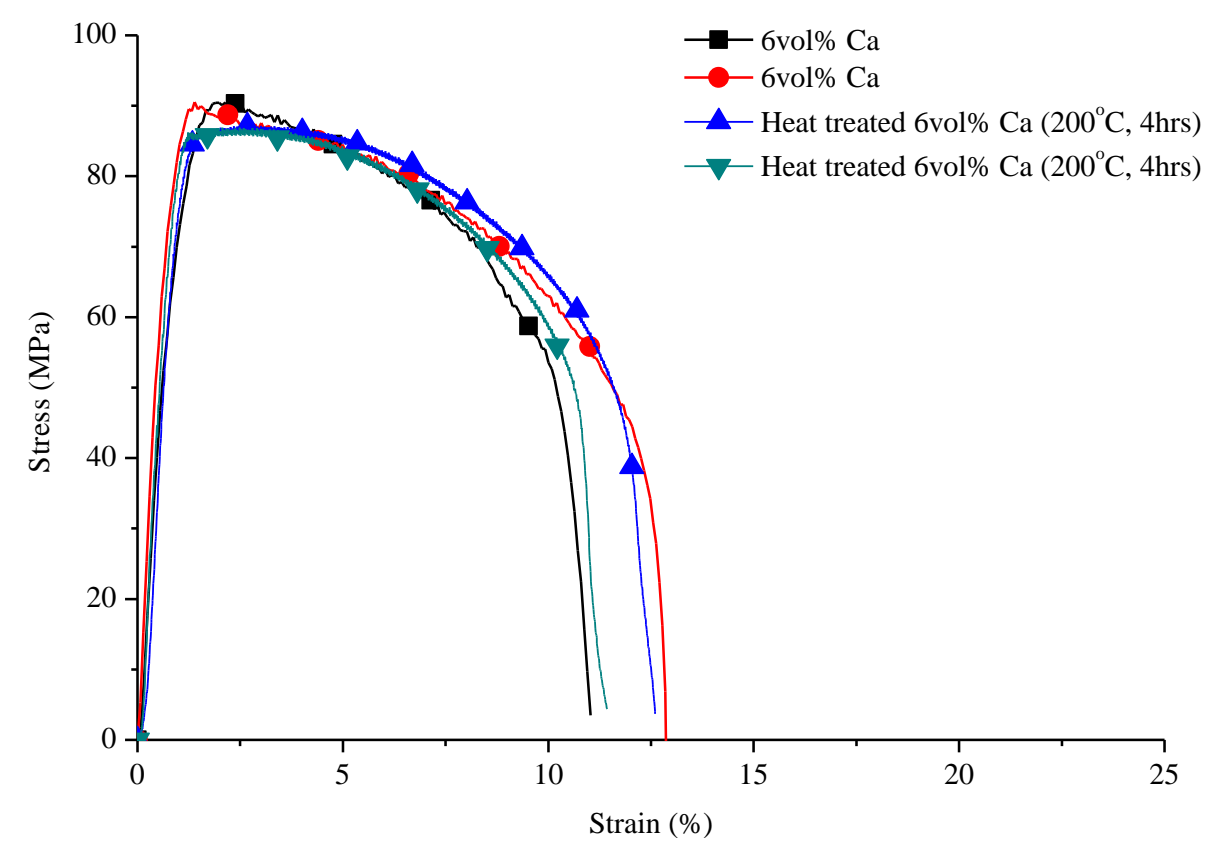

Figure 3.19 Stress-strain plots of Al-6vol\%Ca specimens with $\eta=6.27$.

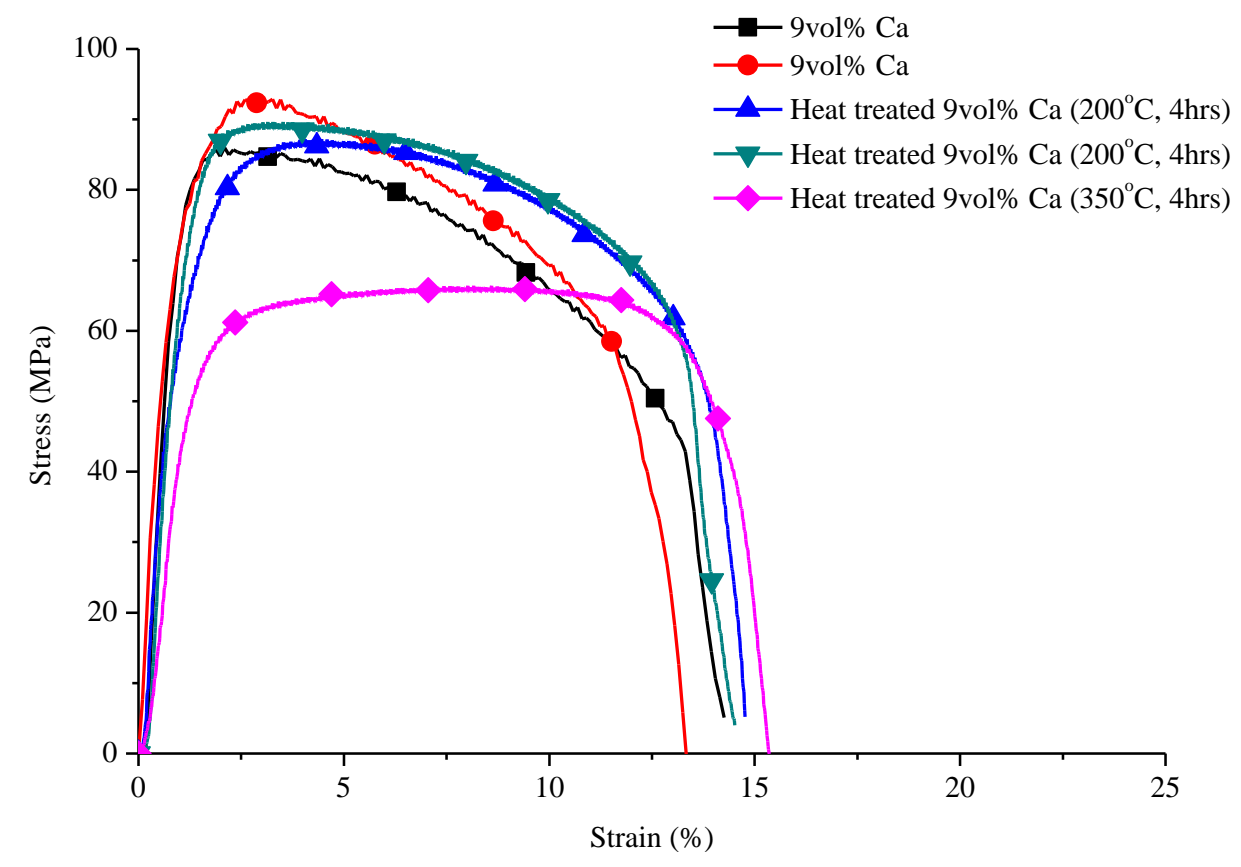

Figure 3.20 Stress-strain plots of Al-9vol\%Ca specimens with $\eta=6.27$. 


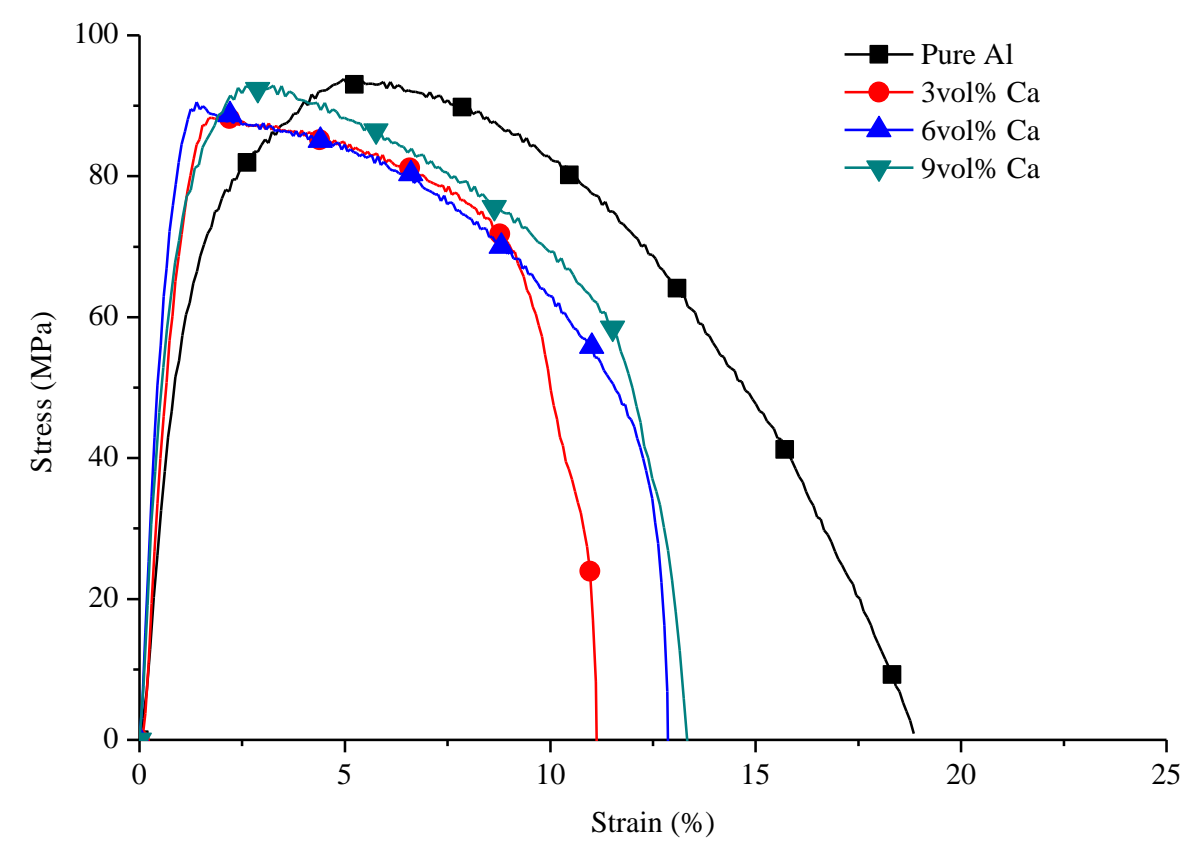

Figure 3.21 Stress-strain plots of non heat-treated specimens with $\eta=6.27$.

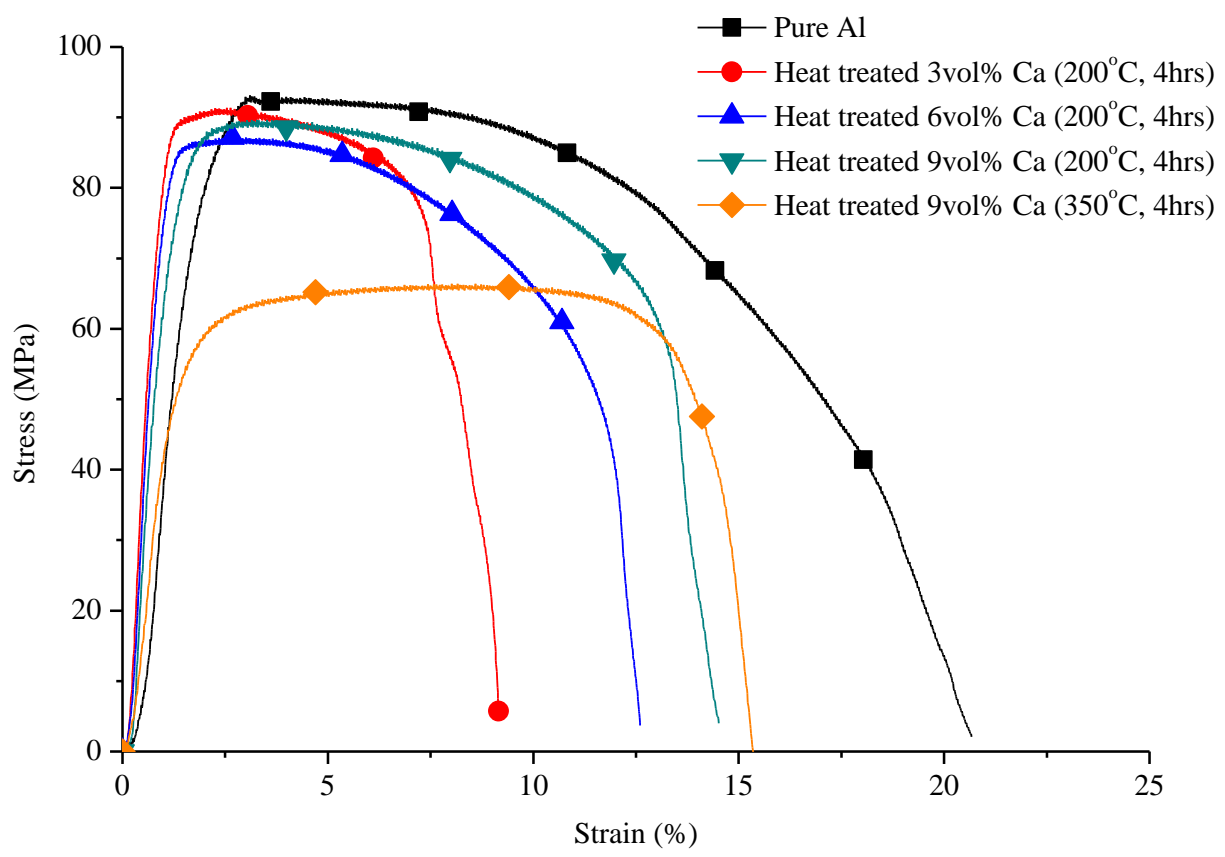

Figure 3.22 Stress-strain plots of heat-treated specimens with $\eta=6.27$. 


\subsubsection{Fractographies of Al-Ca DMMCs at $\eta=6.27$}

Figure 3.23-24 show the fracture surfaces of Al-9vol\%Ca specimens at $\eta=6.27$. Non-heat treated and heat treated at $200^{\circ} \mathrm{C}$ for four hours specimens show similar fracture surfaces. The $\mathrm{Al}$ matrix formed classic ductile failure dimples, and $\mathrm{Ca}$ filaments were located at the center of most dimples.

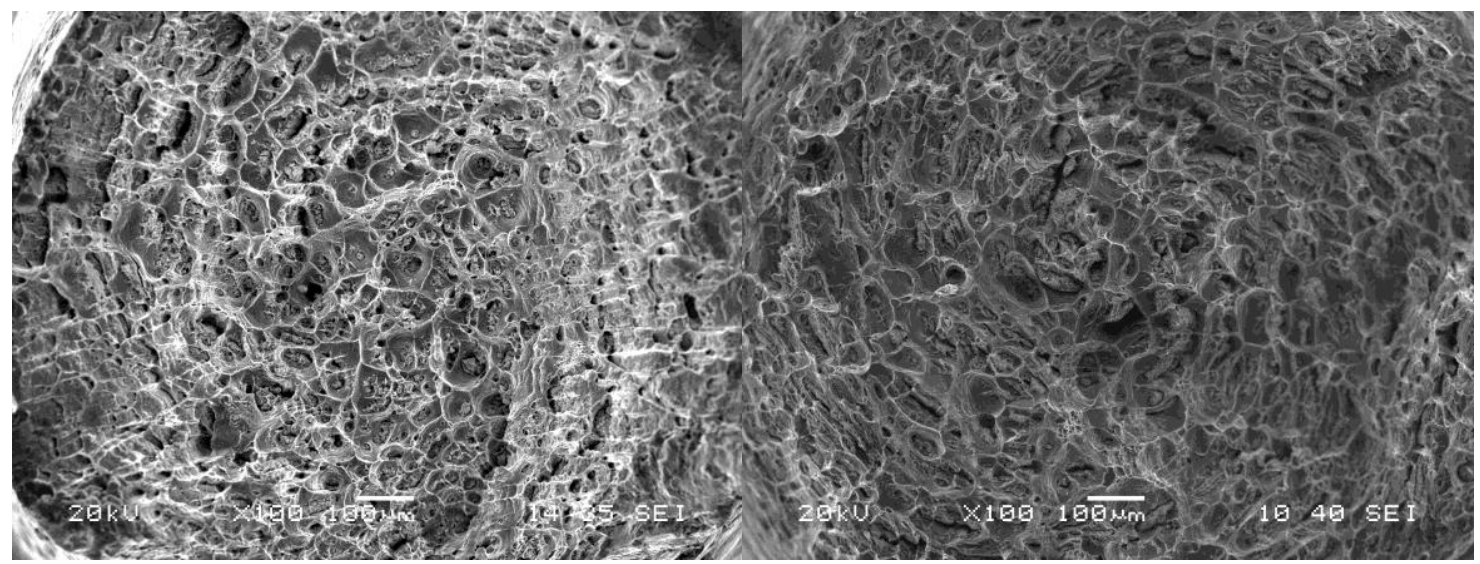

(a)

(b)

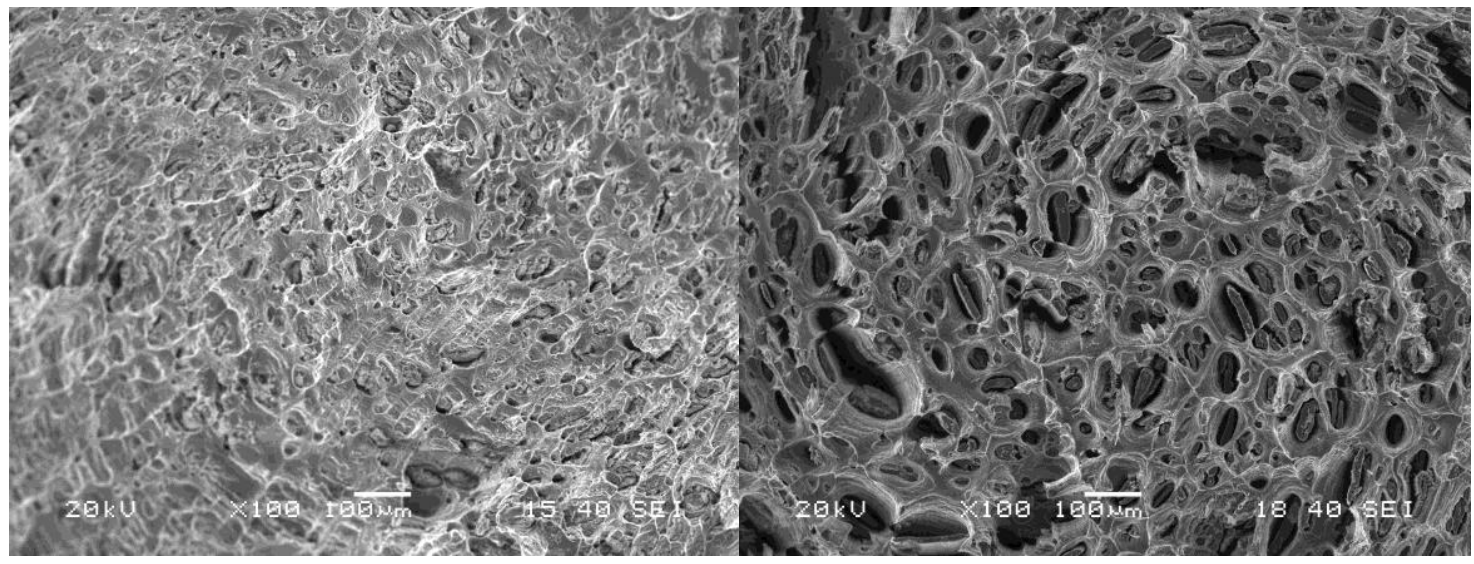

(c)

(d)

Figure 3.23 SEM micrographs of fracture surfaces for Al-9Vol $\% \mathrm{Ca}(\eta=6.27)$ wires with heat treatments. (a) without heat treatment (b) $200^{\circ} \mathrm{C}, 4$ hours (c) $200^{\circ} \mathrm{C}, 4$ hours (d) $350^{\circ} \mathrm{C}$ for 4 hours. 


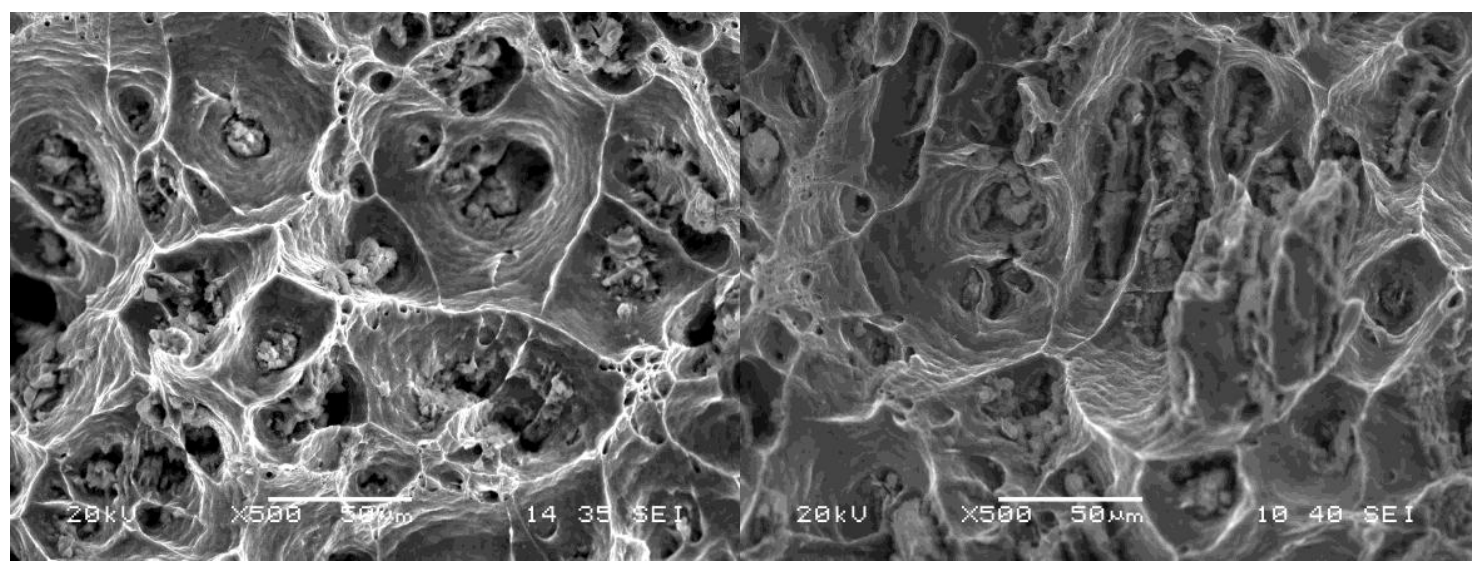

(a)

(b)

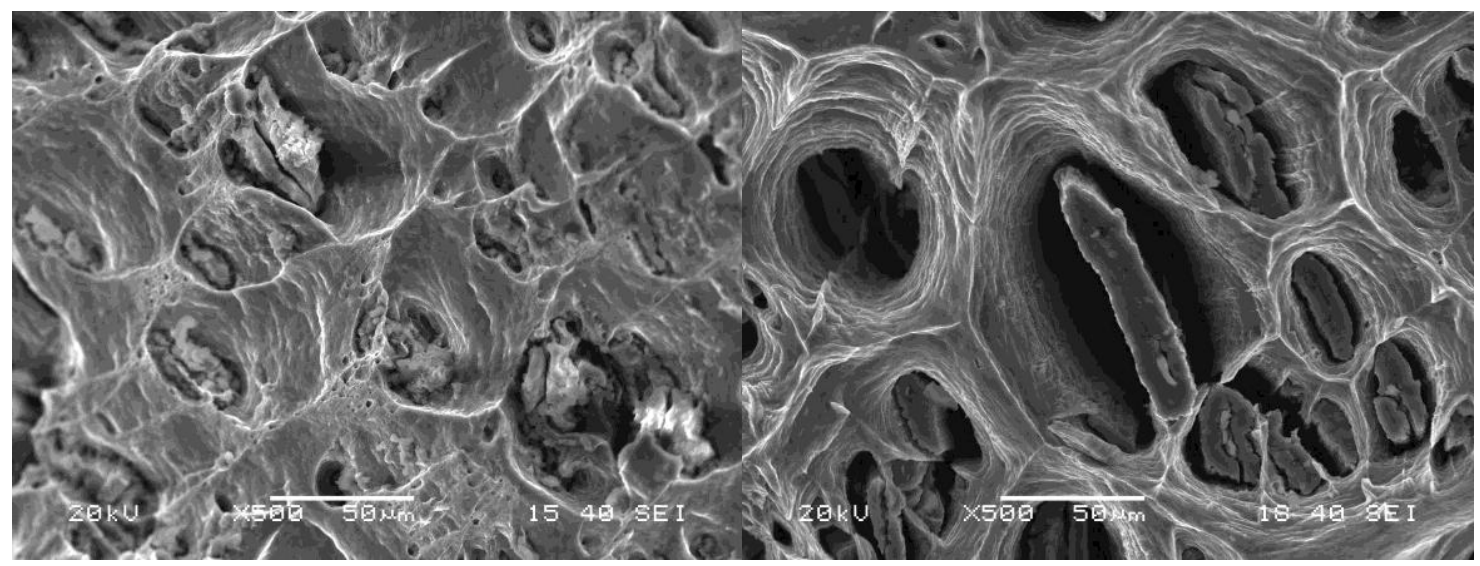

(c)

(d)

Figure 3.24 SEM micrographs of fracture surfaces for Al-9Vol $\% \mathrm{Ca}(\eta=6.27)$ wires with heat treatments. (a) without heat treatment (b) $200^{\circ} \mathrm{C}, 4$ hours (c) $200^{\circ} \mathrm{C}, 4$ hours (d) $350^{\circ} \mathrm{C}$ for 4 hours.

\subsubsection{Quantitative analysis for Ca filaments}

Figure 3.25 shows back-scattered-electron images from polished metallographic specimens on Al-9vol\%Ca wires taken after tensile testing. Dark gray regions are the Al matrix, and light gray regions are $\mathrm{Ca}$ filaments. The white regions are intermetallic phases formed during heat treatment. The white region is increased by heat treatment at 
higher temperature $\left(350^{\circ} \mathrm{C}\right)$

The fracture surface of specimens with heat treatment at $350^{\circ} \mathrm{C}$ for 4 hours show a morphology different from those of specimens with no heat treatment and specimens heat treated at $200^{\circ} \mathrm{C}$ for 4 hours. The fractography of the Ca filaments have some similarities to those of brittle material, which was unexpected since pure $\mathrm{Ca}$ is a highly ductile metal. EDS analysis was performed on polished metallographic specimens after they were tensile tested (Table 3.3). The outer areas of the Ca filaments (points 1,2, and 3) contain $\sim 50 \mathrm{at} . \% \mathrm{Ca}$ and the inner areas of the Ca filaments (points 4, 5, and 6) have $~ 70$ at.\% Ca. Although these findings do not accurately match the at\% ratios of $\mathrm{Al}_{4} \mathrm{Ca}(80: 20)$ and $\mathrm{Al}_{2} \mathrm{Ca}(67.7: 33.3)$, the differences are probably attributable to the analysis error of standardless EDS. The Ca filaments in Al-9vol\%Ca wires heat treated at $350^{\circ} \mathrm{C}$ for 4 hours formed at least two different intermetallic phases. Previous XRD analysis for heattreated specimens and standardless EDS analysis of Al-9vol\%Ca with heat treatment at $325^{\circ} \mathrm{C}$ for 1 hour showed that $\mathrm{Al}_{4} \mathrm{Ca}$ forms first. Thus, the outer regions of the $\mathrm{Ca}$ filaments (points 1, 2, and 3) are probably $\mathrm{Al}_{4} \mathrm{Ca}$. In the same way, the inner regions of the Ca filaments (points 4, 5, and 6) are probably $\mathrm{Al}_{2} \mathrm{Ca}$. 


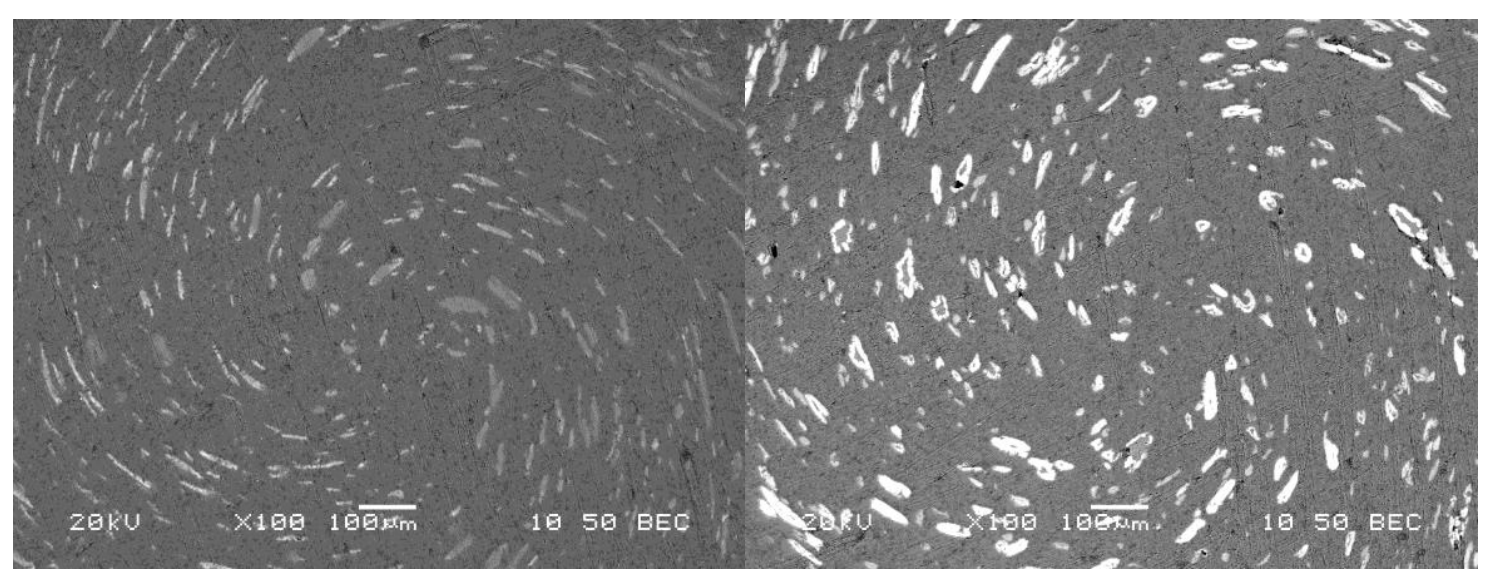

(a)

(b)

Figure 3.25 SEM micrographs of polished fracture surfaces for $\mathrm{Al}-9 \mathrm{Vol} \% \mathrm{Ca}(\eta=6.27)$ wires with heat treatments. (a) $200^{\circ} \mathrm{C}, 4$ hours (b) $350^{\circ} \mathrm{C}$ for 4 hours.

Table 3.4 Elemental analysis by standardless EDS for Al-9vol\%Ca $(\eta=6.27)$ with heat treatment at $350^{\circ} \mathrm{C}$ for 4 hours

\begin{tabular}{ccc}
\hline \multirow{2}{*}{ Point } & \multicolumn{2}{c}{ Atomic \% } \\
\cline { 2 - 3 } & $\mathrm{Al}$ & $\mathrm{Ca}$ \\
\hline 1 & 46 & 54 \\
2 & 47 & 53 \\
3 & 46 & 54 \\
\hline 4 & 28 & 72 \\
5 & 32 & 68 \\
6 & 27 & 73 \\
\hline
\end{tabular}

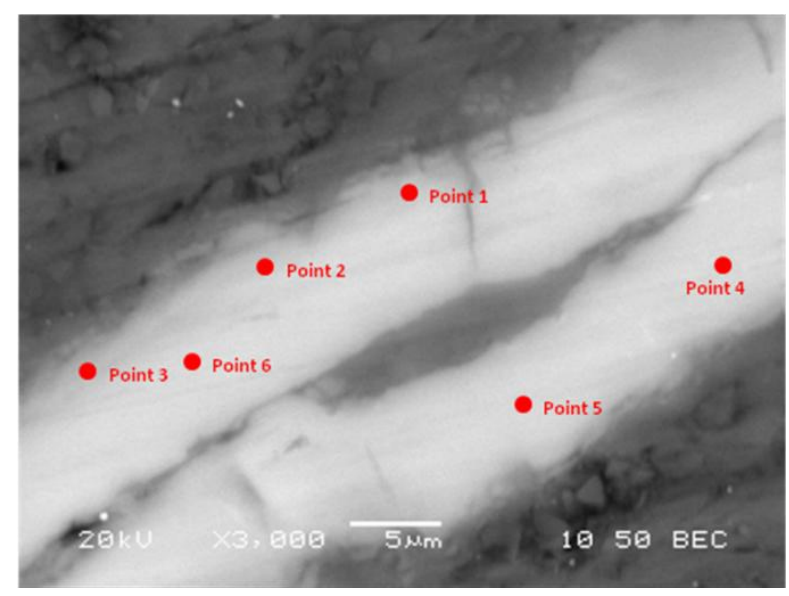

\subsubsection{Ultimate tensile strength and mean free path}

Figure 3.26 and Table 3.4 show tensile test results for specimens with $\eta=6.27,8.55$, 12.45 and 13.76. Tensile tests were performed at room temperature. These specimens 
were too small to permit use of an extensometer, so the slopes of the elastic portion of the stress-strain curves do not give accurate information on elastic modulus. Values shown in Table 3.4 are the average values from two to four tensile tests at each level of deformation true strain. Plots shown in Figure 3.26 are the plots for the tests that had the maximum ultimate tensile strength value at each deformation true strain.

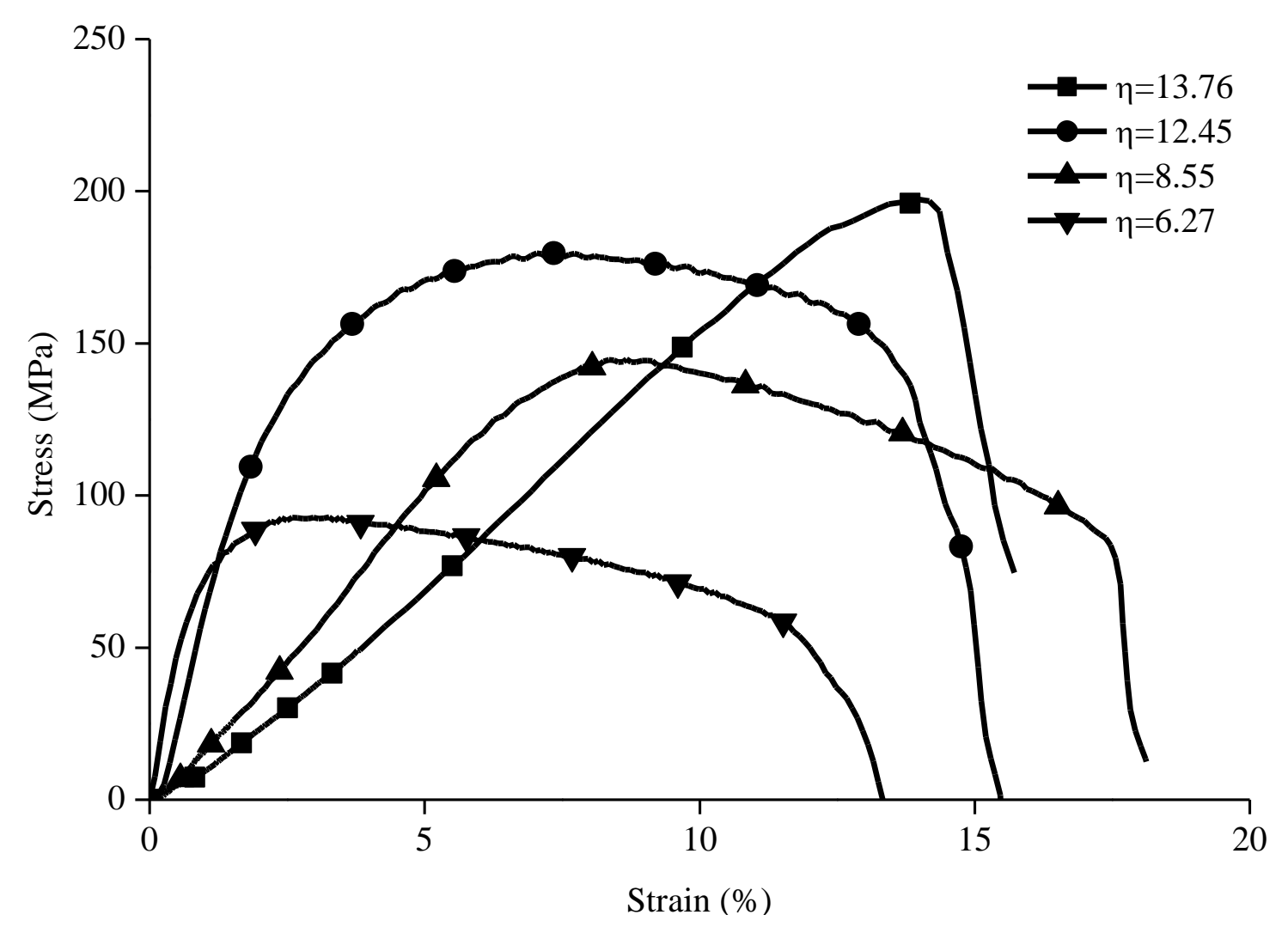

Figure 3.26 Stress-strain plots of Al-9vol\%Ca specimens with $\eta=6.27,8.55,12.45$ and 13.76. Note: The samples were too small to allow use of an extensometer, so the slopes of the elastic portions of the plots do not accurately represent elastic modulus. 
Table 3.5 Average values of ultimate tensile strength and maximum strain for Al$9 \mathrm{vol} \% \mathrm{Ca}$ specimens without heat treatment at $\eta=6.27,8.55,12.45$ and 13.76 .

\begin{tabular}{lll}
\hline $\begin{array}{l}\text { Specimen } \\
(\text { True Strain, } \eta)\end{array}$ & UTS $(\mathrm{MPa})$ & Max. Strain $(\%)$ \\
\hline 6.27 & 93 & 13 \\
8.55 & 145 & 18 \\
12.45 & 179 & 16 \\
13.76 & 197 & 16 \\
\hline
\end{tabular}

The mean free path between Ca filaments was calculated with a 50mm-long unit line on SEM micrographs of specimens with deformation true strains of $\eta=6.27,8.55,10.34$, 12.45, and 13.76. The relationship between mean free path and ultimate tensile strength is shown in Figure 3.27. 


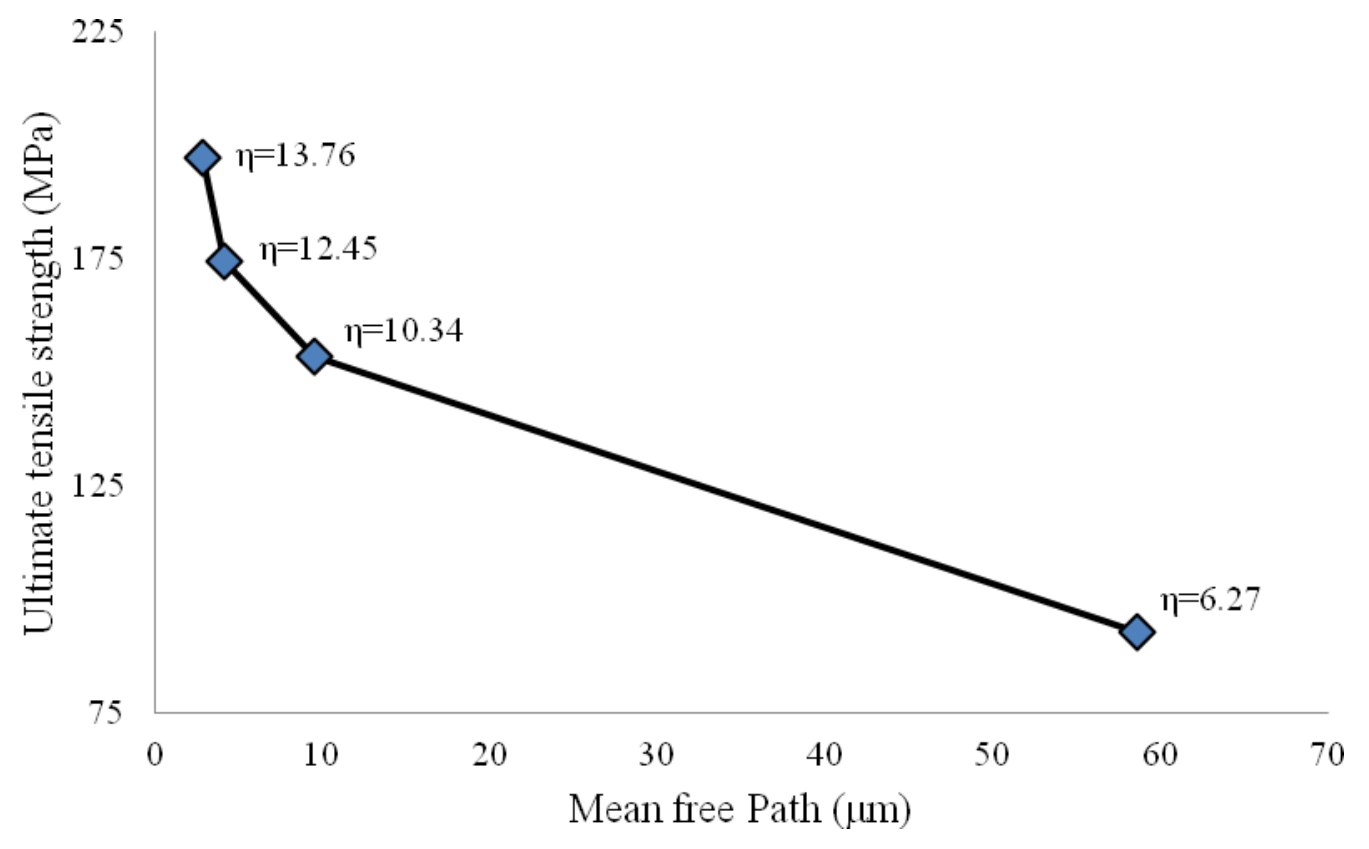

Figure 3.27 The relationship between ultimate tensile strength and mean free path between $\mathrm{Ca}$ filaments. This sharp increase in strength as mean free path decreases is typical of DMMCs [4,15-20]. This topic is discussed in greater detail in Section 3.2.6.

\subsubsection{Ultimate tensile strength with the rule of mixtures}

The tensile strength of DMMCs with aligned continuous filaments is usually predicted by the rule of mixtures equation [4-6]:

$$
\sigma_{U T S}=\sigma_{m} V_{m}+\sigma_{f, U T S} V_{f}
$$

where $\sigma_{U T S}$ and $\sigma_{f, U T S}$ are the ultimate tensile strength of the composite wire and filaments, respectively, and $V_{m}$ and $V_{f}$ are the volume fraction of matrix and filaments, 
respectively. $\sigma_{m}$ is the flow stress of the matrix at the strain $\varepsilon_{U T S}$ at fracture. The choice of $\sigma_{m}$ depends to a certain extent on the ductility of the filaments and on the stress-strain relationship of both filaments and matrix. The upper limit of $\sigma_{m}$ is the ultimate tensile strength of the cold-worked matrix [7]. In the Al-9vol\%Ca DMMC, $\sigma_{m}$ is $80 \mathrm{MPa}[8]$ and $\sigma_{f, \text { UTS }}$ is $55 \mathrm{MPa}$ (estimated by conversion from its hardness value [9]. Thus, applying the rule of mixtures for Al-9vol\%Ca DMMC, the ultimate tensile strength is $\sigma_{U T S}=78 \mathrm{MPa}$ hows that the UTS value of $\mathrm{Al}-9 \mathrm{vol} \% \mathrm{Ca}$ wire at $\eta=13.76$ is higher by a factor of 2.5 than the value predicted by the rule of mixtures. This strongly suggests that one or more of the strengthening effects described in Chapter 1 are operating in $\mathrm{Al}-$ $\mathrm{Ca}$ at higher $\eta$ values.

\subsubsection{Strengthening of Al-9vol\%Ca DMMC}

Many studies [7, 10-22] have been done to correlate UTS with deformation true strain for DMMCs. An exponential relationship has frequently been observed to exist between ultimate tensile strength and deformation true strain. The Hall-Petch barrier model is often used to explain the strengthening mechanism of DMMCs [19-20, 22]. The Hall-Petch model predicts increasing strength as the thickness and spacing of the second phase filaments decrease. With the progressively finer filamentary microstructure that accompanies increasing the deformation true strain, $\eta$, the $\mathrm{Ca}$ second phase acts as a more effective network of barriers to dislocation production and movement in the $\mathrm{Al}$ matrix phase. Further motion requires generation of new dislocations in the neighboring 
area by the local stress field produced by the blocked dislocations. As a result, the composite is strengthened.

The Hall-Petch relationship can be applied to DMMCs as:

$$
\sigma=\sigma_{0}+k \lambda^{-1 / 2}
$$

where $\sigma$ is the ultimate tensile strength (UTS), $\sigma_{0}$ and $k$ are constants, and $\lambda$ is the filament spacing. Embury [12] has proposed a modified Hall-Petch model to explain the strengthening of DMMCs:

$$
\sigma=\sigma_{0}+k d_{0} \exp (0.25 \eta)
$$

where $\sigma$ is UTS, $\sigma_{0}$ and $k$ are constants, $d_{0}$ is the initial filament spacing, and $\eta$ is deformation true strain. This empirical equation was confirmed by Russell et al. for Ti-Y DMMC [19]. Similarly, Sakai et al. found that UTS = $565 \exp (n \eta)$ for $\mathrm{Cu}-\mathrm{Ag}$ DMMC where $n$ is a factor that varies with Ag content [23]. By exponential regression (Figure 3.28), it was found that the relationship between UTS and $\eta$ that best fits the data for Al9vol\%Ca DMMC is:

$$
U T S=45.3 \exp (0.10 \eta)
$$




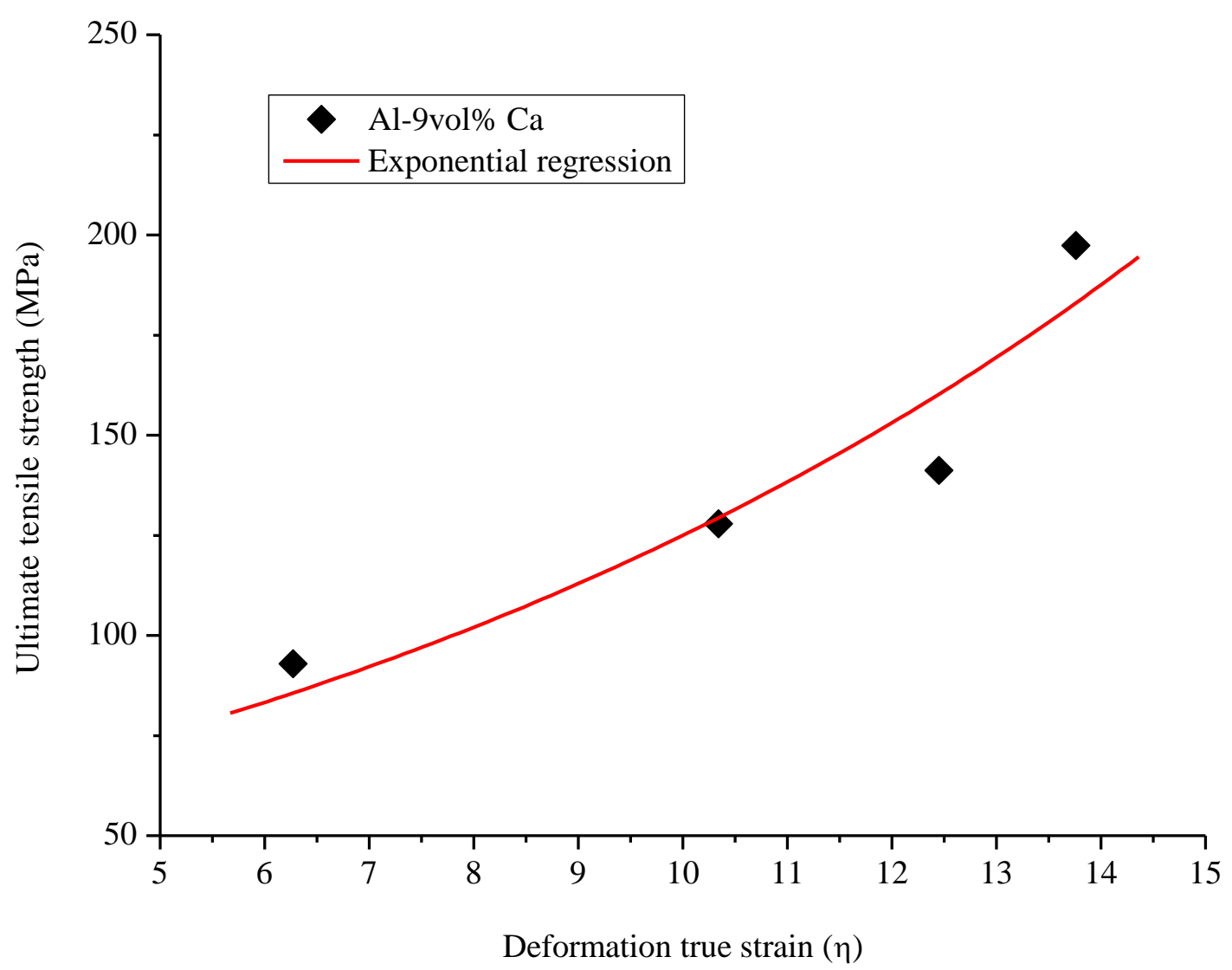

Figure 3.28 UTS on deformation true strain and exponential regression of UTS for Al9vol\%Ca.

Although the Hall-Petch barrier model for explanation of the strengthening mechanism in Al-9vol\%Ca DMMC was used in this study, the modified linear rule of mixture model has certain similarities to the Hall-Petch model [24-25]. Both models attribute the strength to the difficulty of spreading plastic flow through the Al-Ca interfaces. Since the modified linear rule of mixture model also leads to a Hall-Petch type relationship, it can be regarded as a suitable supplementary explanation of the Hall-Petch barrier model. However, there is less resemblance between the Hall-Petch barrier model and the dislocation substructure incompatibility model [24, 26]. The dislocation 
substructure incompatibility model is based on the strengthening effect of the additional (geometrically necessary) dislocations generated during deformation of two-phase materials as a result of the greater strain incompatibility between adjacent grains in a twophase material.

\subsection{References}

1. Reed-Hill, R.E. and R. Abbaschian, Physical metallurgy principles. 3rd ed. The PWS-Kent series in engineering. 1992, Boston: PWS-Kent Pub. xv, 926 p.

2. Porter, D.A., K.E. Easterling, and M.Y. Sherif, Phase transformations in metals and alloys. 3rd ed. 2009, Boca Raton, FL: CRC Press. xix, 500 p.

3. Smithells, C.J., E.A. Brandes, and G.B. Brook, Smithells metals reference book. 7th ed. 1992, Oxford ; Boston: Butterworth-Heinemann. 1 v. (various pagings).

4. Agarwal, B.D., L.J. Broutman, and K. Chandrashekhara, Analysis and performance of fiber composites. 3rd ed. 2006, Hoboken, N.J.: John Wiley. xiv, $562 \mathrm{p}$.

5. Callister, W.D., Materials science and engineering : an introduction. 7 th ed. 2007, New York: John Wiley \& Sons. xxv, 721, A41, G14, S5, I22 p.

6. Nielsen, L.F., Composite materials : properties as influenced by phase geometry. 2005, Berlin: Springer-Verlag. xv, 259 p.

7. Bevk, J., J.P. Harbison, and J.L. Bell, Anomalous increase in strength of in situ formed $\mathrm{Cu}-\mathrm{Nb}$ multifilamentary composites. Journal of Applied Physics, 1978. 
49(12): p. 6031 - 6038.

8. Kaufman, J.G., Properties of aluminum alloys : fatigue data and the effects of temperature, product form, and processing. 2008, Materials Park, Ohio: ASM International. vii, $559 \mathrm{p}$.

9. Polmear, I.J., Light alloys : metallurgy of the light metals. 3rd ed. 1995, New York: J. Wiley \& Sons. vii, 362 p.

10. Ellis, T.W. and E.D. Gibson, New Extensions in the Development of Deformation Processed Metal-Metal Matrix Composites. First International Conference on Processing Materials for Properties, 1993: p. 19-22.

11. Embury, J.D., Micromechanical Descriptions of Heavily Deformed Materials. Scripta Metallurgica Et Materialia, 1992. 27(8): p. 981-986.

12. Embury, J.D., A.S. Keh, and R.M. Fisher, Substructure Strengthening in Mechanical Working Processes. Journal of Metals, 1965. 17(9): p. 1016-\&.

13. Everett, R.K., Strengthening Mechanisms in Deformation Processed CompositeMaterials. Scripta Metallurgica, 1988. 22(8): p. 1227-1230.

14. Gantovnik, V., et al., Advances in deformation processed gold composites. Gold Bulletin, 2000. 33(4): p. 128-+.

15. Jensen, J.A., et al., Hcp Matrix In-situ Composites. Light Metals 1995, 1995: p. $1367-1374$.

16. Kim, S.T., P.M. Berge, and J.D. Verhoeven, Deformation-Processed CopperChromium Alloys - Optimizing Strength and Conductivity. Journal of Materials Engineering and Performance, 1995. 4(5): p. 573-580.

17. Pourrahimi, S., H.N. Hashemi, and S. Foner, High-Strength High-Conductivity 
Cu-Nb Microcomposite Wire by Powder-Metallurgy. Journal of Materials Science Letters, 1990. 9(12): p. 1484-1487.

18. Russell, A., et al., A new method for strengthening gold. Gold Bulletin, 1998. 31(3): p. 88-92.

19. Russell, A.M., T.W. Ellis, and L.S. Chumbley, In-Situ Strengthening of Titanium with Yttrium. Journal of Materials Science, 1995. 30(8): p. 2070-2076.

20. Russell, A.M., et al., A high-strength, high-conductivity Al-Ti deformation processed metal metal matrix composite. Composites Part A-Applied Science and Manufacturing, 1999. 30(3): p. 239-247.

21. Thieme, C.L.H., S. Pourrahimi, and S. Foner, High strength Al metal-matrix microcomposite wire with $20 \mathrm{vol} \% \mathrm{Nb}$ and ultimate tensile strengths up to 1030 MPa. Journal Name: Scripta Metallurgica et Materialia; (United States); Journal Volume: 28:8, 1993: p. Medium: X; Size: Pages: 913-918.

22. $\mathrm{Xu}, \mathrm{K} ., \mathrm{K}$. Wongpreedee, and A.M. Russell, Microstructure and strength of a deformation processed Al-20\%Sn in situ composite. Journal of Materials Science, 2002. 37(24): p. 5209-5214.

23. Sakai, Y. and H.J. SchneiderMuntau, Ultra-high strength, high conductivity CuAg alloy wires. Acta Materialia, 1997. 45(3): p. 1017-1023.

24. Spitzig, W.A., A.R. Pelton, and F.C. Laabs, Characterization of the Strength and Microstructure of Heavily Cold-Worked $\mathrm{Cu}$-Nb Composites. Acta Metallurgica, 1987. 35(10): p. 2427-2442.

25. Raabe, D. and U. Hangen, Simulation of the yield strength of wire drawn Cubased in-situ composites. Computational Materials Science, 1996. 5(1-3): p. 195- 
202.

26. Funkenbusch, P.D. and T.H. Courtney, On the Strength of Heavily Cold-Worked In-situ Composites. Acta Metallurgica, 1985. 33(5): p. 913-922. 


\section{CHAPTER 4. ELECTRICAL PROPERTIES}

\subsection{Electrical conductivity}

High electrical conductivity is one of the most important properties of a conductor material. In this study, electrical resistivity of $\mathrm{Al}-9 \mathrm{vol} \% \mathrm{Ca}$ wire at deformation true strain, $\eta=8.55$, was measured with a Keithley Model 580 micro-ohmmeter with Model 5804 test leads [1]. Figure 4.1 shows a schematic drawing of specimen with test leads for electrical resistivity measurements.

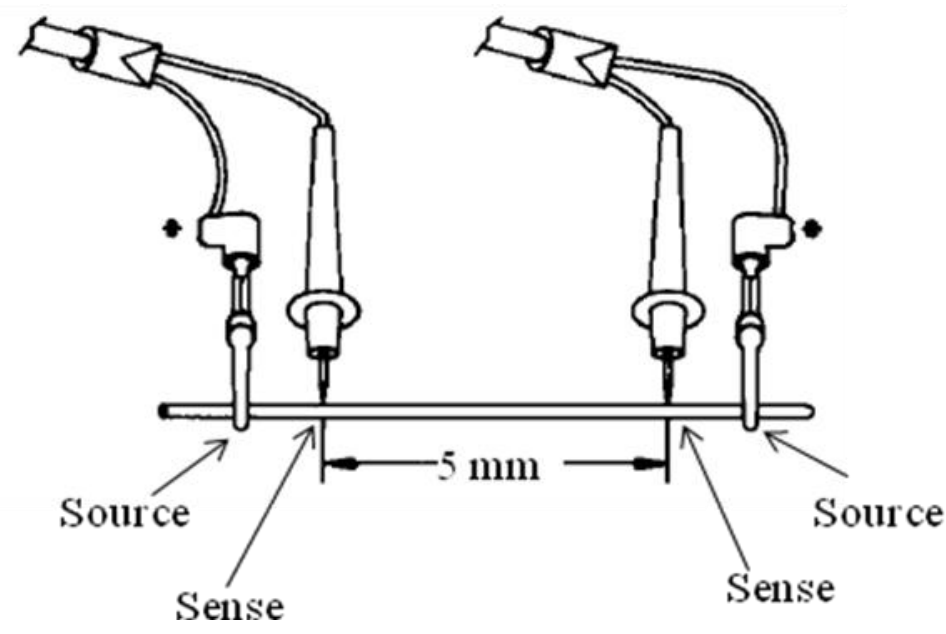

Figure 4.1 Schematic drawing of specimen with test leads for electrical resistivity measurements [1]

Table 4.1 shows electrical conductivities of specimens given heat treatment durations of varying durations at $300^{\circ} \mathrm{C}$. Previous results from XRD analysis from APS 
showed that $\mathrm{Al}_{4} \mathrm{Ca}$ is formed after heat treatment at $275^{\circ} \mathrm{C}$ for $10 \mathrm{~min}$ and $\mathrm{Al}_{2} \mathrm{Ca}$ is formed after heat treatment at $275^{\circ} \mathrm{C}$ for 1 hour. Table 4.1 indicates that values of electrical conductivity vary between specimens given two different heat treatment times (15 min and $45 \mathrm{~min}$ ). Additional study for electrical conductivity of Al-Ca DMMCs would be desirable to more clearly define the formation of intermetallic phases with various heat treatments.

Table 4.1 Electrical conductivity for Al-9vol\%Ca at $\eta=8.55$ with heat treatments at $300^{\circ} \mathrm{C}$ for various times.

\begin{tabular}{ccc}
\hline Heat treatment time $(\min )$ & Resistivity $(\mu \Omega \cdot \mathrm{m})$ & Conductivity $\left((\mu \Omega \cdot \mathrm{m})^{-1}\right)$ \\
\hline 5 & 0.027 & 36.6 \\
10 & 0.027 & 36.6 \\
15 & 0.027 & 36.6 \\
30 & 0.029 & 34.8 \\
45 & 0.029 & 34.8 \\
60 & 0.030 & 33.3 \\
120 & 0.030 & 33.3 \\
180 & 0.030 & 33.3 \\
240 & 0.030 & 33.3 \\
300 & 0.030 & 33.3 \\
720 & 0.030 & 33.3 \\
1440 & 0.030 & 33.3 \\
\hline
\end{tabular}




\subsection{References}

1. $\quad$ http://www.keithley.com/data?asset $=50834$. 


\section{CHAPTER 5. KINETICS EXPERIMENTS}

\subsection{Phase identification with increasing temperature}

Figure 5.1 shows XRD data acquired at the Advanced Photon Source at Argonne Laboratory during kinetics experiments performed on $\mathrm{Al}-9 \mathrm{vol} \% \mathrm{Ca}$ processed to a deformation true strain of $\eta=8.55$. To detect intermetallic phase formation, XRD patterns were taken every $3.5 \mathrm{sec}$ during heating from room temperature to $430^{\circ} \mathrm{C}$ with a heating rate of $50^{\circ} \mathrm{C} / \mathrm{min}$. After heating to $430^{\circ} \mathrm{C}$, the temperature was maintained at $430^{\circ} \mathrm{C}$ for 10 min; then the sample was cooled at $-50^{\circ} \mathrm{C} / \mathrm{min}$. A total of $153 \mathrm{XRD}$ patterns were obtained during heating; the XRD patterns shown in Figure 5.1 were selected at approximately one third and two thirds of the span from room temperature to the maximum temperature used. During heating the specimen's Ca reacted with the Al matrix to form $\mathrm{Al}_{4} \mathrm{Ca}$ and possibly $\mathrm{Al}_{2} \mathrm{Ca}$. The pure Ca peaks disappeared before $430^{\circ} \mathrm{C}$ was reached. The intensities and numbers of visible diffraction peaks did not change while the sample was held at $430^{\circ} \mathrm{C}$ for $10 \mathrm{~min}$; all four patterns shown for $430^{\circ} \mathrm{C}$ on Fig. 5.1 are essentially identical. No indication is visible in Fig. 5.1 of any $\mathrm{Ca}$ transformation to the bcc phase, which the phase diagram (Fig. 2.3) predicts would not occur until the specimen temperature was at $455^{\circ} \mathrm{C}$. 


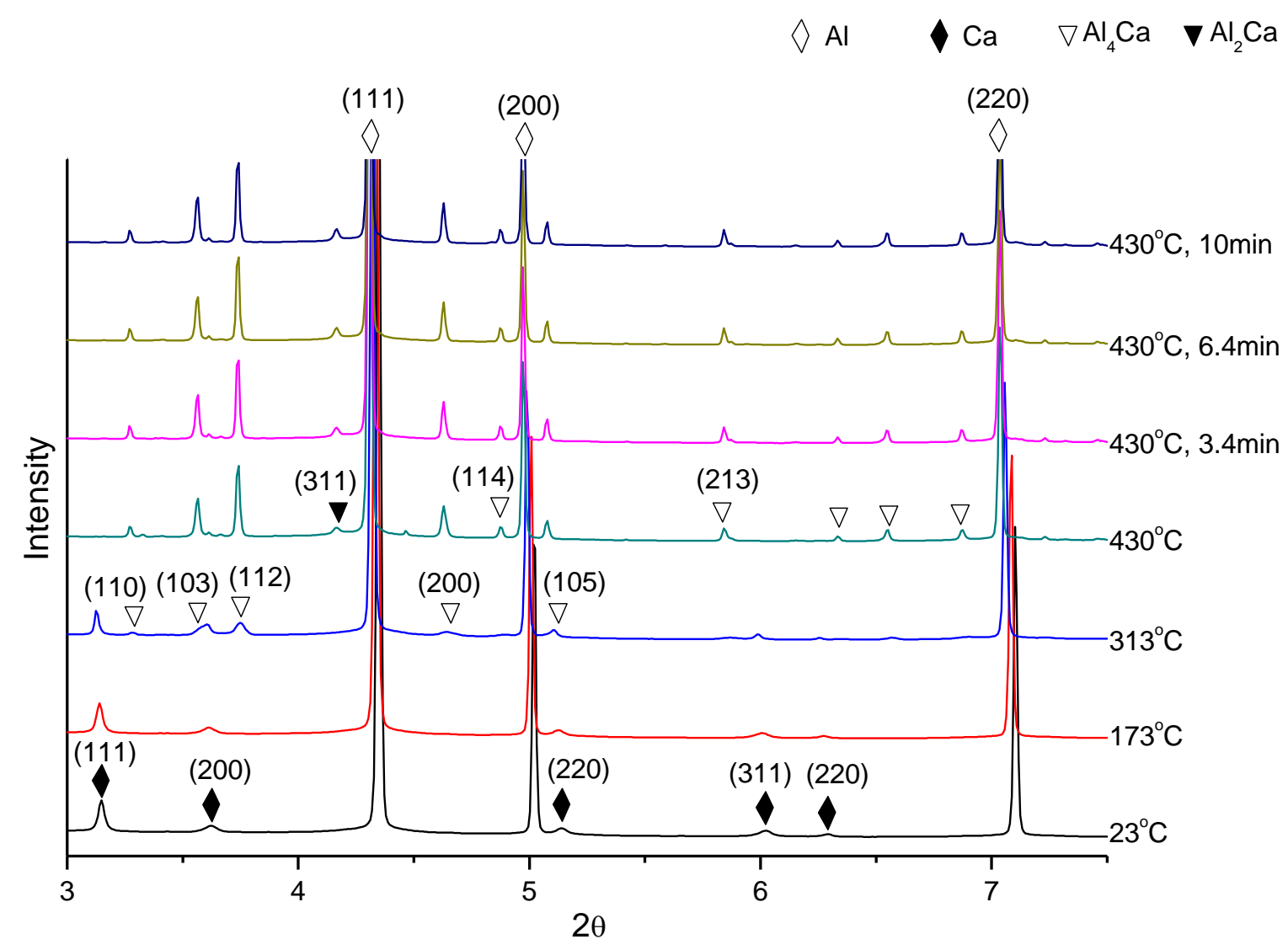

Figure 5.1 XRD patterns of $\mathrm{Al}-9 \mathrm{vol} \% \mathrm{Ca}$ at $\eta=8.55$ during heating from room temperature to $430^{\circ} \mathrm{C}$. Peaks shift leftward as temperature rises as lattice parameter increases from thermal expansion.

The $\mathrm{Al}_{4} \mathrm{Ca}$ phase would be expected to form in this composite, since the equilibrium phases predicted by the phase diagram at these temperatures are $\mathrm{Al}$ and $\mathrm{Al}_{4} \mathrm{Ca}$. However, the more thermodynamically stable intermetallic compound in the Al-Ca system is presumably $\mathrm{Al}_{2} \mathrm{Ca}$, since its higher melting point suggests it would have a more negative free energy of formation $(\Delta \mathrm{G})$ than $\mathrm{Al}_{4} \mathrm{Ca}$. Intriguingly, one small peak that matches the (311) peak position in $\mathrm{Al}_{2} \mathrm{Ca}$ appears in the $430^{\circ} \mathrm{C}$ patterns; however, it would be 
inappropriate to conclude that $\mathrm{Al}_{2} \mathrm{Ca}$ is actually present in this specimen based on the presence of a single peak. Conceivably a thin zone of $\mathrm{Al}_{2} \mathrm{Ca}$ could form temporarily around the Ca filaments as a transient intermediate phase as the composite moves toward establishing the equilibrium $\mathrm{Al}+\mathrm{Al}_{4} \mathrm{Ca}$ composition.

\subsection{Thermal expansions of $\mathrm{Al}$ and $\mathrm{Ca}$}

Figure 5.1 shows that every peak position shifts during heating as a result of thermal expansion. Figure 5.2 shows thermal expansion peak shifting of $\mathrm{Al}$ (111) and $\mathrm{Ca}$ (111) with calculated $\mathrm{d}$-spacing. To calculate thermal expansion $\mathrm{d}$-spacing changes, the coefficients of thermal expansion (CTE) for $\mathrm{Al}$ and $\mathrm{Ca}$ are used by $23.1 \times 10^{-6} /{ }^{\circ} \mathrm{C}$ and $22.3 \times 10^{-6} /{ }^{\circ} \mathrm{C}[1]$, respectively. However the CTEs for most materials vary as temperature changes. A quadratic equation for CTE provides a more accurate expresion for thermal expansion. The quadratic equation for CTE of Al [2] is:

$$
C T E=-0.583 \times 10^{-3}+23.107 \times 10^{-6} T+8.024 \times 10^{-9} T^{2}
$$

The quadratic equation for CTE of Ca was not found in the literature, so in this study, the CTE at room temperature was used for calculating thermal expansion.

The calculated d-spacings obtained from the XRD patterns (Table 5.1) at various temperatures do not exactly match the expected values for the pure elemental constituents of Al-9vol\%Ca. The small differences observed ( $0.2 \%)$ may be attributable to the heavy deformation and high residual stresses present in $\mathrm{Al}-9 \mathrm{vol} \% \mathrm{Ca}$ at $\eta=8.55$ at room 
temperature, to impurities in the $\mathrm{Al}$ and $\mathrm{Ca}$, and/or to experimental errors in the $\mathrm{XRD}$ measurements.

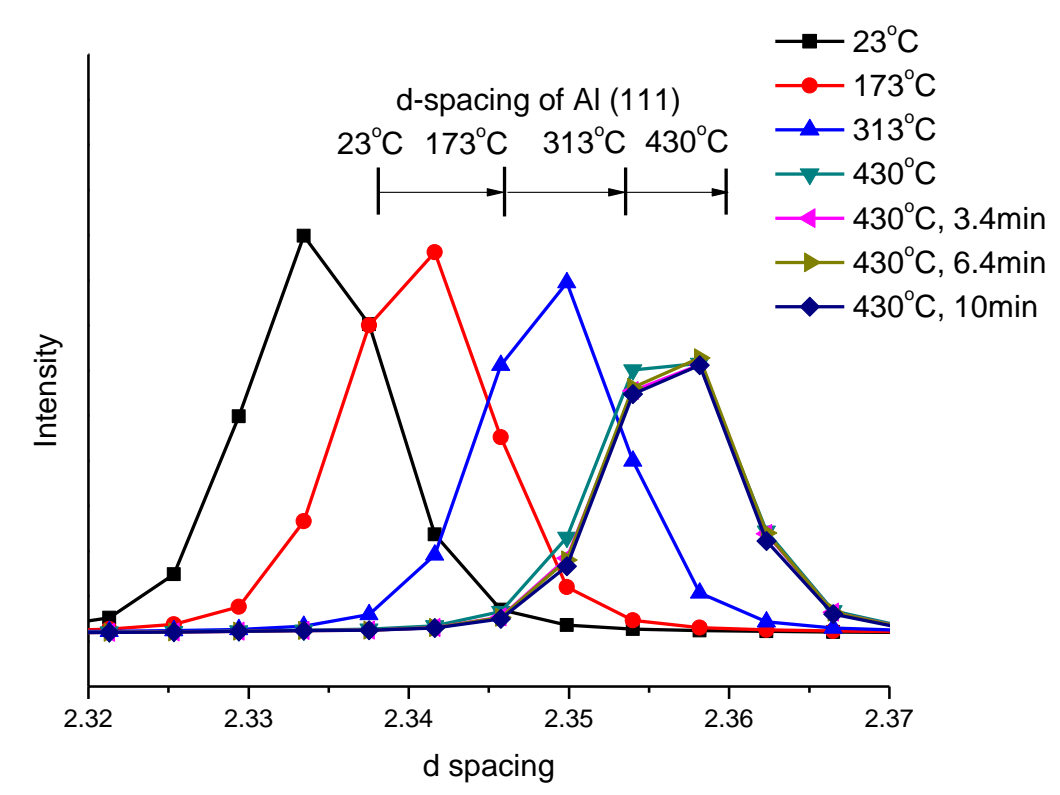

(a) $\mathrm{Al}(111)$

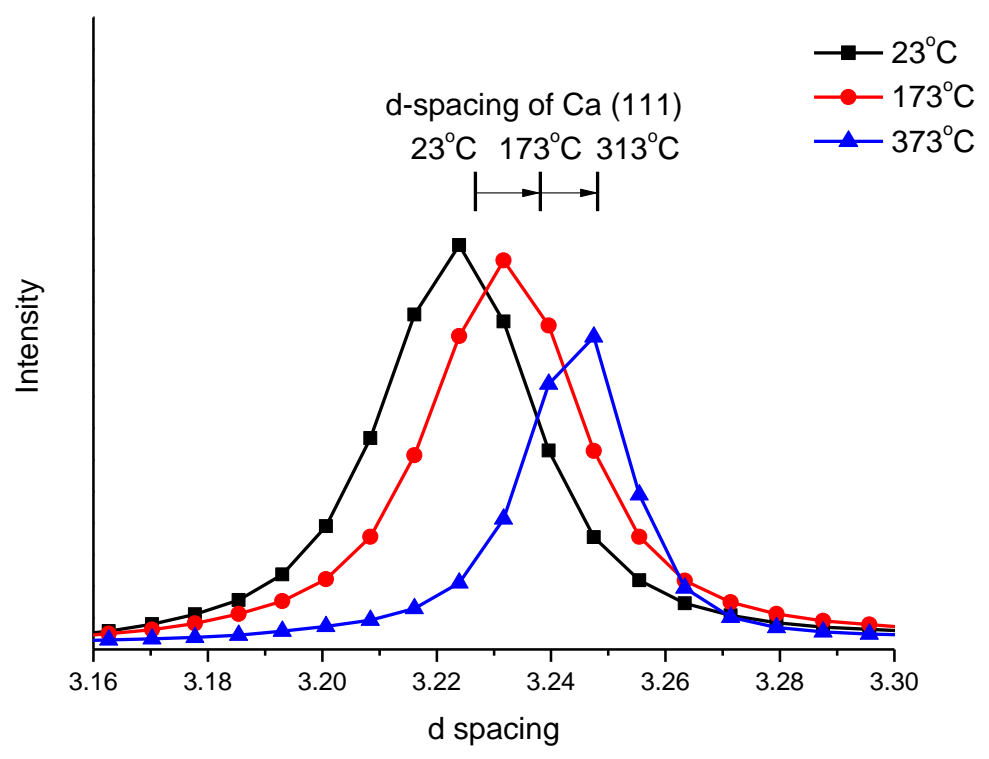

(b) $\mathrm{Ca}(111)$

Figure 5.2 Increase of d-spacing by thermal expansion of $\mathrm{Al}$ (111) and $\mathrm{Ca}$ (111). The black arrows indicate the shifted d-spacing with increase temperature. 
Table 5.1 Changing of d-spacing by thermal expansion of $\mathrm{Al}$ (111) and $\mathrm{Ca}$ (111)

\begin{tabular}{|c|c|c|c|c|c|}
\hline & & \multicolumn{4}{|c|}{ d-spacing $(\AA ̊)$} \\
\hline & & $23^{\circ} \mathrm{C}$ & $173^{\circ} \mathrm{C}$ & $313^{\circ} \mathrm{C}$ & $430^{\circ} \mathrm{C}$ \\
\hline \multirow{3}{*}{$\mathrm{Al}(111)$} & $\begin{array}{c}\text { Predicted by thermal } \\
\text { expansion effects in } \\
\text { pure Al }\end{array}$ & 2.338 & 2.346 & 2.355 & 2.363 \\
\hline & $\begin{array}{l}\text { Observed values for } \\
\mathrm{Al} \text { in } \mathrm{Al}-9 \mathrm{vol} \% \mathrm{Ca}\end{array}$ & 2.333 & 2.341 & 2.349 & 2.356 \\
\hline & Differences & 0.005 & 0.005 & 0.006 & 0.007 \\
\hline \multirow{3}{*}{$\mathrm{Ca}(111)$} & $\begin{array}{l}\text { Predicted by thermal } \\
\text { expansion effects in } \\
\text { pure } \mathrm{Al}\end{array}$ & 3.227 & 3.238 & 3.248 & \\
\hline & $\begin{array}{l}\text { Observed values for } \\
\mathrm{Ca} \text { in } \mathrm{Al}-9 \mathrm{vol} \% \mathrm{Ca}\end{array}$ & 3.223 & 3.234 & 3.245 & \\
\hline & Differences & 0.004 & 0.004 & 0.003 & \\
\hline
\end{tabular}

\subsection{Variation of grain size with increasing temperature}

An analysis of peak broadening during heating was made using Scherrer's equation [3]. Diffraction peaks broaden when the average crystallite size of the specimen becomes very small (sub-micrometer sizes). To estimate a lower bound on grain size, the peak broadening expressed in terms of full width at half maximum (FWHM) for a specific diffraction plane can be measured. Other effects can also contribute to peak broadening (e.g., dislocation density and instrument effects) so the Scherrer equation can provide only a lower bound on grain or cell size, not the actual size. Three peaks from Al and one 
peak from $\mathrm{Ca}$ were selected to measure FWHM. The $\mathrm{Ca}$ (111) is the strongest Ca peak, although it disappeared between $313^{\circ}$ and $430^{\circ} \mathrm{C}$ as the $\mathrm{Ca}$ was consumed by intermetallic compound formation. After reaching $430^{\circ} \mathrm{C}$, intensities and $\mathrm{FWHMs}$ of all Al peaks did not change during the $10 \mathrm{~min}$ hold at $430^{\circ} \mathrm{C}$.

For calculation of the lower bound on grain size, the Scherrer equation is:

$$
\text { size }=\frac{k \times \lambda}{\cos (\theta) \times(F W H M)}
$$

where $k$ is a shape factor, and $\lambda$ is $\mathrm{x}$-ray wavelength. In this study, the shape factor had a value of 0.93 [4], and the X-ray wavelength was shifted by calculation to be $1.54 \AA$.

During deformation at room temperature, dislocation density increases due to strain hardening. If the strain-hardened metal is annealed hot enough and long enough, recovery and recrystallization will occur. Recrystallization is usually complete in cold-worked metals after approximately one hour at $0.4 \mathrm{~T}_{\mathrm{m} . \mathrm{pt} .}$ For $\mathrm{Al}$ and $\mathrm{Ca}$ of reasonably high

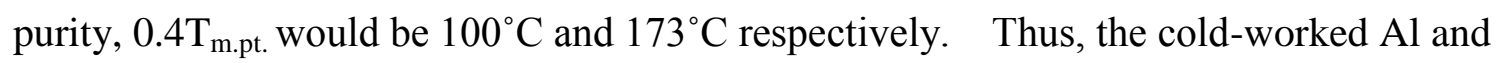
$\mathrm{Ca}$ in this composite would have recrystallized completely during the first part of this experiment. If annealing is continued after recrystallization is complete, grain growth is expected to occur [5]. Table 5.1 shows the calculated grain size of selected d-spacings between certain planes in $\mathrm{Al}$ and Ca. During heating, the grain size of each phase increased. The lower bound on grain size of Ca as calculated from FWHM data for the (111) diffraction peak increased from $66 \mathrm{~nm}$ at room temperature to $102 \mathrm{~nm}$ at $313^{\circ} \mathrm{C}$. The lower bound on grain size of $\mathrm{Al}$ as determined from FWHM data on the (111), (200), 
and (220) diffraction peaks increased from $105 \mathrm{~nm}$ to $123 \mathrm{~nm}$, from $128 \mathrm{~nm}$ to $143 \mathrm{~nm}$, and $206 \mathrm{~nm}$ to $224 \mathrm{~nm}$, respectively as the temperature increased from $23^{\circ} \mathrm{C}$ to $430^{\circ} \mathrm{C}$. Figure 5.3 shows the variations of these lower bounds on grain size for specific planar dspacings of $\mathrm{Al}$ and $\mathrm{Ca}$. 
Table 5.2 Grain size as calculated from FWHM data for selected diffraction peaks in Al and $\mathrm{Ca}$ in $\mathrm{Al}-9 \% \mathrm{Ca}$ composite

\begin{tabular}{|c|c|c|c|c|}
\hline Peak & Temperature $\left({ }^{\circ} \mathrm{C}\right)$ & $2 \theta$ (degree) & FWHM $\left(10^{-3} \mathrm{rad}\right)$ & $\begin{array}{l}\text { Lower bound on } \\
\text { grain size }(\mathrm{nm})\end{array}$ \\
\hline $\mathrm{Ca}(111)$ & 23 & 27.63 & 2.443 & 66 \\
\hline $\mathrm{Ca}(111)$ & 173 & 27.57 & 2.356 & 68 \\
\hline $\mathrm{Ca}(111)$ & 313 & 27.46 & 1.571 & 102 \\
\hline $\mathrm{Al}(111)$ & 23 & 38.52 & 1.745 & 105 \\
\hline $\mathrm{Al}(111)$ & 173 & 38.41 & 1.658 & 110 \\
\hline $\mathrm{Al}(111)$ & 313 & 38.27 & 1.571 & 116 \\
\hline $\mathrm{Al}(111)$ & 430 & 38.14 & 1.484 & 123 \\
\hline $\mathrm{Al}(200)$ & 23 & 44.78 & 1.571 & 128 \\
\hline $\mathrm{Al}(200)$ & 173 & 44.64 & 1.518 & 133 \\
\hline $\mathrm{Al}(200)$ & 313 & 44.48 & 1.484 & 135 \\
\hline $\mathrm{Al}(200)$ & 430 & 44.33 & 1.396 & 143 \\
\hline $\mathrm{Al}(220)$ & 23 & 65.19 & 1.658 & 206 \\
\hline $\mathrm{Al}(220)$ & 173 & 64.99 & 1.606 & 211 \\
\hline $\mathrm{Al}(220)$ & 313 & 64.73 & 1.571 & 214 \\
\hline $\mathrm{Al}(220)$ & 430 & 64.48 & 1.484 & 224 \\
\hline
\end{tabular}




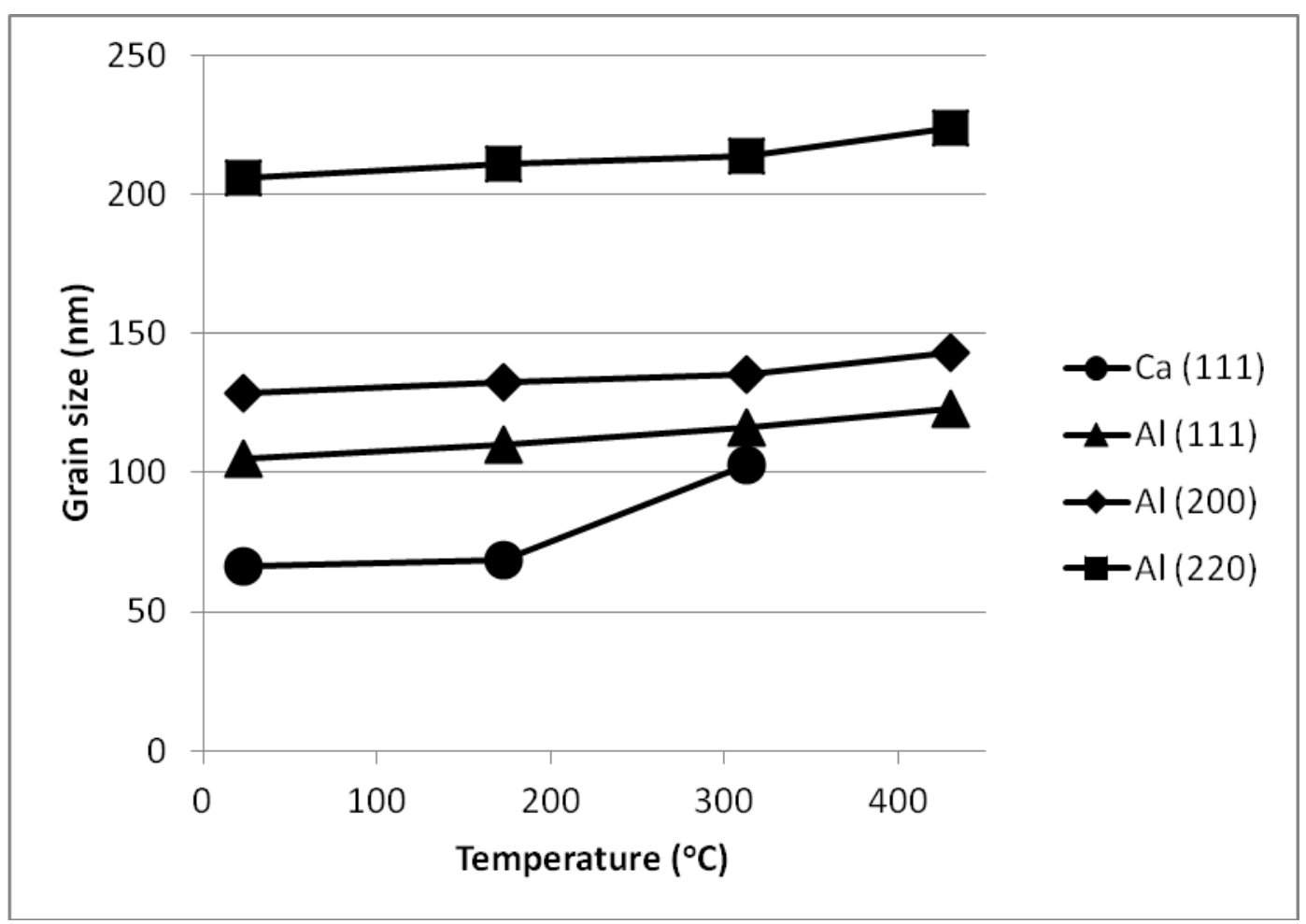

Figure 5.3 Variations of the lower bound of grain size for $\mathrm{Al}$ and $\mathrm{Ca}$ phases in $\mathrm{Al}-9 \% \mathrm{Ca}$ composite with increasing temperature as determined by FWHM measurements and the Scherrer equation.

It should be noted that these comparisons of lower bounds on grain sizes are complicated by the fact that dislocation density contributes to peak broadening and the room-temperature values are for heavily strain-hardened metal (high dislocation density), while the high-temperature values are for fully recrystallized metal (low dislocation density). 


\section{$5.4 \quad$ References}

1. Smithells, C.J., E.A. Brandes, and G.B. Brook, Smithells metals reference book. 7th ed. 1992, Oxford ; Boston: Butterworth-Heinemann. 1 v. (various pagings).

2. Papadaki.Ep, Tabulation of Coefficients of a Quadratic Function for ThermalExpansion of Various Alloys and Other Engineering Materials. Materials Science and Engineering, 1972. 10(4): p. 195-\&.

3. Scherrer, P., Bestimmung der Grösse und der inneren Struktur von Kolloidteilchen mittels Röntgenstrahlen. Göttinger Nachrichten Gesell., 1981. 2.

4. Patterson, A.L., The Scherrer formula for $x$-ray particle size determination. Physical Review, 1939. 56(10): p. 978-982.

5. Porter, D.A., K.E. Easterling, and M.Y. Sherif, Phase transformations in metals and alloys. 3rd ed. 2009, Boca Raton, FL: CRC Press. xix, 500 p. 